\title{
Targeted PEG-poly(glutamic acid) complexes for inhalation protein delivery to the lung
}

\author{
A. Nieto-Orellana, ${ }^{a}{ }^{1}$ H. Li, ${ }^{a}, 1$ R. Rosiere, ${ }^{b}$ N. Wauthoz, ${ }^{b}$ H. Williams, ${ }^{c}$ C. J. Monteiro, ${ }^{a}$ C. Bosquillon, ${ }^{a}$ N. \\ Childerhouse, ${ }^{d}$ G. Keegan, ${ }^{d}$ D. Coghlan, ${ }^{d}$ G. Mantovani ${ }^{a,}{ }^{*}$ and S. Stolnik ${ }^{a, *}$
}

${ }^{a}$ Molecular Therapeutics and Formulation Division, School of Pharmacy, University of Nottingham, Nottingham, UK; ${ }^{b}$ Laboratory of Pharmaceutics and Biopharmaceutics (ULBGAL), Université Libre de Bruxelles, Bruxelles, BE; ${ }^{c}$ Centre for Biomolecular Sciences, University of Nottingham, Nottingham, UK; ${ }^{d}$ Vectura Group plc, Chippenhafm, UK.

${ }^{1}$ These authors contributed equally to this paper

* Corresponding authors.

\begin{abstract}
Pulmonary delivery is increasingly seen as an attractive, non-invasive route for the delivery of forthcoming protein therapeutics. In this context, here we describe protein complexes with a new 'complexing excipient' - vitamin $\mathrm{B}_{12}$-targeted poly(ethylene glycol)-block-poly(glutamic acid) copolymers. These form complexes in sub-200 $\mathrm{nm}$ size with a model protein, suitable for cellular targeting and intracellular delivery. Initially we confirmed expression of vitamin $\mathrm{B}_{12}$-internalization receptor (CD320) by Calu-3 cells of the in vitro lung epithelial model used, and demonstrated enhanced $B_{12}$ receptor-mediated cellular internalization of $B_{12}$-targeted complexes, relative to non-targeted counterparts or protein alone. To develop an inhalation formulation, the protein complexes were spray dried adopting a standard protocol into powders with aerodynamic diameter within the suitable range for lower airway deposition. The cellular internalization of targeted complexes from dry powders applied directly to Calu-
\end{abstract}


3 model was found to be 2-3 fold higher compared to non-targeted complexes. The copolymer complexes show no complement activation, and in vivo lung tolerance studies demonstrated that repeated administration of formulated dry powders over a 3 week period in healthy BALB/C mice induced no significant toxicity or indications of lung inflammation, as assessed by cell population count and quantification of IL-1 $1 \beta, I L-6$, and TNF- $\alpha$ proinflammatory markers. Importantly, the in vivo data appear to suggest that $\mathrm{B}_{12}$-targeted polymer complexes administered as dry powder enhance lung retention of their protein payload, relative to protein alone and non-targeted counterparts. Taken together, our data illustrate the potential developability of novel $\mathrm{B}_{12}$-targeted poly(ethylene glycol)poly(glutamic acid) copolymers as excipients suitable to be formulated into a dry powder product for the inhalation delivery of proteins, with no significant lung toxicity, and with enhanced protein retention at their in vivo target tissue.

\section{Introduction}

Pulmonary delivery is increasingly investigated as an alternative route for the delivery of biotherapeutics, including proteins [1]. Several proteins and peptides - e.g. cyclosporine A to treat asthma, and interleukin-2 to treat pulmonary metastases of renal cell carcinoma $[2,3]$ have been investigated for delivery to the lung. In 2014, an inhaled insulin preparation Afrezza was approved by the US Food and Drug Administration [4], and is a currently available option in diabetes treatment. However, the lung presents specific barriers for macromolecular/protein therapeutics. Susceptibility to enzymatic degradation, poor absorption across epithelial barrier, as well as lung induced immunogenicity are significant challenges to be addressed if this approach is to be adopted as a viable alternative for protein delivery $[5,6]$. Covalent attachment of PEG (generally referred to as PEGylation) has evolved 
as the technique of choice in the bid to increase protein resistance to enzymatic degradation and reduced immunogenicity $[7,8]$. PEGylation has been shown to enhance protein absorption following nasal administration [9, 10], and several studies showed promising delivery of PEGylated therapeutics to both the upper and lower respiratory tract for either systemic or local therapeutic effects $[11,12]$.

To date, chemical conjugation to a therapeutic protein has been used in a vast majority of PEGylation studies $[13,14]$. However, it does not answer all the challenges of protein delivery, with a primary disadvantage being a potential decrease in the protein's therapeutic effect due to irreversible modification/steric shielding of its active site $[15,16]$. Non-covalent PEGylation, i.e. formation of protein-polymer non-covalent complexes has been explored as a potentially suitable alternative. In a seminal work from Kataoka's group, stable complexes in nanometer size range were assembled from PEG-polyanion or -polycation copolymers and charged macromolecules, including proteins [17]. Non-covalent PEGylated complexes were also produced from insulin and oligolysine or oligoarginine-type peptide polymers functionalized with PEG [18]. An alternative to non-covalent PEGylation based on electrostatic interactions between PEG-polyelectrolyte copolymer and selected protein, PEG bearing a terminal cholanic moiety ( $\mathrm{mPEG}_{5 \mathrm{kDa}}$-cholane) was utilized to generate polymer conjugates through non-covalent hydrophobic interactions with a range of protein and peptides, including recombinant human granulocyte colony stimulating factor (rh-G-CSF) [19], palmytoilated vasoactive intestinal peptide (VIP) [20], and recombinant human growth hormone (rh-GH) [21]. These non-covalent protein-polymer complexes can be assembled by simply mixing protein and polymer components under optimized conditions, avoiding the often complex conjugation chemistries required for covalent PEGylation. The intrinsically reversible nature of these interactions potentially allow complex disassembly under specific 
conditions - e.g. those found in the proximity of the intended biological target - which addresses the potential disadvantages covalent conjugation discussed above.

In this work, we present a further development in the non-covalent PEGylation approach, by engineering ligand-targeted non-covalent complexes which exploit cell-specific transport pathways for the intracellular delivery of therapeutic protein. To the best of our knowledge, this is the first example of ligand-targeted polymer-protein ionic complexes used for intracellular delivery of complexed protein.

Accordingly, here we engineered cyanocobalamin (vitamin $\mathrm{B}_{12}$ ) ligand-targeted complexes based on $\mathrm{B}_{12}$-PEG-poly(glutamic acid), using lysozyme as a model protein cargo. A family of $B_{12}$-PEG-poly(glutamic acid) copolymers with linear and miktoarm polymer topology was synthesized. These are used as a new 'complexing excipient' to assemble nano-sized complexes with the model protein, which can then be spray-dried into inhalable dry powders for inhalation delivery to the lung epithelium. In in vitro studies, Calu-3 cells were chosen as lung epithelial model and were grown as polarized layers in air-liquid interface culture (AIC) conditions to promote mucus secretion, normally considered to mimic lung physiological conditions [22]. Data show enhanced cellular internalization of targeted complexes, relative to non-targeted counterparts or 'free' protein. Toxicity studies demonstrated no complement activation, and in vivo lung tolerability assessment shows no significant signs of lung inflammation on repeated administration of formulated dry powders to healthy mice. In vivo lung deposition data illustrate ability of the complexes formulated as dry powders to deposit and retain model protein cargo in the lung tissue following pulmonary administration.

\section{Methods}


a-dibenzocyclooctyne-vitamin $\mathbf{B}_{12}$ (DBCO-B ${ }_{12}$ ). Cyanocobalamin (vitamin $B_{12}, 50 \mathrm{mg}, 0.037$ mmol, 1 eq.) was dissolved in anhydrous DMSO (5 mL) under inert atmosphere. 1,1'carbonyldiimidazole (CDI) $(9.7 \mathrm{mg}, 0.060 \mathrm{mmol}, 1.6 \mathrm{eq}$.$) was then added, and the reaction$ was stirred at $30^{\circ} \mathrm{C}$ for $1.5 \mathrm{~h}$ followed by addition of a solution of dibenzocyclooctyne-amine (30 mg, $0.11 \mathrm{mmol}, 3$ eq.) in DMSO (5 mL). The resulting solution was stirred at room temperature protected from light for $24 \mathrm{~h}$. The mixture was then precipitated in diethyl ether, centrifuged, and the solid residue was dissolved in methanol and purified by preparative-TLC ('PrOH : $\left.n-\mathrm{BuOH}: \mathrm{H}_{2} \mathrm{O}: \mathrm{NH}_{4} \mathrm{OH} 30: 45: 21: 4\right)$. The product was extracted from the relevant TLC band using methanol, then the resulting suspension was filtered, and after solvent removal under reduced pressure DBCO-B ${ }_{12}$ was isolated as a pink-red solid. Yield: $11 \mathrm{mg}, 22 \%$. Mass spectrometry and RP HPLC (Supporting Information, Figure S1) confirmed the purity of the isolated DBCO-B 12 : expected $\mathrm{m} / \mathrm{z}\left[\mathrm{M}-\mathrm{Na}^{++}\right]$theor. 851.85 , found 851.33 .

$B_{12}-P G_{3 k}-m i k-\left(G_{17}\right)_{3}$ and $B_{12}-P G_{3 k}-l i n-\left(G_{24}\right)$. Azide-PEG $G_{3 k}-m i k-\left(G_{17}\right)_{3}(40 \mathrm{mg}, 0.0022$ mmol, 1 eq.) or azide-PEG ${ }_{3 k}$-lin-(GA 24$)(100$ mg, 0.013 mmol, 1 eq.) (Supporting Information, Figure S1 and S2) were dissolved in deionized water (3 mL). DBCO-B 12 (7 mg, $0.004 \mathrm{mmol}, 2$ eq., or $44 \mathrm{mg}, 0.026 \mathrm{mmol}, 2$ eq.) to form $B_{12}-P E_{3 k}-$ mik-poly $\left(G_{17}\right)_{3}$ and $B_{12}-P E G_{3 k}-l i n-\left(G A_{24}\right)$ copolymers, respectively was dissolved in DMSO $(3 \mathrm{~mL})$ and then added to the round bottom flask containing the relevant copolymer. The mixture was stirred at room temperature protected from the light overnight. The solution was then dialyzed (MWCO $3.5 \mathrm{kDa}$ ) against deionized water, and after freeze-drying $B_{12}-P E G_{3 k}-$ mik- $\left(G_{17}\right)_{3}$ and $B_{12}-P E G_{3 k}-l i n-\left(G A_{24}\right)$ were isolated as pink solids.

B $_{12}-$ PEG $_{3 k}-$ mik- $\left(G_{17}\right)_{3}$ yield: 39 mg, 91 \%. ${ }^{1} \mathrm{H}$ NMR (400 MHz, $\left.\mathrm{D}_{2} \mathrm{O}, \delta, \mathrm{ppm}\right):$ 4.44-4.28 (bs, $\mathrm{HNCHCO}$ ), 3.75-3.60 (s, OCH${ }_{2}$ of PEG), 2.52-1.90 (m, $\left.\mathrm{CH}_{2} \mathrm{CH}_{2} \mathrm{COOH}\right) . \mathrm{M}_{\mathrm{n}, \mathrm{NMR}}=21.0 \mathrm{kDa}, \mathrm{M}_{\mathrm{n}, \mathrm{SEC}}$ 
$=4.8 \mathrm{kDa}, \bigoplus_{\mathrm{SEC}}=1.59 . \mathrm{B}_{12}-\mathrm{PEG}_{\mathbf{3 k}}-$ lin-$\left(\mathrm{GA}_{24}\right)$ yield: $121 \mathrm{mg}, 96 \% .{ }^{1} \mathrm{H} \mathrm{NMR}\left(400 \mathrm{MHz}, \mathrm{D}_{2} \mathrm{O}, \delta\right.$, ppm): 7.83-7.66 (s, $\mathrm{CH}_{\text {aromatic }}$ ), 7.50-7.33 (s, $\mathrm{CH}_{\text {aromatic }}$ ), 4.47-4.05 (bs, HNCHCO), 3.76-3.58 (s, $\mathrm{OCH}_{2}$ of PEG), $2.50-1.86$ ( $\left.\mathrm{m}, \mathrm{CH}_{2} \mathrm{CH}_{2} \mathrm{COOH}\right) . \mathrm{M}_{\mathrm{n}, \mathrm{NMR}}=9.8 \mathrm{kDa}, \mathrm{M}_{\mathrm{n}, \mathrm{SEC}}=4.4 \mathrm{kDa}, \mathrm{Ð}=1.23$.

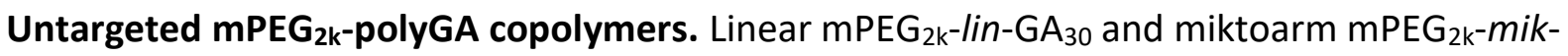
$\left(\mathrm{GA}_{10}\right)_{3}$ copolymers were synthesized in our previous work.[23]

Preparation of polymer-protein complexes. ( $\mathrm{mPEG}_{2 \mathrm{k}}-\mathrm{lin}-\mathrm{GA}_{30}$ )-lysozyme complexes were prepared at relative molar charge ratios $r=2.5$ where $r$ is the charge ratio between the number of glutamic acid residues in the copolymer (negatively charged at physiological $\mathrm{pH}$ ), and the 17 lysine and arginine residues (positively charged at physiological pH) of lysozyme. Polymers and protein were separately dissolved in phosphate buffer (PB, $10 \mathrm{mM}, \mathrm{pH} 7.4)$ and appropriate aliquots were mixed to achieve $r=2.5$. For example, to make $1 \mathrm{~mL}$ of complexes at $70 \mu \mathrm{g} \mathrm{mL} \mathrm{m}^{-1}$ protein concentration for nanoparticle tracking analysis, $21 \mu \mathrm{g}$ of $\mathrm{mPEG}_{2 \mathrm{k}}$-lin$\mathrm{GA}_{30}$ and $70 \mu \mathrm{g}$ of lysozyme were mixed in $1 \mathrm{~mL}$ of $10 \mathrm{mM}$ PB. Specific protein and polymer concentrations are reported in the description of individual experiments below.

To prepare targeted polymer-protein complexes, $\mathrm{PPEG}_{2 \mathrm{k}}$-lin- $\mathrm{GA}_{30}$ and $\mathrm{B}_{12}$-PEG-polyGA copolymers were mixed at relative molar ratios of 85:15 (mol:mol), respectively. Polymers mixture and lysozyme were then mixed at relative molar charge ratio of 2.5.

To monitor protein cellular uptake, lysozyme used in all subsequent studies was fluorescently labelled using sulfo-Cyanine 5 (Cy5) succinimidyl (NHS) ester (Lumiprobe), according to manufacturer protocol. After dialysis, protein concentration and degree of labelling were determined using dye:protein (F/P) molar ratios' equations as described in the Supporting Information. 
Nanoparticle Tracking Analysis (NTA). The hydrodynamic diameter of $\mathrm{B}_{12}$-targeted and nontargeted polymer-protein complexes was measured by NTA (Nanosight LM14). All measurements were performed at $25^{\circ} \mathrm{C}$. NTA 2.0 Build 127 software was used for data acquisition and analysis. The samples were measured for $80 \mathrm{~s}$. Mean size \pm SD values correspond to the arithmetic values calculated for all the particles analyzed by the software. Polymer-protein complexes were prepared at charge ratios of 2.5 in $10 \mathrm{mM}$ phosphate buffer, $\mathrm{pH}$ 7.4. Protein concentration was kept constant $\left(70 \mu \mathrm{g} \mathrm{mL} \mathrm{L}^{-1}\right)$ for all measurements. Free protein and polymers were used as controls.

Formulation of complexes as dry powders by spray-drying. The complexes were formulated into dry powders following procedure optimized previously [24]. The composition of dry powders was: 0-10 $\%(w / w)$ protein-polymer complexes, $10 \%(w / w)$ leucine, $6.6 \%(w / w)$ phosphate buffer salts, and trehalose as bulking agent (up to $100 \%(w / w)$ ).

Cell culture. Human airway epithelial cells (Calu-3) were routinely cultured in DMEM/F-12 medium. Medium was supplemented with Foetal Bovine Serum (FBS, $10 \% v / v$ ), non-essential aminoacids $(1 \% \mathrm{v} / \mathrm{v})$, L-glutamine $(1 \% \mathrm{v} / \mathrm{v})$, penicillin $\left(100\right.$ units $\left.\mathrm{mL}^{-1}\right)$ and streptomycin $(0.1$ $\mathrm{mg} \mathrm{mL}^{-1}$ ). DPBS and trypsin/EDTA were used to wash and detach adherent cells in the process of cell splitting. Cells were always incubated at $37^{\circ} \mathrm{C}$ and $5 \% \mathrm{CO}_{2}$.

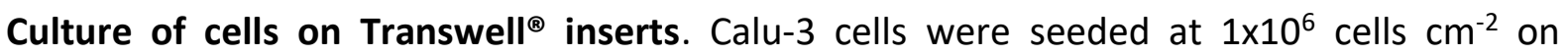
Transwell ${ }^{\circledR}$ inserts (12 mm diameter, $0.4 \mu \mathrm{m}$ pore size; Corning Life Sciences, USA) and cultured for 14 days, with medium replacement every two days. Cells were cultured using airinterface culture (AIC) conditions [22] known to promote mucus secretion, starting from day 2 post-seeding on Transwell $^{\circledR}$ inserts. Cell confluence and cell layer integrity before treatments with test samples was confirmed by transepithelial electrical resistance (TEER) 
measurements (EVOM voltohmmeter, World Precision Elements, USA). Cells included in the experiments always had values higher than $550 \Omega \mathrm{cm}^{-2}$.

cDNA synthesis and quantitative PCR analysis. Total RNA was extracted using RNeasy Mini Kit (Qiagen, Hilden, Germany) according to manufacturer's instructions. RNA concentration and purity were assessed using NanoDrop spectrophotometer (Thermo Scientific, Wilmington, DE). Five-hundred nanograms of total RNA were reverse transcribed to complementary DNA (cDNA) by QuantiTect Reverse Transcription Kit (Qiagen). Genomic DNA elimination was carried out twice, during RNA extraction and before the cDNA synthesis. qPCR reactions were performed in 96-well white-walled plates using $2 x$ Brilliant II SYBR ${ }^{\circledR}$ Green QPCR Master Mix (Agilent) with the following primer sets: cubilin forward primer: 5'CGTGGAACACACAAACTTTAGG-3' and reverse primer: 5'-CCAGTGAGGGGATCTGATTG-3'; TCN2 receptor (CD320) forward primer: 5'-CACCCACCAAGTTCCAGTGCCG-3' and reverse primer: 5'-GTTCCACAGCCGAGCTCGTCG-3'; TCN2 forward primer: 5'GCTGGTTGTGGCACAGTA-3' and reverse primer: 5'-AGGTCCACAGGCCATCAAT-3'. Glyceraldehyde-3-phosphate dehydrogenase (GAPDH) was used as a standardization control (forward primer: 5'-AGGTGAAGGTCGGAGTCAAC-3' and reverse primer: 5'GATGACAAGCTTCCCGTTCT-3'). $\Delta \Delta$ Cq method was used to calculate relative gene expression.

Cellular uptake of pyr-B $\mathrm{B}_{12}$ fluorescent probe. Calu-3 and Caco-2 cells were cultured on Transwell ${ }^{\circledR}$ inserts over 14 and 21 days, under air-liquid or liquid-liquid interface respectively. Culture medium was removed from filter-cultured cells and replaced with Hank's Balanced Salt Solution (HBSS) in both Transwell ${ }^{\circledR}$ compartments for TEER measurements. Following the measurement of TEER, pyr-B ${ }_{12}$ probe (synthesized as described in the Supporting Information) was dissolved in DMEM medium without phenol red at concentration of $200 \mu \mathrm{g} \mathrm{mL}^{-1}$, and 500 
$\mu \mathrm{L}$ of this solution was added to the apical chamber of the Transwell ${ }^{\circledR}$ insert. Cells were then incubated at $37^{\circ} \mathrm{C}$ for 3 hours and analyzed by flow cytometry (Beckman Coulter Astrios EQ) in at least triplicate experiments, with more than 10,000 cells measured in each sample.

The effect of a competitive ligand on receptor-mediated cellular internalization of fluorescent pyr- $B_{12}$ probe was studied in the presence of an excess of free vitamin $B_{12} ; 500 \mu \mathrm{L}$ of a $1.0 \mathrm{mg}$ $\mathrm{mL}^{-1}$ solution of cyanocobalamin $\left(\mathrm{B}_{12}\right)$ in DMEM medium was added to the apical chamber of Transwell ${ }^{\circledR}$ inserts. Cells were subsequently incubated at $37^{\circ} \mathrm{C}$ for $30 \mathrm{~min}$, then the medium was replaced with a stock solution of fluorescent pyr- $\mathrm{B}_{12}$ probe $(500 \mu \mathrm{L}$, final probe concentration $200 \mu \mathrm{g} \mathrm{mL}-1$ ) plus free vitamin $B_{12}$ at the same concentration as the preincubation solution. Cells were incubated at $37^{\circ} \mathrm{C}$ for 3 hours, fixed with formaldehyde and analyzed by flow cytometry (Beckman Coulter Astrios EQ). Experiments were made in at least triplicates, with more than 10,000 cells measured in each sample.

Cellular internalization of polymer-protein complexes applied as suspension. Calu-3 cells were cultured on Transwell ${ }^{\circledR}$ inserts over 14 days as described above. Culture medium was removed and replaced with Hank's Balanced Salt Solution (HBSS) prior to the experiment. Polymer-protein complexes were applied as a suspension in HBSS at concentration of $3 \mu \mathrm{g}$ $\mathrm{mL}^{-1}$ protein. Following TEER measurement (to assess cell layer integrity), the complexes suspension $(0.5 \mathrm{~mL})$ was added to the apical chamber of the Transwell ${ }^{\circledR}$ insert. Cells were then incubated at $37^{\circ} \mathrm{C}$ for $3 \mathrm{~h}$ and fixed with $2 \%$ formaldehyde followed by analysis by flow cytometry in at least quadruplicate experiments, with more than 10,000 cells measured in each sample.

The effect of a competitive ligand on receptor-mediated uptake of $\mathrm{B}_{12}$ targeted complexes was studied in the presence of an excess of free cyanocobalamin (vitamin $\mathrm{B}_{12}$ ). Firstly, $500 \mu \mathrm{L}$ 
of a $1.0 \mathrm{mg} \mathrm{mL}^{-1}$ solution of cyanocobalamin $\left(B_{12}\right)$ in HBSS was added to the apical chamber of quadruplicate Transwell ${ }^{\circledR}$ inserts. Cells were then incubated at $37^{\circ} \mathrm{C}$ for 30 min following addition of targeted polymer-protein nanocomplex suspension $(500 \mu \mathrm{L}$, final protein concentration $\left.3 \mu \mathrm{g} \mathrm{mL}^{-1}\right)$. Cells were incubated again at $37^{\circ} \mathrm{C}$ for $3 \mathrm{~h}$, washed and fixed before analyzed by flow cytometry. Experiments were made in at least quadruplicate, with more than 10,000 cells measured in each sample.

\section{Cellular internalization of protein-polymer complexes applied as dry powder formulations.}

Calu-3 cells were cultured on Transwell ${ }^{\circledR}$ inserts as previously described. Dry powders were sprayed twice $\left(2 \mathrm{mg}\right.$ per dose) using a Dry Powder Insufflator ${ }^{\mathrm{TM}}$ model DP4-M ${ }^{\circledR}$ (PennCentury ${ }^{\circledast}$ ) into the Transwell $^{\circledast}$ inserts as follows. Four Transwell ${ }^{\circledR}$ inserts were placed into a desiccator at equal distance from the center [25] (also illustrated in Supporting information, Figure S13). $2 \mathrm{mg}$ of dry powder formulations were then sprayed twice from a Penn-Century ${ }^{\circledR}$ device. Next, $500 \mu \mathrm{L}$ of Hank's Balanced Salts Solution (HBSS) were added to the basolateral chamber of the Transwell ${ }^{\circledR}$ inserts and cells were incubated at $37^{\circ} \mathrm{C}$ and $5 \% \mathrm{CO}_{2}$ for $3 \mathrm{~h}$. Cells were then detached with trypsin/EDTA, washed twice with DPBS, fixed with $2 \%$ formaldehyde and lysozyme uptake was analyzed by flow cytometry in quadruplicate experiments, with more than 10,000 cells measured in each sample.

In vitro assessment of complement activation. [ $\mathrm{B}_{12}-\mathrm{PEG}-$ lin- $\left.\left(\mathrm{GA}_{30}\right)\right]$-lysozyme complexes or free lysozyme were incubated with normal human serum (NHS) and the residual hemolytic capacity was measured to study the complement activation. NHS was received from healthy volunteers (Phlebotomy Department, Nottingham University Hospitals, NHS Trust) and, once sensitized, suspended at a final concentration of $1 \times 10^{8}$ cells $\mathrm{mL}^{-1}$ in veronal-buffer saline 
$\left(\mathrm{VBS}^{2+}\right.$, containing $0.5 \mathrm{mM} \mathrm{Mg}^{2+}$ and $\left.0.15 \mathrm{mM} \mathrm{Ca}^{2+}\right) \cdot \mathrm{VBS}^{2+}$ and $\mathrm{NHS}$ were mixed with lysozyme-polymer complexes or free lysozyme at a final protein concentration of $1.12 \mathrm{mg} \mathrm{mL}^{-}$

${ }^{1}$ so that the final dilution of NHS in the reaction mixture was $1 / 4(\mathrm{v} / \mathrm{v})$ in a final volume of 400 $\mu \mathrm{L}$. The suspension was incubated at $37^{\circ} \mathrm{C}$ for $60 \mathrm{~min}$ under gentle stirring. The mixture was then diluted $1 / 25(\mathrm{v} / \mathrm{v})$ in $\mathrm{VBS}^{2+}$ and aliquots at different dilutions were added to a specific volume of sensitized sheep erythrocytes. The suspensions were incubated for $45 \mathrm{~min}$ at $37^{\circ} \mathrm{C}$ under gentle stirring and the reaction was then stopped by adding ice-cold $\mathrm{NaCl}(0.15 \mathrm{M})$. The mixture was centrifuged at 2,000 rpm for 5 minutes to precipitate un-lysed erythrocytes. The supernatant was collected and the optical density was measured at $\lambda=415 \mathrm{~nm}$ (Cary Eclipse Spectrophotometer).

Mixture of sensitized sheep erythrocytes in $\mathrm{VBS}^{2+}$ without NHS was used here as positive control and employed to correct the baseline absorbance values. Mixture of sensitized sheep erythrocytes with addition of distilled water which would result in total hemolysis was utilized as negative control. In this study, the data were expressed as the percentage of complement activation relative to $100 \%$ complement activation observed with the positive control samples.

\section{In vivo evaluation of the complexes formulated as dry powders}

Animals and husbandry conditions. Female BALB/c mice (Charles River, Arbresle, France) were kept under conventional housing conditions $\left(22 \pm 2^{\circ} \mathrm{C}, 55 \pm 10 \%\right.$ humidity, and 12 -hour day/night cycle). All studies and manipulations were approved by the CEBEA ethical committee of the Faculty of Medicine, ULB (Commission d'Ethique du Bien-Etre Animal, Université libre de Bruxelles, Belgium) (Ethical protocol $\mathrm{N}^{\circ} 585 \mathrm{~N}$ ). The laboratory federal agreement number is LA 1230568. 
Characterisation of dry powder formulations emitted by the dry powder insufflator. Aerosol particles generated from Dry Powder Insufflator ${ }^{\mathrm{TM}}$ model DP4-M ${ }^{\circledR}$ (Penn-Century $^{\circledR}$, Philadelphia, USA) were confirmed to be suitable for endotracheal administration into the mice by using a Spraytec ${ }^{\circledR}$ laser diffractometer. The emitted aerosol, created using Dry Powder Insufflator ${ }^{\mathrm{TM}}$ model $\mathrm{DP}^{-\mathrm{M}^{\circledR}}{ }^{\circledR}$, was presented dispersed in air directly and perpendicular to the laser beam for size measurement. For all formulations tested (Table 1) a loading powder mass of $2 \mathrm{mg}$ was evaluated $(n=10)$. High emitted mass values $(>80 \%)$, particle size D50 $\leq 5 \mu \mathrm{m}$ and RSD values $\leq 25 \%$ for emitted masses were considered suitable for the administration of dry powder formulations to the mice (Supporting information, Table S1).

Local pulmonary tolerance of the complexes. Solution of LPS and dry powder formulations were administered by the non-invasive endotracheal route using an aerosolizing system (Microsprayer ${ }^{\mathrm{TM}}$ model IA-1C ${ }^{\circledR}$ ) or a dry powder insufflator designed for mice (Dry Powder Insufflator ${ }^{\mathrm{TM}}$ model DP4-M ${ }^{\circledR}$, Penn-Century), respectively, as described elsewhere $[26,27]$.

Composition of formulations tested is shown in Table 1. Five groups were compared: (i) nontreated mice negative control (i.e. group baseline, $n=6$ ), (ii) mice treated with unlabeled dry powder (denoted as UDP) (control dry powders, with no protein nor copolymers, excipients only) ( $n=5$ ), (iii) mice treated with unlabeled dry powder-protein (UDP-P) (dry powders containing lysozyme, but not polymers ) ( $n=5$ ), (iv) mice treated with unlabeled dry powder containing protein-targeted complexes (UDP-TC) (dry powders containing 85:15 [mPEG 2 -lin-

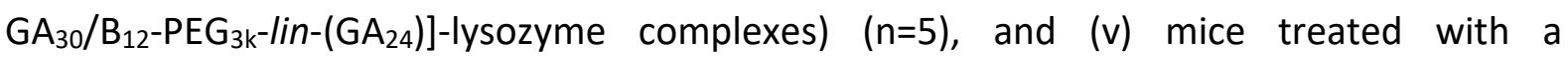
lipopolysaccharide (LPS) solution (single administration of $1 \mu \mathrm{g}$ dose) as positive control $(n=6)$. Mice were treated with $2 \mathrm{mg}$ dose of dry powders three time a week for three consecutive 
weeks.

Bronchoalveolar lavage fluids (BALFs) were analyzed in terms of cell composition (total and differential cell count) and pro-inflammatory markers concentration (cytokines IL-1 $\beta$, IL-6, and TNF- $\alpha$ ), as previously described [27]. Mice were euthanized by a lethal intraperitoneal injection of $12 \mathrm{mg}$ sodium phenobarbital (Nembutal ${ }^{\circledR}$, Ceva Santé Animale, Brussels, Belgium) $8 \mathrm{~h}$ (for the LPS group) or $24 \mathrm{~h}$ (for the dry powder inhaler groups) after the last inhaled administration. BALFs were collected using a 20-gauge cannula (Surflo ${ }^{\circledR}$ catheter, Terumo, Leuven, Belgium) with 3 flushes of $0.7 \mathrm{~mL}$ cold PBS and conserved on ice until total cell count analysis (Z2 ${ }^{\mathrm{TM}}$ Coulter Counter ${ }^{\circledR}$, Beckman Coulter, Suarlée, Belgium). BALF were centrifuged at $160 \times \mathrm{g}$ at $4^{\circ} \mathrm{C}$, supernatants were collected and conserved at $-80^{\circ} \mathrm{C}$ for cytokine quantification. Differential cell counts were performed on cytospin preparations after staining with May Grünwald and Giemsa (Sigma-Aldrich). A total of 200 cells were counted per slide and were referred to as alveolar macrophages, lymphocytes or polymorphonuclear neutrophils according to their morphology. Cytokine concentrations were determined by ELISA for mouse IL-1 $\beta$, IL-6, and TNF- $\alpha$ (DuoSet ${ }^{\circledR}$ ELISA, RnD Systems) according to the manufacturer's protocols. The limits of quantification for the techniques used were $15.6 \mathrm{pg}$ $\mathrm{mL}^{-1}$ for IL-1 $\beta$ and IL-6, and $31.3 \mathrm{pg} \mathrm{mL}^{-1}$ for TNF- $\alpha$.

In vivo pulmonary deposition and retention. The deposition of the dry powder formulations was evaluated after pulmonary delivery. Lysozyme-Cy5-containing DPI formulations (LDP-P, LDP-TC and LDP-NT, composition in Table 1) were administered to mice ( 2 mice per group) by the endotracheal route, as described above. After 0,3 and 14 hours, mice were sacrificed using sodium pentobarbital, the lungs were collected and blocked using Optimum Cutting Temperature (OCT) solution (Tissue-Tek ${ }^{\circledast}$ OCT compound, Sakura). Five non-serial cryo- 
sections of $7 \mu \mathrm{m}$ per lung were prepared and mounted on SuperFrost ${ }^{\mathrm{TM}}$ slides (Thermo Fischer Scientific) using a DAPI solution (DAPI Counterstain, Abott Laboratories, Des Plaines, IL, USA) and finally covered with a coverslip. The slides were observed under a Leica SP8 confocal microscope (Leica Microsystems, Diegem, Belgium) with filters (Zeiss, Germany) at $546 \mathrm{~nm}$ (bandwidth $12 \mathrm{~nm}$ ) and $610 \mathrm{~nm}$ (bandwidth $65 \mathrm{~nm}$ ) used for excitation and emission, respectively, for Cy5 labelled protein. Due to sub-optimal spectral overlap, prolonged exposure (1000 ms) was needed to acquire images. A DAPI filter (Zeiss) was used for DAPI. The images were processed (i.e. fluorescence intensity, mean grey values) using ImageJ Software (National Institutes of Health, USA). Quantitative data are presented as the ratio of average of the grey mean values of Cy5 to DAPI areas ( $n=5$ tissue slices), as described in Dawson et al [28].

Table 1. Composition of dry powder formulations used in the in vivo studies.

\begin{tabular}{|c|c|c|c|c|c|}
\hline & \multirow{2}{*}{$\begin{array}{l}\text { Formulation } \\
\text { code }\end{array}$} & \multirow{2}{*}{$\begin{array}{l}\text { Lysozyme/ } \\
\text { Complexes (w/w) }\end{array}$} & \multicolumn{3}{|c|}{ Excipients } \\
\hline & & & $\begin{array}{l}\text { Leucine } \\
(\% \mathrm{w} / \mathrm{w})\end{array}$ & $\begin{array}{l}\text { Buffer salts } \\
(\% \mathrm{w} / \mathrm{w})\end{array}$ & $\begin{array}{l}\text { Trehalose } \\
(\% \mathrm{w} / \mathrm{w})\end{array}$ \\
\hline \multirow{3}{*}{$\begin{array}{l}\text { unlabeled dry } \\
\text { powder (UDP) }\end{array}$} & UDP & $0 \%$ complexes & 10 & 6 & Up to 100 \\
\hline & UDP-P & $5 \%$ lysozyme & 10 & 6 & Up to 100 \\
\hline & UDP-TC & $\begin{array}{l}10 \% \text { targeted } \\
\text { complexes }^{\mathrm{a}}\end{array}$ & 10 & 6 & Up to 100 \\
\hline \multirow{3}{*}{$\begin{array}{c}\text { Cy5 labelled dry } \\
\text { powder (LDP) }\end{array}$} & LDP-P & $5 \%$ lysozyme & 10 & 6 & Up to 100 \\
\hline & LDP-TC & $\begin{array}{l}10 \% \text { targeted } \\
\text { complexes }^{\mathrm{a}}\end{array}$ & 10 & 6 & Up to 100 \\
\hline & LDP-NT & $\begin{array}{l}10 \% \text { non-targeted } \\
\text { complexes }\end{array}$ & 10 & 6 & Up to 100 \\
\hline
\end{tabular}

${ }^{a}$ corresponding to $\sim 5 \% \mathrm{w} / \mathrm{w}$ of lysozyme.

UDP-P denotes dry power containing unlabeled protein, UDP-TC denotes dry power containing unlabeled protein complexes with $\mathrm{B}_{12}$-targeted polymer, LDP-TC denotes dry powder containing labelled protein complexes with $\mathrm{B}_{12}$-targeted polymers, LDP-NT denotes dry powder containing labelled protein with nontargeted polymer.

Unlabeled dry powder formulations were used for local pulmonary tolerance studies, and Cy5-labelled protein dry powder formulations were used for pulmonary deposition and retention studies. 


\section{Results and Discussion}

Delivery of therapeutic macromolecules into, or across cells forming epithelial barrier is a recognized therapeutic challenge. Potential solutions include approaches that exploit normal biological pathways of cellular internalization and transcytosis of nutrients, vitamins, as well as macromolecules $[29,30]$. In our previous study, we demonstrated that vitamin $B_{12}$ can i) be used as a ligand to enhance internalization of model sub-200 $\mathrm{nm}$ polystyrene particles by epithelial cells, ii) influence their intracellular trafficking pathways, and iii) enhance transport of decorated nanoparticles across Calu-3 cell layer [31, 32]. Here, we apply the $B_{12}$ directed cellular internalization and transport to achieve targeted delivery of polymer-protein complexes in vitro and in vivo. Accordingly, we synthesized a family of targeted $\mathrm{B}_{12}-\mathrm{PEG}_{3 \mathrm{k}^{-}}$ polyGA copolymers and utilized these to generate polymer-protein complexes via ionic, noncovalent interactions between polymer and model protein charged functionalities.

Synthesis of targeted $B_{12}$-PEG-polyGA copolymers. The $B_{12}$-targeted copolymers, $B_{12}-P E G-$ polyGA (Figure 1), were produced through a modification of an approach we developed previously for synthesis of analogous non-targeted counterparts (Supporting information, Figures S2 and S3) [23]. The synthesis of both linear and miktoarm $\mathrm{B}_{12}$-targeted polymers started from $\mathrm{O}$-(2-aminoethyl)polyethylene glycol $(3.0 \mathrm{kDa})$, and involved $\mathrm{N}$ carboxyanhydride (NCA) polymerization of $y$-benzyl-L-glutamate $N$-carboxyanhydride (NCA) to generate, after hydrolysis of the benzyl ester protecting groups, a poly(glutamic acid) polyanion block. $\mathrm{B}_{12}$-targeted copolymers were prepared from a 3kDa PEG block, which is longer than the $2 \mathrm{kDa}$ PEG used for the non-targeted analogues, to potentially increase the 
exposure of $\mathrm{B}_{12}$ ligands at the surface of the corresponding protein-polymer complexes.

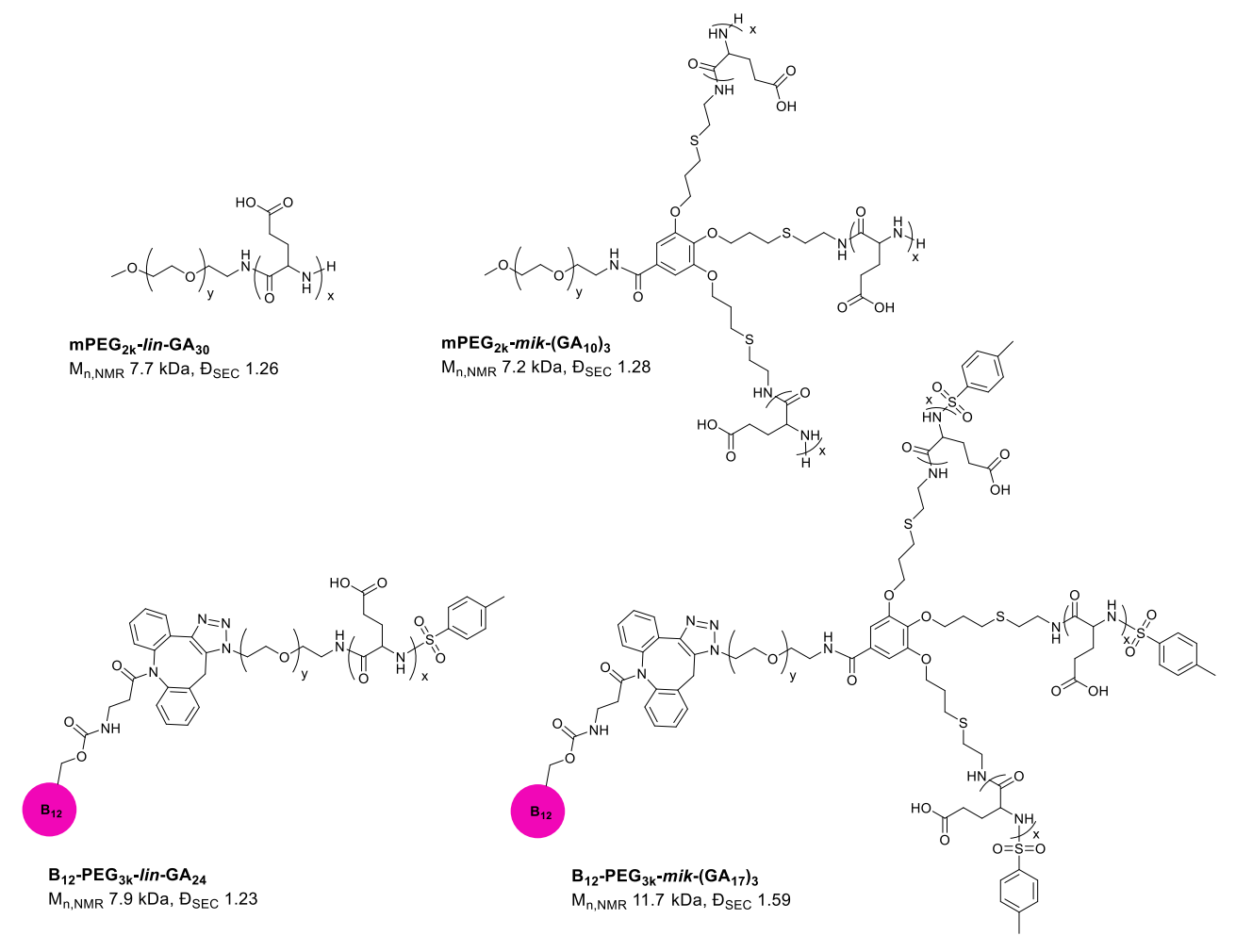

Figure 1. Chemical structure of non-targeted (top), and B 12 -targeted (bottom) PEG-poly(glutamic acid) copolymers with linear and miktoarm topology.

In the final step, the required $B_{12}$ ligand was introduced in linear azide-PEG $G_{3 k}-\operatorname{lin}-\left(G_{24}\right)(\mathbf{1})$ and miktoarm azide- $P E G_{3 k}-m i k-\left(G_{17}\right)_{3}(2)$ intermediates by copper-free strain-promoted Huisgen 1,3-dipolar cycloaddition (Supporting information, Figures S2 and S3) [33, 34]. To this aim, a-dibenzocyclooctyne-vitamin $\mathrm{B}_{12}$ (DBCO-B12) was synthesized by activating the $\mathrm{CH}_{2} \mathrm{OH}$ group at $\mathrm{C}_{5}$ of cyanocobalamin pentose moiety with carbonyldiimidazole(CDI) for 30 min in DMSO, followed by the addition of commercially available $\alpha$-dibenzocyclooctyne-amine, to form a stable carbamate linker. Reaction with the azide-containing intermediates (1) and (2) in water-DMSO followed by dialysis afforded the final linear $B_{12}-P^{-} G_{3 k}-l i n-\left(G_{24}\right)$ and miktoarm 
$\mathrm{B}_{12}-\mathrm{PEG}_{3 \mathrm{k}}-$ mik- $\left(\mathrm{GA}_{17}\right)_{3}$ protein-complexing copolymers (Figure 2$)$.
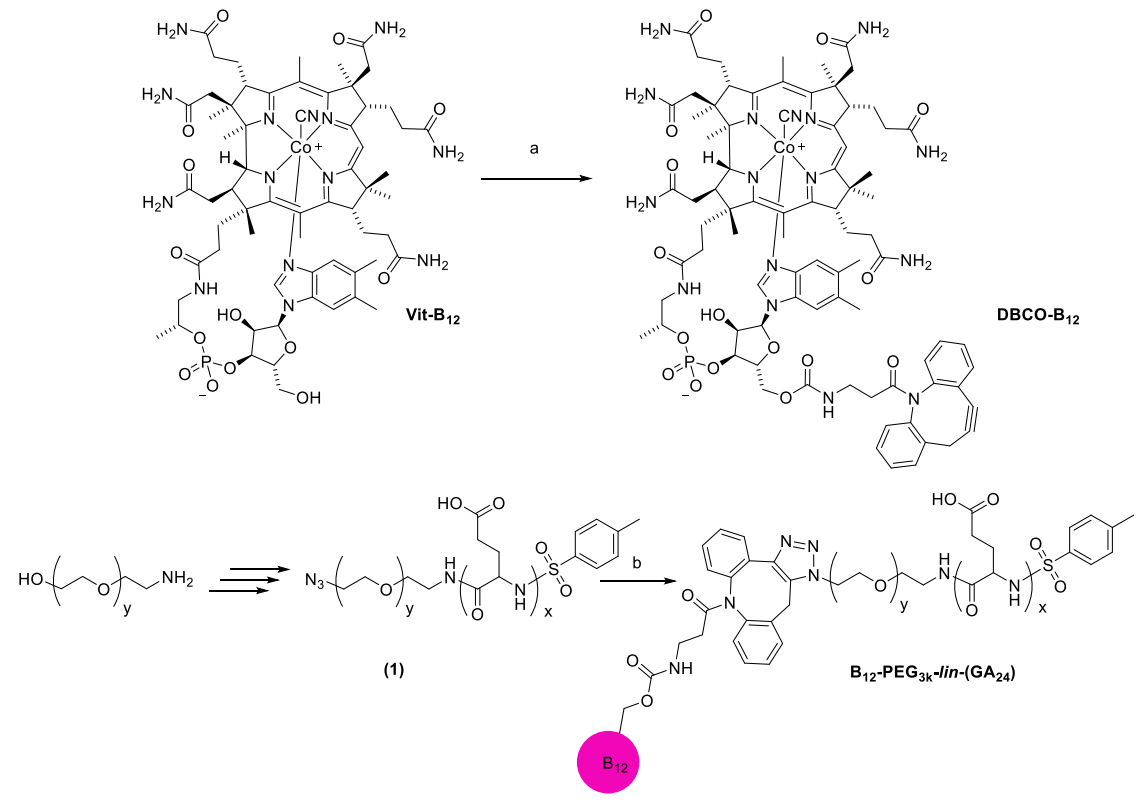

Figure 2. Synthesis of vitamin $B_{12}$-targeted $B_{12}-P E G_{3 k}-$ lin- $\left(G_{24}\right)$ copolymers. Reactions and conditions: a) i. 1,1'carbonyldiimidazole, ii. dibenzocyclooctyne-amine (DBCO-amine) b) DBCO- $\mathrm{B}_{12}$, DMSO/H2O, overnight. $\mathrm{B}_{12}-$ $P E G_{3 k}-m i k-\left(G_{17}\right)_{3}$ was prepared in an analogous manner, from miktoarm azide-PEG $\mathrm{C}_{3 k}-m i k-\left(\mathrm{GA}_{17}\right)_{3}$ intermediate (2) (Supporting information, Figure S2).

The successful click conjugation of DBCO- $\mathrm{B}_{12}$ to azide-PEG $\mathrm{P}_{3 \mathrm{k}}-b$-polyGA was confirmed by 2D Heteronuclear Single-Quantum Correlation (HSQC) and 1D ${ }^{1} \mathrm{H}$ NMR (Figure 3). Due to the complexity of the NMR spectra of $B_{12}-P G_{3 k}-l i n-\left(G_{24}\right)$ and $B_{12}-P E G_{3 k}-m i k-p o l y\left(G A_{17}\right)_{3}$ copolymers, model low molecular weight azides and cyclooctynes were synthesized and analyzed to identify diagnostic peaks which would allow us to monitor this reaction (Supporting information, Figure S6). The $\alpha-\mathrm{CH} 2$ protons of the cyclooctyne ring were found to be particularly suitable for this, due to their relatively large ${ }^{1} \mathrm{H}$ NMR downfield shift $(\sim 0.7-$ $0.8 \mathrm{ppm}$ ) following click cycloaddition (Figure 3). 

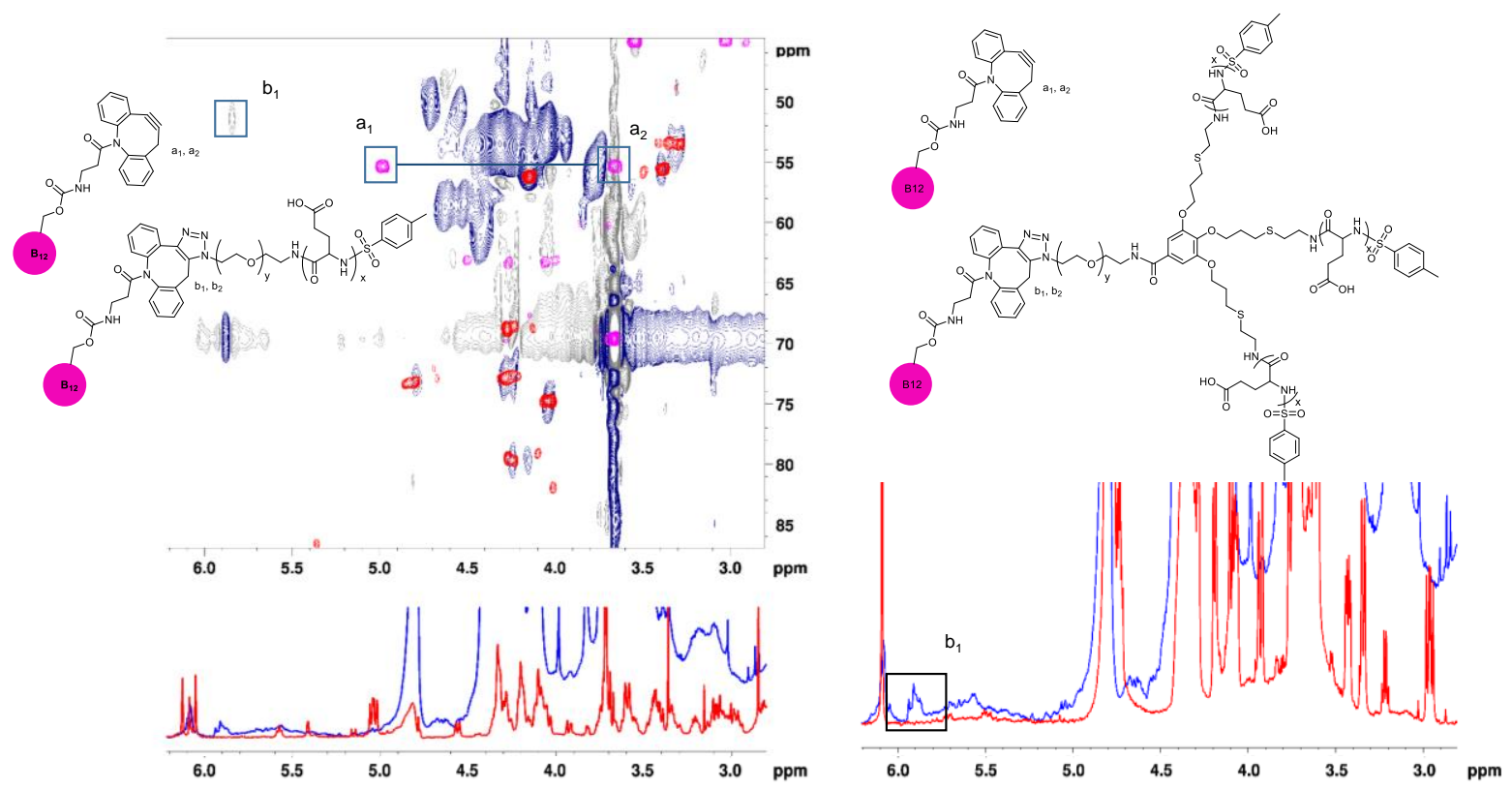

Figure 3. ${ }^{1} \mathrm{H}$ NMR and HSQC spectra of the $\alpha-\mathrm{CH}_{2}$ proton signal of the $\alpha$-dibenzocyclooctyne-amine before (a1, a2) and after (b1, b2) the copper-free click conjugation of DBCO-B 12 to azide-PEG $3 k-l i n-\left(G_{24}\right)$ (1) (left) and azide-PEG $3 k-$ mik-(GA $\left.A_{17}\right)_{3}(2)$ (right).

More specifically, one of the two $\alpha-\mathrm{CH}_{2}$ protons of $\alpha$-dibenzocyclooctyne- $\mathrm{B}_{12}\left(\mathrm{DBCO}-\mathrm{B}_{12}\right)$ at 5.0 and $56 \mathrm{ppm}$, for ${ }^{1} \mathrm{H}$ and ${ }^{13} \mathrm{C}$, respectively, was found to shift to 5.9 and $52 \mathrm{ppm}$, following click cycloaddition with linear $\mathrm{N}_{3}-\mathrm{PEG}_{3 \mathrm{k}}-\mathrm{lin}-\left(\mathrm{GA}_{24}\right)$ azide precursor (1), which confirmed successful conjugation. For the miktoarm $\mathrm{B}_{12}-\mathrm{PEG}_{3 \mathrm{k}}-$ mik-poly $\left(\mathrm{OBn}-\mathrm{GA}_{17}\right)_{3}$ copolymer, although the quality of the HSQC NMR data was not suitable for confirming the presence of the desired product due to a poor signal intensity, $1 \mathrm{D}{ }^{1} \mathrm{H}$ NMR indicate the appearance of the diagnostic signal at $5.9 \mathrm{pm}$ for the clicked $\mathrm{B}_{12}$ adduct, thus confirming the success of the click reaction. Size exclusion chromatography of the purified final polymers confirmed complete removal of the excess of unreacted $\alpha$-dibenzocyclooctyne- $B_{12}$ (Supporting information, Figure S4), whilst efficiency of functionalization was estimated by UV-vis spectrometry $(\lambda=$ $540 \mathrm{~nm})$ at 93 and $97 \%$ for linear $\mathrm{B}_{12}-\mathrm{PEG}_{3 \mathrm{k}}$-lin- $\left(\mathrm{GA}_{24}\right)$ and miktoarm $\mathrm{B}_{12}-\mathrm{PEG}_{3 \mathrm{k}}-$ mik- $\left(\mathrm{GA}_{17}\right)_{3}$, respectively. 
Targeted PEG-poly(GA)-lysozyme complexes. PEG-poly(GA) copolymer-protein complexes with lysozyme as a model protein cargo were assembled using a mixture of $\mathrm{B}_{12}$-targeted and non-targeted PEG-poly(GA) copolymers. In this study a 15:85 molar ratio, respectively was selected. We appreciate that the density of surface exposed targeting ligand, and indeed its clustering, has a profound effect on nanoparticles internalization, as illustrated in previous research from our and other groups. Using another nano-sized targeted system with folate ligand we previously achieved a reasonable level of cellular internalization for a range of ligand 'surface functionalization' [33], and based on that a 15:85 ratio was considered as a good starting point. A polymer-protein relative molar charge ratio of 2.5 - defined as the molar ratio between glutamic acid polymer repeating units, assumed to be all negatively charged at $\mathrm{pH}$ 7.4, and cationic amino acids of lysozyme - was used, as we have previously shown efficient complexation of PEG-poly(GA) copolymers to lysozyme under these conditions [23]. The data (Supporting information, Figures S10 and S11) indicate a formation of polymerprotein complexes in the $120-180 \mathrm{~nm}$ size range - suitable size for endocytosis - for targeted and non-targeted systems, as assessed by nanoparticle tracking analysis (NTA). Gel electrophoresis analysis of complexes suspended in cell culture medium shows that majority of lysozyme remains complexed during 3 hours of cellular internalization study, when suspended in cell growth medium, and is released on change in $\mathrm{pH}$ to 4.5 in simulated lysosomal environment (Supporting information, Figure S12).

Expression of mRNA and function of $B_{12}$ receptors. The presence of components involved in vitamin $B_{12}$-specific transport pathways has been widely confirmed in intestinal epithelium models, such as in vitro cultures of Caco-2 cells $[34,35]$, and $B_{12}$ receptors have been successfully targeted for intestinal delivery of proteins $[36,37]$, and in vitro transport of 
nanoparticles across intestinal epithelium. In the latter, $B_{12}$ transport can occur through two different receptors: cubilin and transcobalamin receptor (CD320, or TCN2R) [38]. Evidence of vitamin $B_{12}$ transport mechanisms in the lung epithelium, and its in vitro cell models, is scarce. We have previously demonstrated, using a combination of molecular biology and immunostaining techniques, that Calu-3 bronchial cell line expresses the $B_{12}$-IF receptor (cubilin), the transcobalamin receptor ('TCN2 receptor', CD320), and the transcobalamin II protein ('TCN2') [31]. The present work confirms (Figure 4a) at mRNA level, expression of cubilin (human CUBN gene), transcobalamin receptor (CD320 gene) and transcobalamin II protein (human TCN2 gene). mRNA expression of the cubilin receptor was found to be very low, relative to control gene expression. It should be noted that the mechanism of vitamin $\mathrm{B}_{12}$ uptake via cubilin receptor requires the initial complexation of $\mathrm{B}_{12}$ with Intrinsic Factor (IF, or Gastric Intrinsic factor, GIF), a glycoprotein that is produced by parietal cells in the stomach [39]. Thus it may not be surprising that cubilin-dependent transport pathway would be downregulated in Calu-3 cells, which originate from the lung tissue. Conversely, transcobalamin receptor (CD320)-mediated transport requires initial binding of vitamin $B_{12}$ to TCN2 carrier protein, followed by uptake of the resulting complex by CD320 (transcobalamin) receptor-mediated endocytosis $[40,41]$. The TCN2 protein in this complex is eventually degraded in the lysosomes, releasing cobalamin (vitamin $\mathrm{B}_{12}$ ) which is further processed intracellularly [40]. In this work, expression of mRNA for transcobalamin II protein in Calu-3 cell culture was confirmed by qPCR (Figure 4a) while in a previous study we have shown TCN2 protein expression in Calu-3 cells in a qualitative manner, by immunostaining [31]. Taken together, our results indicate that Calu-3 cell model used in this study possess all the functional components required for cellular internalization of cobalamin (vitamin $B_{12}$ ) molecules via transcobalamin (CD320) receptor-mediated transport. 
a)

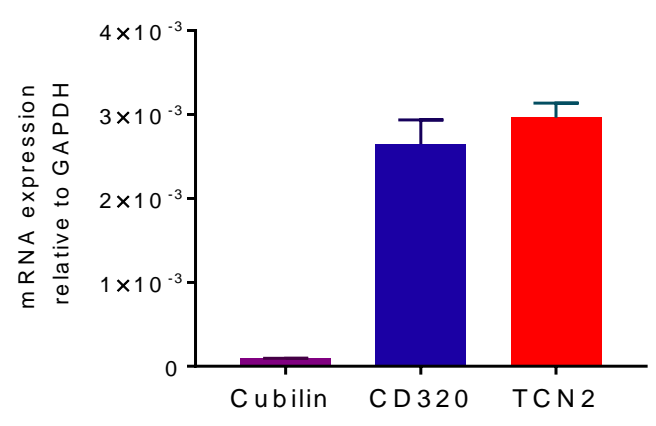

b)

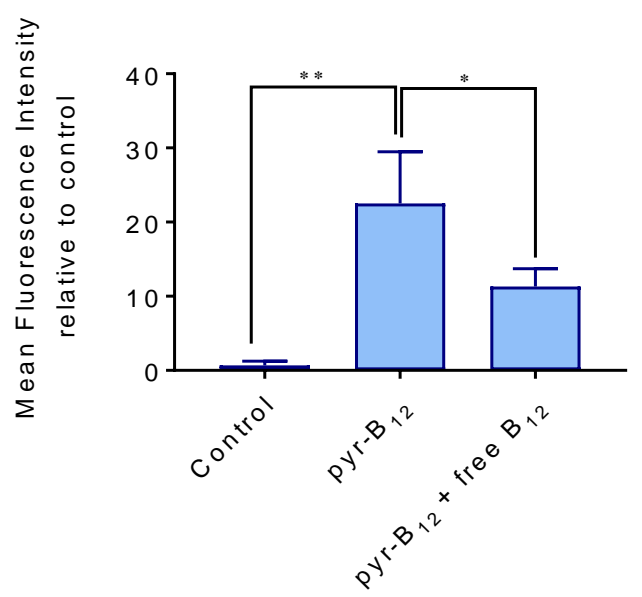

Figure 4. a) mRNA expression of cubilin, CD320 and TCN2 relative to GAPDH (as housekeeping gene) by Calu-3 cells. b) Cellular internalization of pyr-B $\mathrm{B}_{12}$ fluorescent probe by Calu-3 cells in the presence or absence of free vitamin $\mathrm{B}_{12}$ competitive ligand. Control: untreated cells. One-way ANOVA was used for statistical analysis. ${ }^{*} \mathrm{P} \leqslant$ $0.05, * * \mathrm{p} \leqslant 0.01,{ }^{* * *} \mathrm{p} \leqslant 0.001, * * * * \mathrm{p} \leqslant 0.0001$. Flow cytometry conducted at $\lambda_{\mathrm{ex}} 401 \mathrm{~nm}$ and $\lambda_{\mathrm{em}} 421 \mathrm{~nm}$.

To confirm functional, endocytic activity of vitamin $B_{12}$ receptors in Calu-3 epithelial model employed in this study, we designed a low molecular weight $B_{12}$-fluorescent probe, pyr- $B_{12}$. This O-alkyl pyranine-based fluorescent compound was selected due to its structural similarity to Lucifer Yellow, which is known to have low cell membrane permeability, while possessing functionalities appropriate for conjugating to vitamin $\mathrm{B}_{12}$. Accordingly, $\mathrm{O}$-alkyl pyranine blue-fluorescent dye with narrow Stokes shift $\left(\lambda_{\text {ex }}=401 \mathrm{~nm}, \lambda_{\mathrm{em}}=421 \mathrm{~nm}\right)$, was linked to the 5' hydroxyl group of the ribose ring of cyanocobalamin, in a similar way to the approach followed for the synthesis of DBCO-B12, in four steps, starting from 8hydroxypyrene-1,3,6-trisulfonic acid trisodium salt (pyranine), and cyanocobalamin ( $\left.\mathrm{B}_{12}\right)$ (Supporting Information, Figure S8). For comparative purposes, in another experiment cellular internalization of pyr- $\mathrm{B}_{12}$ by the established cell model expressing both cubilin and TCN2 $B_{12}$ receptors, intestinal Caco-2 cell line $[42,43]$, was also assessed (Supporting 
Information, Figure S9). Data in Figure $4 \mathbf{b}$ show a significant reduction of pyr-B ${ }_{12}$ cellular internalization in the presence of an excess of 'free' vitamin $B_{12}$ competitive ligand. This indicates a prominent, but not exclusive, role of $B_{12}$-specific transport in the cellular internalization of pyr- $\mathrm{B}_{12}$ probe, likely occurring through TCN2 receptor mediated transport.

Complement activation. An undesired effect associated with pulmonary delivery is the immunogenicity of drug delivery systems, protein cargoes, or both. Accordingly, immunogenic formulations/proteins can lead to reduced efficacy, inflammation, anaphylaxis and autoimmunity. These side-effects can result from a range of factors, including the intrinsic nature of specific protein therapeutics, and their tendency to aggregate, either during storage or in vivo, which leads to their increased immunogenicity [44-46]. The complement system has key roles in innate and adaptive immune responses. Although most complement proteins are generated in the liver as inactive precursor enzymes, the lung may also act as a local source of complement proteins [47]. In this study normal human serum was selected as a source of complement proteins, due to the ease of serum availability compared to the extraction of complement proteins present in the lungs. The ability of free lysozyme and $\mathrm{B}_{12-}$ targeted lysozyme complexes to activate the complement system was evaluated (Figure 5). At the concentration investigated $\left(1.12 \mathrm{mg} \mathrm{mL}^{-1}\right)$, 'free' lysozyme was found to activate the complement system to around $50 \%$ level, whilst for lysozyme complexes with targeted $\mathrm{B}_{12}$ $\mathrm{PEG}_{3 \mathrm{k}}-$ poly $(\mathrm{GA})$ polymers, these values decreased to 16 and $25 \%$ when linear or miktoarm copolymers were used, respectively (Figure 5).

PEG is known to decrease protein immunogenicity, following covalent PEG-protein conjugation [48]. Therefore, the reduction in immunogenic response observed for the PEGpoly(GA)-lysozyme complexes could be ascribed to the similar effect of steric stabilization 
provided by PEG chains on the complexed lysozyme. Interestingly, linear polymer showed somewhat higher protection than miktoarm copolymers, potentially indicating some differences in their complexation with the protein. Taken together, these results suggest that protein complexation with PEG-poly(GA) copolymers can reduce the complement activation triggered by model protein, lysozyme, and that, within specific contexts, this approach could potentially serve as a strategy to reduce immunogenicity of protein therapeutics.

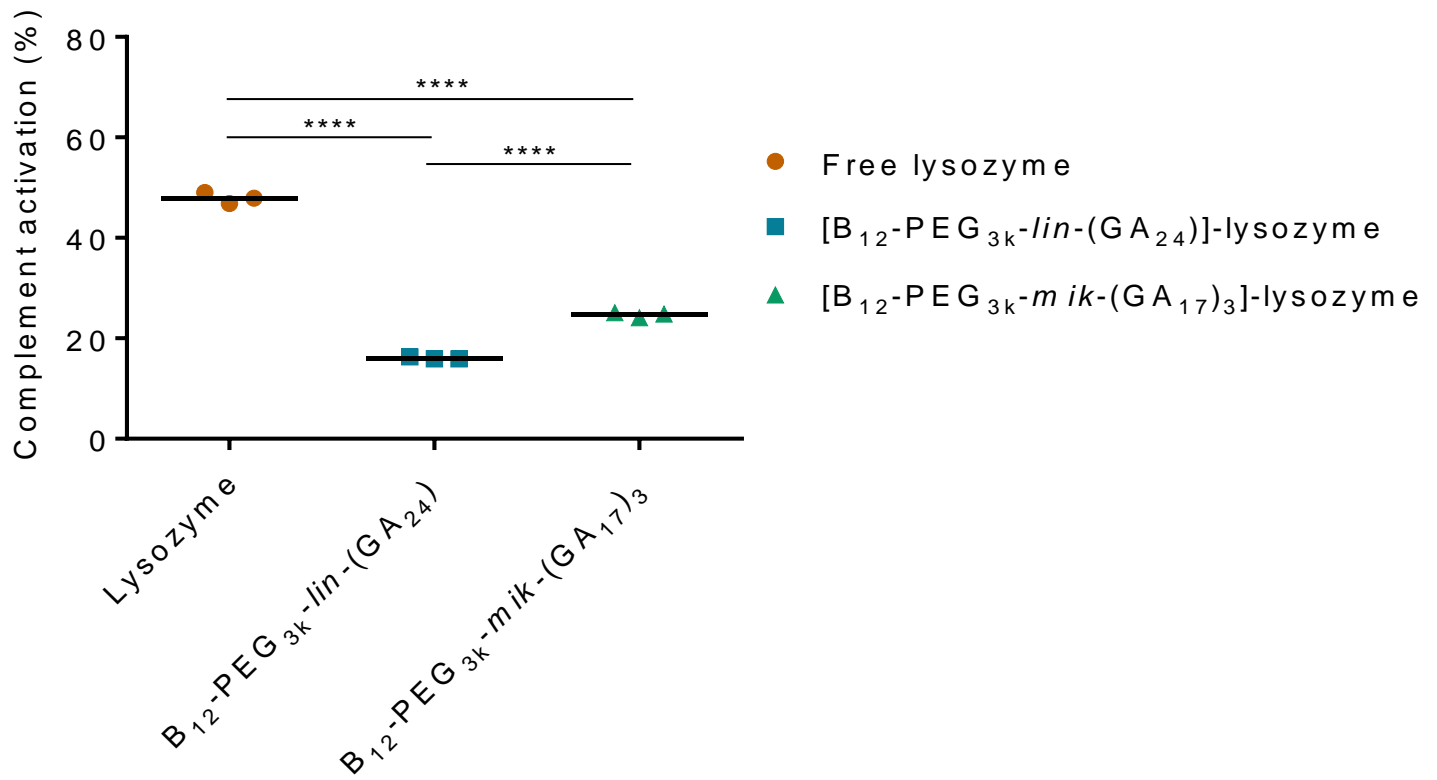

Figure 5. Complement activation by free lysozyme, linear [85:15 mPEG $2 k$-lin-GA30/B12-PEG $\mathrm{B}_{3 k}$-lin-(GA 24$)$ ]-lysozyme and miktoarm [85:15 mPEG $2 \mathrm{k}-$ mik- $\left(\mathrm{GA}_{10}\right)_{3} / \mathrm{B}_{12}-\mathrm{PEG}_{3 \mathrm{k}}-$ mik- $\left.\left(\mathrm{GA}_{17}\right)_{3}\right]$-lysozyme complexes. The data expressed as the percentage of complement activation relative to $100 \%$ complement activation observed with the positive control samples (where no haemolysis have occurred). Lysozyme concentration was kept constant to $1.12 \mathrm{mg}$ $\mathrm{mL}^{-1}$ for all samples. One-way ANOVA was used for statistical analysis. $* * * \mathrm{p}<0.001, * * * * \mathrm{p}<0.0001$.

Cellular internalization of $\mathbf{B}_{12}$-targeted protein-polymer complexes in vitro. Data in Figure 6 demonstrate significantly increased cellular internalization of targeted $B_{12}-P G_{3 k}-$ poly $(G A)-$ protein complexes, compared to 'free' Cy5-lysozyme or non-targeted mPEG $2 k$-poly(GA)lysozyme complexes. Interestingly, this effect was independent on the topology of the complexing polymers - linear $B_{12}-P E G_{3 k}-l i n-\left(G_{24}\right)$, vs. miktoarm $B_{12}-P E G_{3 k}-m i k-\left(G A_{17}\right)_{3}$. 
Importantly, cellular internalization of targeted complexes decreased significantly in the presence of an excess of 'free' vitamin $\mathrm{B}_{12}$ competitive ligand, confirming a prominent, but not exclusive, role of a vitamin $B_{12}$-specific transport mechanism in the complexes trafficking by cells.
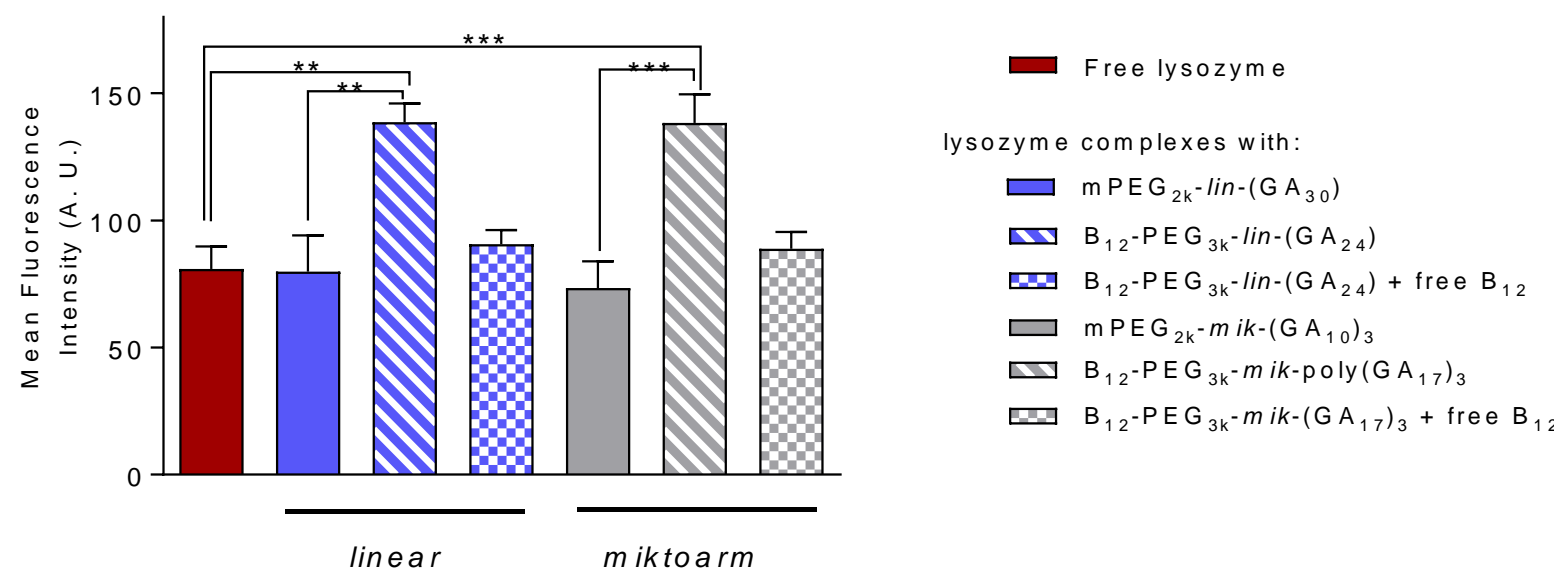

Figure 6. Cellular internalization of $\mathrm{B}_{12}$-targeted and non-targeted PEG-poly(GA)-Cy5-lysozyme complexes by Calu-3 cells grown as polarized epithelial cell layers. Suspensions of complexes were applied at protein concentration of $3 \mu \mathrm{g} \mathrm{mL}^{-1}$ and incubated with cells for $3 \mathrm{~h}$ prior to flow cytometry analysis. Cells were grown as polarized layers on Transwell supports under air-liquid interface conditions. ' + free $\mathrm{B}_{12}$ ' denotes presence of excess of soluble $B_{12}$ competitive ligand in the medium, 'free lysozyme' indicates that cells were treated with a solution of Cy5-lysozyme in the absence of PEG-poly(GA) complexing copolymers. One-way ANOVA was used for statistical analysis. ${ }^{* *} \mathrm{p}<0.01, * * * \mathrm{p}<0.001$.

The observed level of cellular internalization of 'free' cy5-lysozyme (Figure 6) was somewhat unexpected. Data on similar experiments on cellular uptake of lysozyme are scarce, but recent in vivo studies reported on absorption of lysozyme in the intestinal tract [49], which appears to be occurring by non-saturable and saturable processes, the latter pointing to an involvement of endocytic pathway(s). Furthermore, it has recently been suggested that receptor-mediated endocytosis of lysozyme in renal proximal tubules may be mediated by megalin and cubilin [50]; the mRNA expression, although at a very low level, of the latter 
receptor was confirmed in the cell model used in this study. Furthermore it should be noted that complexation of lysozyme with non-targeted copolymers resulted in similar level of internalization as for 'free' lysozyme (Figure 6), a result that would be unexpected if one considers that PEGylation is generally recognized to reduce cellular uptake of colloidal size particulates [51]. As noticed above, the $\mathrm{B}_{12}$-mediated pathway does not appear to be an exclusive transport mechanism for tested systems in the cellular model used, and hence further studies to decipher internalization pathways would be needed, e.g. [52]. These are however beyond the scope of the current work that aims to design targeted excipients for inhalable dry powder formulations.

It should be noted that our study used polarized, differentiated epithelial cell layer grown at air-liquid interface, and although a number of previous reports studied intracellular delivery of self-assembled protein carrying systems, these are conducted on a variety of non-polarized cells, such as HeLa and dendritic cells $[53,54]$, which makes direct comparisons difficult.

Aiming at developing inhalable formulations, we spray-dried PEG-poly(GA)-protein complexes using a 'standard' process and excipients. In these formulations, trehalose was selected as the matrix excipient due to its well characterized ability to stabilize biologics. When spray dried, trehalose creates an amorphous matrix that forms hydrogen bonds with biologic materials and protects structural integrity following the removal of water. Other excipients that are approved for inhalation formulations, such as mannitol and lactose, are known to crystallize when spray dried, limiting their ability to provide a protective amorphous matrix. The amorphous nature of trehalose renders the particles hygroscopic and highly cohesive. This limits the ability of passive inhalers to efficiently disperse the powder to a respirable size ( $<5 \mu \mathrm{m}$ aerodynamic diameter) for lung delivery. Leucine is a surface active 
amino acid that accumulates at the surface of the droplet during the spray drying process. This results in high concentrations of leucine localized to the particle surface in comparison to the particle interior. This deposition changes the properties of the spray dried particle, decreasing cohesion and therefore reducing the energy required to efficiently disperse the powder to a respirable size during inhalation. The addition of leucine dramatically improves the fine particle fraction achievable from the device, directly translating into improved deposition properties of the powder [24]. The resulting formulations possessed aerodynamic properties suitable for inhalable product, with particle size $\left(D_{50}\right)<5 \mu \mathrm{m}$ (Supporting information, Table S1). 10\% loading level was selected to ensure stability of the nanocomplexes during the spray drying process and to maintain efficient aerosol performance. In this instance, the powders exhibited comparable aerosol performance when formulated as the placebo formulation (trehalose and leucine) and as the nano-complex loaded powder (loaded at $10 \%$ level), indicating that inclusion of the nano-complexes did not change the particle properties. These formulations were shown to maintain lysozyme biological activity [24]. They were applied as dry powders to Calu-3 cell layers grown at air-liquid interface, and in in vivo studies, by Penn-Century ${ }^{\circledR}$ insufflator device. Particle morphology, size and size distribution prior and following spraying by the insufflator are shown in Figure 7 (and Supporting Information, Tables S1, S2 and Figure S14). SEM images in Figure 7 illustrate spherical particle shape of dry powders prior and following spraying with insufflator device for formulations prepared with PEG-poly(GA)-lysozyme complexes. Interestingly, some loss of spherical morphology for powders containing 'free' lysozyme is seen, indicating in turn that complexation of the protein with PEG-poly $(G A)$ provided a level of structural stabilization of the formulations. 


\section{(PEG-lin-GA ${ }_{30}$ ) - Lysozyme Complexes}

A

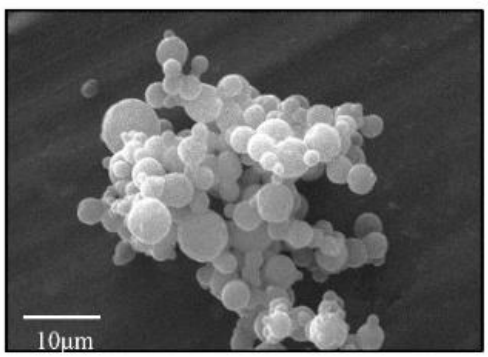

B

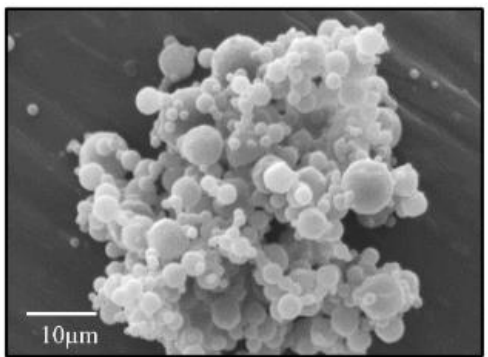

(PEG-mik- $\left.\left(\mathrm{GA}_{10}\right)_{3}\right)$ -

Lysozyme Complexes
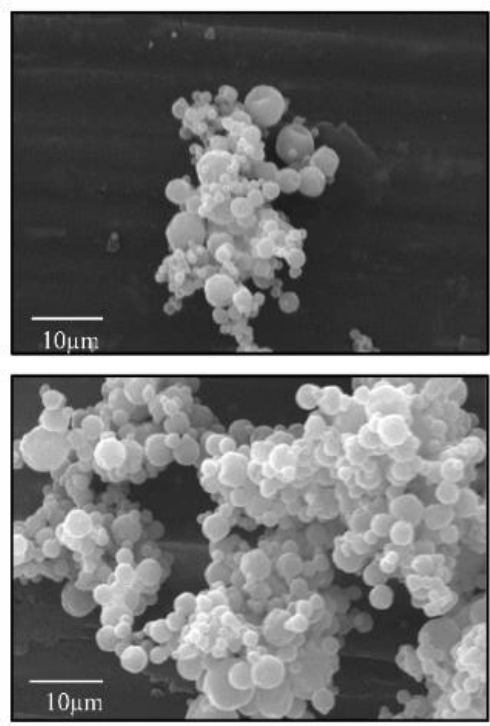

Free lysozyme
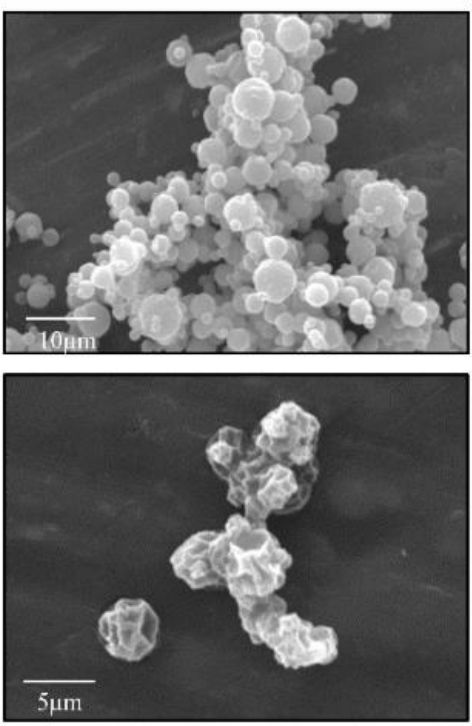

Figure 7. Scanning electron microscopy images of PEG-poly(GA)-lysozyme complexes formulated as dry powders by spray drying. Upper row A) dry powder formulations prior spraying and lower row B) following spraying of formulated dry powders through a Penn-Century ${ }^{\circledR}$ insufflator device. All dry powders contain $6.6 \%(\mathrm{w} / \mathrm{w})$ phosphate salts, $10 \%(\mathrm{w} / \mathrm{w})$ leucine and up to $100 \%(\mathrm{w} / \mathrm{w})$ trehalose. Image for free lysozyme after spraying through Penn-Century ${ }^{\circledast}$ insufflator is presented at enlarged scale to emphasize morphology change.

In line with the results obtained for cells treatment with suspensions of PEG-poly(GA)-protein complexes (Figure 6), application of respective dry powders demonstrates a significantly higher cellular internalization of targeted $\left[\mathrm{B}_{12}-\mathrm{PEG}_{3 k}\right.$-poly $\left.(\mathrm{GA})\right]$-Cy5-lysozyme complexes, relative to 'free' lysozyme, or non-targeted complexes (Figure 8). The results hence indicate that i) $B_{12}$-targeted PEG-poly(GA)-lysozyme complexes can be formulated into dry powders by spray drying process, ii) the complexation somewhat protects the powder morphology on subsequent exposure to spraying, and iii) $\mathrm{B}_{12}$-targeted complexes are released from dry powders formulations under aqueous conditions, to then be internalized by the epithelial cells. 


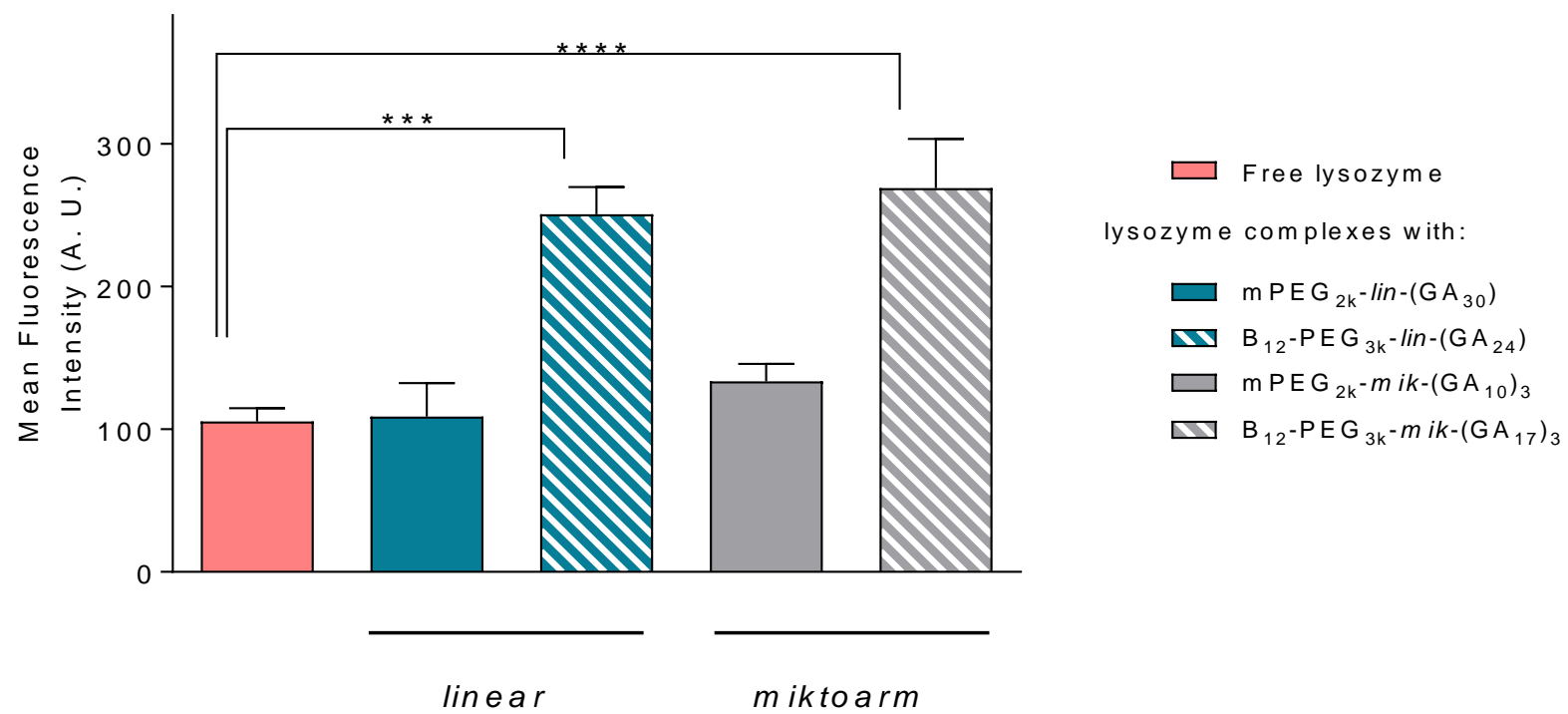

Figure 8. Cellular internalization of $B_{12}$-targeted and non-targeted PEG-poly(GA):Cy5-lysozyme complexes formulated into dry powders in in vitro Calu-3 epithelial model. Samples were applied as dry powders using dry powder insufflator (PenCentury insufflator) directly onto apical side of the Calu-3 cells grown as polarized layers on Transwell supports under air-liquid interface conditions (Supporting information, Figure S13). 'Free lysozyme' denotes dry powder formulated from Cy5-lysozyme in the absence of complexing polymers. All dry powders contain phosphate buffer salts $(6.6 \% \mathrm{w} / \mathrm{w})$, leucine $(10 \% \mathrm{w} / \mathrm{w})$ and trehalose (up to $100 \% \mathrm{w} / \mathrm{w})$. Oneway ANOVA was used for statistical analysis. *** $\mathrm{p}<0.001, * * * * \mathrm{p}<0.0001$.

\section{Local pulmonary tolerance of polymer-protein complexes-based dry powder formulations}

in healthy mice. The safety profile of PEG-poly(GA)-lysozyme complexes formulated as dry powder inhalable formulations was investigated in healthy mice. Previous reports have shown that administration of polymer-based pulmonary formulations can induce inflammatory responses $[55,56]$, whilst the presence in dry powder formulations of poorly soluble material has been shown to induce local irritation and pro-inflammatory effect in the respiratory tract $[57,58]$. In addition, the delivery of proteins to the lungs has been shown to induce immunogenicity, local irritation and toxicity [59-61]. In this work, we evaluated the lung tolerance profile of PEG-poly(GA)-lysozyme dry powders in healthy BALB/c mice, by quantifying cell count and local concentration of IL-1 1, IL- 6 and TNF- $\alpha$ cytokine in bronchoalveolar lavage fluids after endotracheal administrations of $2 \mathrm{mg}$ of dry powders 3 
times per week, for 3 weeks period. The dose and the administration schedules were established taking into account limitations of the preclinical mice model. Aimed, and achieved, administration of $2 \mathrm{mg}$ (Supporting information, Table S1), corresponds to a dose of $\sim 100 \mathrm{mg} / \mathrm{kg}$ of powder mass and $\sim 10 \mathrm{mg} / \mathrm{kg}$ protein - within a range potentially expected of a therapeutic protein to be delivered in humans. The administration schedule was devised taking into account limitations associated with general anaesthesia of mice during endotracheal instillation and their well-being. 48 hours (i.e. three doses per week) was previously assessed as the minimum interval between two such administration procedures $[62,63]$. Systems tested included: dry powder formulation of [mPEG2k-lin-GA30/B12-PEG3klin-(GA24)]-lysozyme targeted complexes (UDP-TC), formulation containing only dry powder excipients (UDP), and system containing 'free' lysozyme formulated with dry powder excipients but with no polymers to complex the protein (UDP-P) (the compositions of these formulations are shown in Table 1).

Firstly, the potential inflammatory response of these formulations was investigated by quantification of the concentration of IL-1 $\beta$, IL-6, and TNF- $\alpha$ pro-inflammatory cytokines [64, 65], in the epithelial lining fluid of the lungs. Mice treated with lipopolysaccharide (LPS) - outer membrane component of Gram-negative bacteria known as a strong stimulator of innate or natural immunity [66] - were used as a positive control group. As expected, a significant increase in IL-1 $\beta, I L-6$, and TNF- $\alpha$ level was observed on LPS treatment, compared to untreated mice (Figure 9). The levels of measured cytokines did not increase significantly above the negative control level (untreated mice group) following administration of dry powder formulations. The data hence clearly illustrate that on a repeated, prolonged administration the tested PEG-poly(GA)-based formulations are well tolerated . 
IL $-1 \beta$

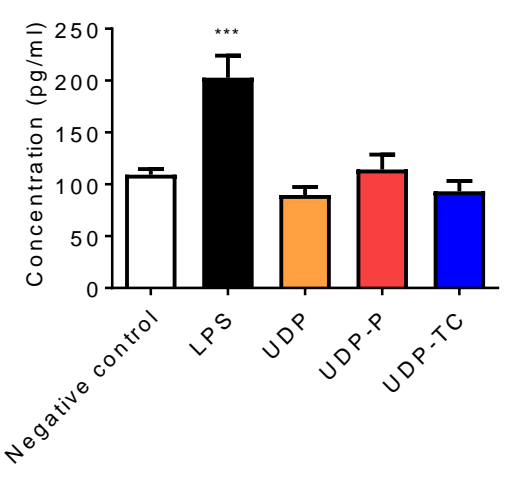

IL-6

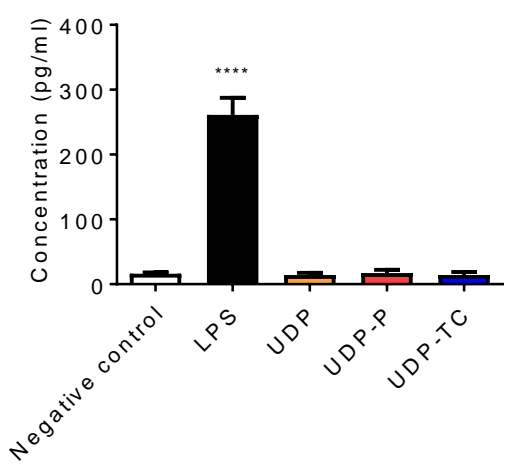

TNF- $\alpha$

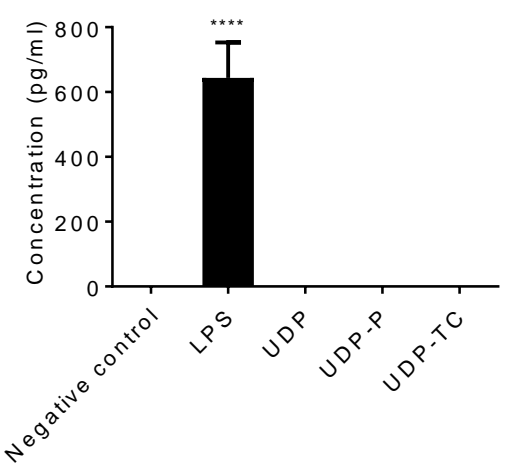

Figure 9. Pro-inflammatory cytokine IL-1 $\beta, I L-6$, and TNF- $\alpha$ gene expression in lung tissues following administration of $2 \mathrm{mg}$ of dry powder formulations 3 times a week for 3 weeks. Mice groups were untreated (negative control) or treated with LPS (positive control), treated with a formulation containing only dry powder excipients (UDP), free lysozyme formulation containing lysozyme and dry powder excipients (UDP-P), and dry powder formulation containing targeted complexes (UDP-TC) - with 85:15 [mPEG $2 \mathrm{k}-l i n-\mathrm{GA}_{30} / \mathrm{B}_{12}-\mathrm{PEG}_{3 \mathrm{k}}-\mathrm{lin}$ $\left(\mathrm{GA}_{24}\right)$ ]-lysozyme composition. One-way ANOVA was used for statistical analysis. ${ }^{* * *} \mathrm{p}<0.001, * * * * \mathrm{p}<0.0001$.

To further investigate the tolerability of the designed dry powder formulations upon pulmonary administration, the differential cell count of alveolar macrophages (AM), polymorphonuclear neutrophils (PMN), and lymphocytes (LM) was also performed (Figure 11). Following single administration of $1 \mu \mathrm{g}$ LPS, the number of AM dramatically decreased to around $50 \%$ relative to untreated mice, whereas the percentage of PMN significantly increased, clearly indicating a pro-inflammatory reaction. On the contrary, all the dry powder formulations had values for AM, PMN and LM at the level similar to untreated mice control. This was qualitatively confirmed by optical microscopy observations (Figure 10). These experiments thus suggest that, under the conditions investigated, $B_{12}-P E G-p o l y(G A)-l y s o z y m e$ complexes-based dry powder formulations are well tolerated in the lungs following endotracheal administration, with no significant toxicity or lung inflammation observed. 

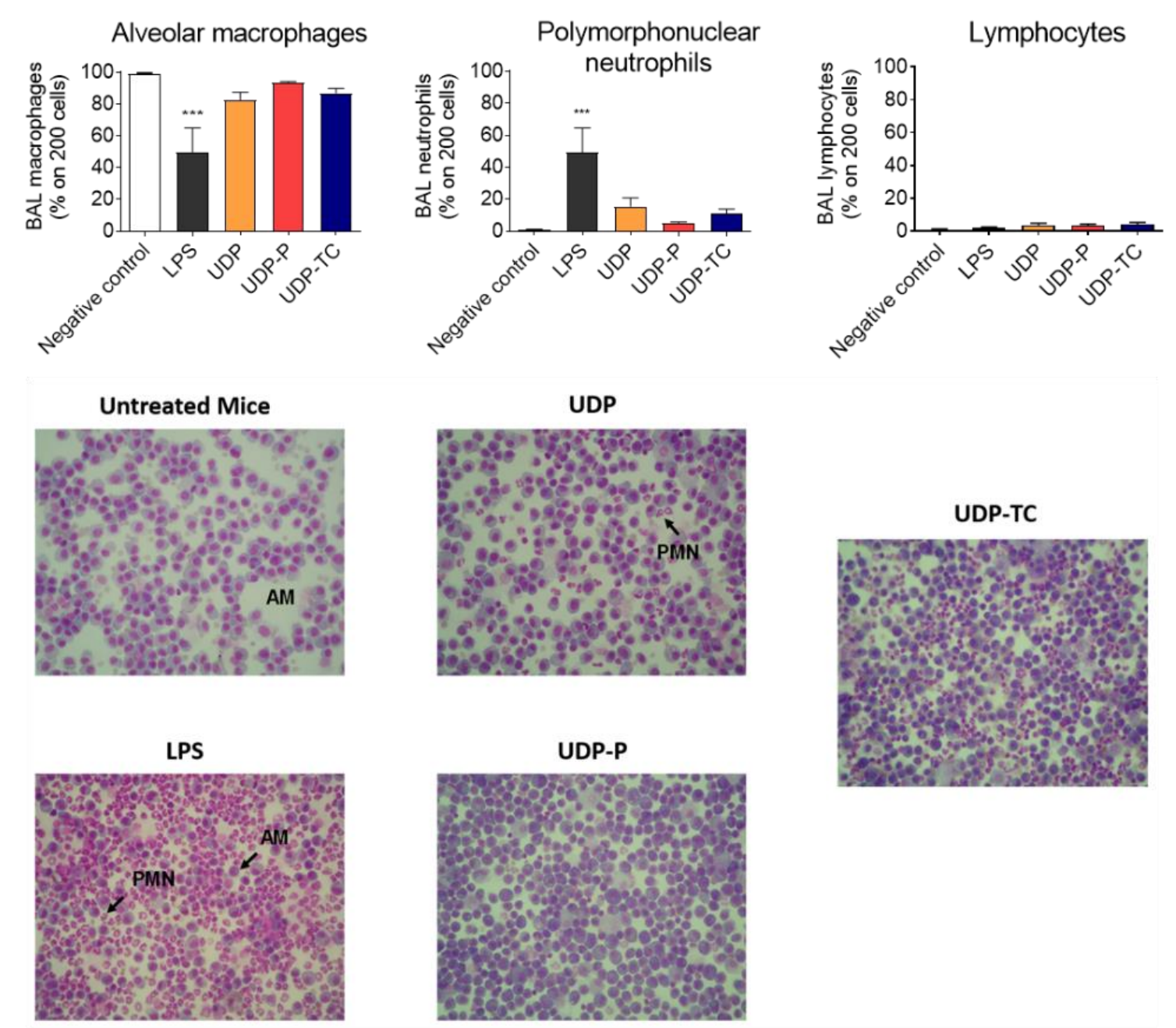

Figure 10. Bronchoalveolar lavage fluid analysis following a single administration of dry powder formulations. Differential cell count and representative images of different cells found in the bronchoalveolar lavage fluid. Mice groups were not treated ((negative control) or treated with single administration of $1 \mu \mathrm{g}$ LPS (positive control), and $2 \mathrm{mg}$ of dry powder formulation containing formulation excipients (UDP), free lysozyme dry powder formulation (UDP-P), or dry powder formulation containing targeted complexes (UDP-TC) [with composition of 85:15 mPEG 2 -lin-GA30/B $12-P_{2} G_{3 k}$-lin-(GA24)]-lysozymes] 3 times a week for 3 weeks. One-way ANOVA was used for statistical analysis. ${ }^{* * *} \mathrm{p}<0.001, * * * * \mathrm{p}<0.0001$.

\section{In vivo pulmonary deposition and retention of polymer-protein complexes-based dry}

powder formulations in healthy mice. Pulmonary delivery of particle formulations can be challenging, due to different particle clearance mechanisms present at various levels of the airway path in the lungs, such as the mucociliary escalator, proteolytic degradation and macrophage capture [67]. However, a design of drug delivery system can potentially overcome these removal mechanisms [67] and, by prolonging the time of exposure of lung 
tissue to relevant protein therapeutics, enhance their therapeutic effects. In this part of our study, the ability of $\mathrm{PEG}_{3 \mathrm{k}}-\left(\mathrm{GA}_{24}\right)$-lysozyme complexes to increase the retention of proteins in the lungs was assessed.

Accordingly, a $2 \mathrm{mg}$ dose of dry powder formulation (Supporting information, Table S2, Figure S14) was administered to healthy mice by the endotracheal route, using a PennCentury insufflator. Figure 11 shows the lung distribution of Cy5-labelled lysozyme following administration of dry powder formulation containing free Cy5-labelled lysozyme (LDP-P), dry powder formulation containing non-targeted $\mathrm{mPEG}_{2 \mathrm{k}}$-lin-(GA $\left.\mathrm{G}_{30}\right)$-labelled lysozyme complexes (LDP-NT), and dry powder formulation containing 85:15 [mPEG ${ }_{2 k}-$ lin-GA $A_{30} / B_{12}-P_{E G} G_{3 k}-l i n-$ $\left(\mathrm{GA}_{24}\right)$ ]-lysozyme targeted complexes (LDP-TC). Five non-serial cryo-sections of $7 \mu \mathrm{m}$ thickness per lung were prepared, imaged by fluorescence microscopy (Supporting Information, Figure S15), and representative examples are shown in Figure 11. Images depict that immediately following administration (at $\mathrm{t}=0 \mathrm{~h}$ ) Cy5-lysozyme powders were indeed deposited in the lungs, which agrees with the previous studies reporting that dry powders with good dispersion properties can be deposited in the respiratory zone in the mouse lungs [68]. Fluorescent images obtained from different lung tissue sections however indicate that the deposition was not homogeneous throughout the lung (Supporting Information Figure S15), which increases complexity in making comparisons between the systems tested. This non-homogeneous deposition pattern have also been observed in other studies $[63,69,70]$. However, analysis of the images (Figure 11, graph) indicates that in different samples imaged at 14 hours after the administration of dry powders the fluorescence arising from Cy5lysozyme is higher, relative to nuclear DAPI staining, for targeted complexes formulations (LDP-TC) in comparison to formulations containing 'free' (LDP-P) and non-targeted Cy5- 
lysozyme complexes (LDP-NT). This would indicate lengthier protein lung retention for the targeted formulation. All data considered, the lung deposition experiment provides an initial evidence of prolonged protein retention following administration of vitamin $B_{12}$-targeted complexes. Further studies are needed to confirm if this prolonged retention is indeed a consequence of the increased cellular internalization of targeted complexes seen in the in vitro cell culture experiment, and if this would lead to a potentially improved therapeutic effect of such delivered protein in the lung. Nevertheless, the in vivo deposition experiment suggests that targeted polymer-protein complexes can influence and potentially extend retention time of the protein cargo in the lungs.
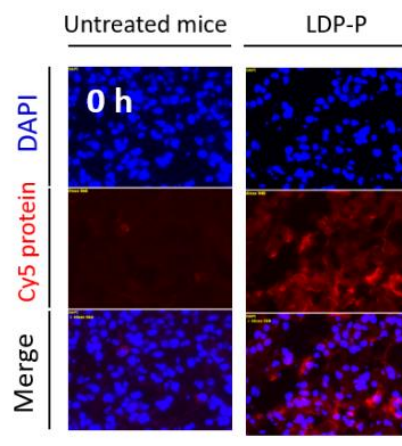

LDP - NT

LDP-TC
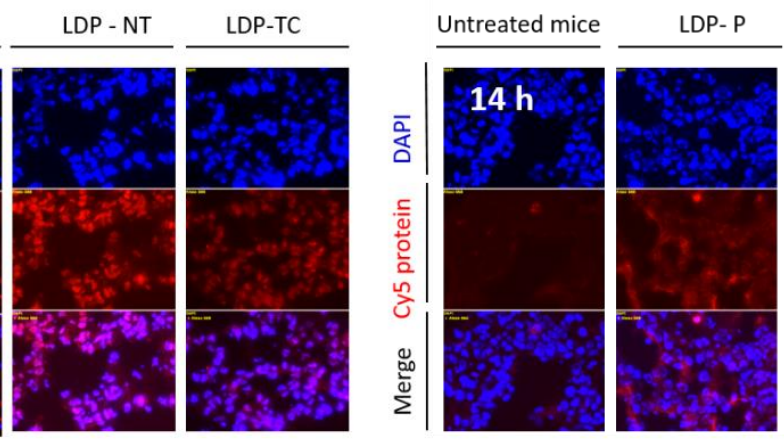

LDP-NT

LDP-TC
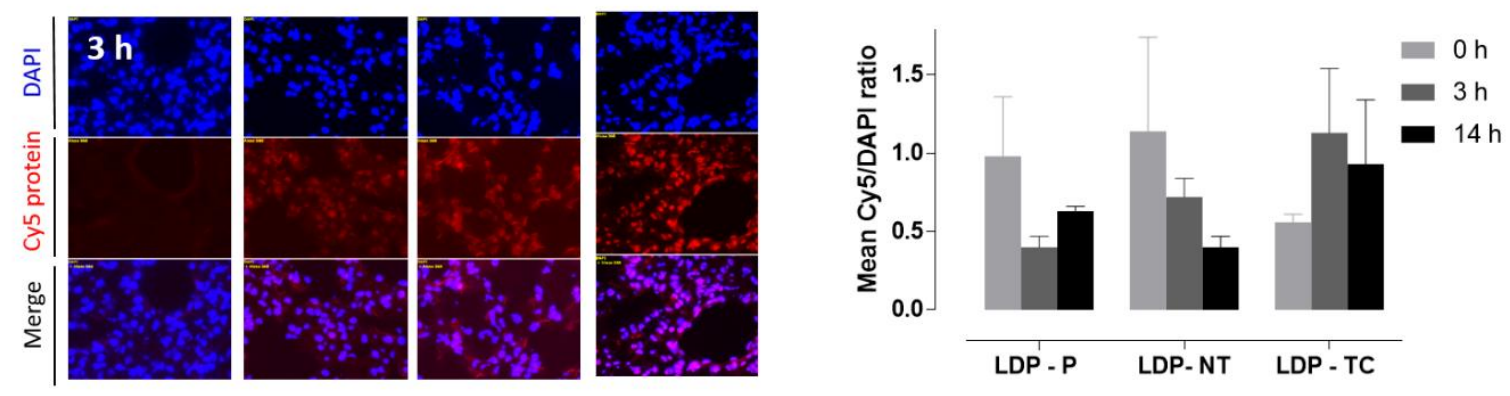

Figure 11. Distribution of fluorescent labelled protein in the lung tissue of healthy mice following endotracheal application using the pulmonary delivery device of $2 \mathrm{mg}$ dry powder formulations at different times after administration (in hours). Examples of a 7- $\mu \mathrm{m}$ longitudinal, non-consecutive lung cryo-sections imaged using a fluorescent microscope at $200 \times$ magnification are shown (also in Supporting Information Figure S15). The images show the distribution of red labelled lysozyme-Cy5 ('Cy5 protein'), blue nuclear stain ('DAPI') and merged images ('Merged'); LDP-TC denotes dry powder formulation of [85:15 mPEG 2 -lin-GA $\left.A_{30} / B_{12}-P E_{3 k}-l i n-\left(G A_{24}\right)\right]-$ lysozyme complexes), LDP-NT drug powder formulation of [ $\mathrm{mPEG}_{2 \mathrm{k}}$-lin-GA30]-lysozyme non-targeted complexes, and LDP-P denotes free protein dry powder (without complexing polymers) formulation. Graph shows calculated ratio of Cy5 to DAPI emission intensity, obtained by analysis of images from 5 non-serial, random cryo-sections 
per lung (adopted from Dawson et al [28]). Low ratio for LDP-TC at $0 \mathrm{~h}$ illustrates the effect of non-homogeneous lung deposition on material present in the cryo-sections prepared for in the analysis.

\section{Conclusions}

In this study, we assessed the potential of vitamin $B_{12}$ ligand-targeted poly(ethylene glycol)block-poly(glutamic acid) copolymers to self-assemble with a protein cargo into polymerprotein complexes, with the aim to design an inhalation product with prolonged lung retention and intracellular delivery of protein to the lung epithelium. Our study shows that PEG-poly(GA)-protein complexes did not trigger significant complement activation, nor did they induce an increased production of pro-inflammatory cytokines in a chronic, repeated administration study in heathy mice. Furthermore, no changes in cell count of alveolar macrophages, polymorphonuclear neutrophils and lymphocytes, relative to untreated control, were observed that would indicate development of an inflammation process in the lung. Hence, toxicity data demonstrate that PEG-poly(GA) polymers based formulations are well tolerated in the lungs following chronic treatment, with no significant toxicity or lung inflammation indications.

The data demonstrate a $\mathrm{B}_{12}$-receptor mediated internalization of $\mathrm{B}_{12}$ ligand-targeted PEGpoly(GA)-protein complexes in vitro in differentiated, polarized Calu-3 cells epithelial model. When fabricated into dry powders for inhalation using a standard spray drying procedure, and applied in vivo, the deposition data show prolonged lung retention of the protein cargo at 14 hours after administration for targeted $B_{12}$-PEG-poly(GA)-protein complexes, relative to non-targeted or 'free' protein formulations. Taken together the results presented in this study show that vitamin $B_{12}-\mathrm{PEG}-$ poly $(\mathrm{GA})$ copolymers have a potential as a new class of targeted 'excipients' for inhalation delivery of protein drugs to the lungs. 


\section{Acknowledgements}

Vectura Group plc and the School of Pharmacy at the University of Nottingham are acknowledged for funding Alejandro Nieto-Orellana and Huitong Li's PhD studentships. The authors would like to thank Dr. Ruggero Foralosso for providing insight and expertise that assisted the research.

Data created during this research are openly available from the corresponding authors (snjezana.stolnik@nottingham.ac.uk and giuseppe.mantovani@nottingham.ac.uk) and at the University of Nottingham Research Data Management Repository (https://rdmc.nottingham.ac.uk/), and data supporting this study are provided as supplementary information accompanying this paper.

\section{References}

[1] J.S. Patil, S. Sarasija, Pulmonary drug delivery strategies: A concise, systematic review, Lung India : Official Organ of Indian Chest Society, 29 (2012) 44-49.

[2] S. Rohatagi, F. Calic, N. Harding, M.L. Ozoux, J.P. Bouriot, S. Kirkesseli, L. DeLeij, B.K. Jensen, Pharmacokinetics, pharmacodynamics, and safety of inhaled cyclosporin A (ADI628) after single and repeated administration in healthy male and female subjects and asthmatic patients, J. Clin. Pharmacol., 40 (2000) 1211-1226.

[3] O. Merimsky, E. Gez, R. Weitzen, H. Nehushtan, R. Rubinov, H. Hayat, T. Peretz, M. BenShahar, H. Biran, R. Katsenelson, V. Mermershtein, D. Loven, N. Karminsky, A. Neumann, D. Matcejevsky, M. Inbar, Targeting pulmonary metastases of renal cell carcinoma by inhalation of interleukin-2, Ann. Oncol., 15 (2004) 610-612.

[4] D.C. Klonoff, Afrezza inhaled insulin: the fastest-acting FDA-approved insulin on the market has favorable properties, J. Diabetes Sci. Technol., 8 (2014) 1071-1073.

[5] M.P. Baker, H.M. Reynolds, B. Lumicisi, C.J. Bryson, Immunogenicity of protein therapeutics: The key causes, consequences and challenges, Self Nonself, 1 (2010) 314-322. [6] A. Hussain, J.J. Arnold, M.A. Khan, F. Ahsan, Absorption enhancers in pulmonary protein delivery, J. Controlled Release, 94 (2004) 15-24. 
[7] A. Abuchowski, J.R. McCoy, N.C. Palczuk, T. van Es, F.F. Davis, Effect of covalent attachment of polyethylene glycol on immunogenicity and circulating life of bovine liver catalase, J. Biol. Chem., 252 (1977) 3582-3586.

[8] P.L. Turecek, M.J. Bossard, F. Schoetens, I.A. Ivens, PEGylation of Biopharmaceuticals: A Review of Chemistry and Nonclinical Safety Information of Approved Drugs, J. Pharm. Sci., 105 (2016) 460-475.

[9] Y.S. Youn, J.E. Jeon, S.Y. Chae, S. Lee, K.C. Lee, PEGylation improves the hypoglycaemic efficacy of intranasally administered glucagon-like peptide- 1 in type 2 diabetic $\mathrm{db} / \mathrm{db}$ mice, Diabetes Obes. Metab., 10 (2008) 343-346.

[10] T.H. Kim, C.W. Park, H.Y. Kim, M.H. Chi, S.K. Lee, Y.M. Song, H.H. Jiang, S.M. Lim, Y.S. Youn, K.C. Lee, Low molecular weight $(1 \mathrm{kDa})$ polyethylene glycol conjugation markedly enhances the hypoglycemic effects of intranasally administered exendin- 4 in type 2 diabetic db/db mice, Biol. Pharm. Bull., 35 (2012) 1076-1083.

[11] M.A. Croyle, A. Patel, K.N. Tran, M. Gray, Y. Zhang, J.E. Strong, H. Feldmann, G.P. Kobinger, Nasal delivery of an adenovirus-based vaccine bypasses pre-existing immunity to the vaccine carrier and improves the immune response in mice, PLoS One, 3 (2008) e3548.

[12] M.N. Sahib, Y. Darwis, K.K. Peh, S.A. Abdulameer, Y.T. Tan, Rehydrated sterically stabilized phospholipid nanomicelles of budesonide for nebulization: physicochemical characterization and in vitro, in vivo evaluations, International journal of nanomedicine, 6 (2011) 2351-2366. [13] K. Kataoka, T. Matsumoto, M. Yokoyama, T. Okano, Y. Sakurai, S. Fukushima, K. Okamoto, G.S. Kwon, Doxorubicin-loaded poly(ethylene glycol)-poly(beta-benzyl-L-aspartate) copolymer micelles: their pharmaceutical characteristics and biological significance, J. Control. Release, 64 (2000) 143-153.

[14] J.K. Dozier, M.D. Distefano, Site-Specific PEGylation of Therapeutic Proteins, Int. J. Mol. Sci., 16 (2015) 25831-25864.

[15] A. Kato, S. Tanimoto, Y. Muraki, K. Kobayashi, I. Kumagai, Structural and functional properties of hen egg-white lysozyme deamidated by protein engineering, Biosci. Biotechnol. Biochem., 56 (1992) 1424-1428.

[16] J.A. Rodriguez-Martinez, R.J. Sola, B. Castillo, H.R. Cintron-Colon, I. Rivera-Rivera, G. Barletta, K. Griebenow, Stabilization of alpha-chymotrypsin upon PEGylation correlates with reduced structural dynamics, Biotechnol. Bioeng., 101 (2008) 1142-1149.

[17] A. Harada, K. Kataoka, Novel Polyion Complex Micelles Entrapping Enzyme Molecules in the Core: Preparation of Narrowly-Distributed Micelles from Lysozyme and Poly(ethylene glycol)-Poly(aspartic acid) Block Copolymer in Aqueous Medium, Macromolecules, 31 (1998) 288-294.

[18] D. Tsiourvas, Z. Sideratou, N. Sterioti, A. Papadopoulos, G. Nounesis, C.M. Paleos, Insulin complexes with PEGylated basic oligopeptides, J. Colloid Interface Sci., 384 (2012) 61-72.

[19] S. Salmaso, S. Bersani, F. Mastrotto, G. Tonon, R. Schrepfer, S. Genovese, P. Caliceti, Selfassembling nanocomposites for protein delivery: Supramolecular interactions between PEGcholane and rh-G-CSF, J. Controlled Release, 162 (2012) 176-184.

[20] E. Ambrosio, M. Barattin, S. Bersani, S. Shubber, S. Uddin, C.F. van der Walle, P. Caliceti, S. Salmaso, A novel combined strategy for the physical PEGylation of polypeptides, J. Controlled Release, 226 (2016) 35-46.

[21] S. Salmaso, S. Bersani, A. Scomparin, A. Balasso, C. Brazzale, M. Barattin, P. Caliceti, A novel soluble supramolecular system for sustained rh-GH delivery, J. Controlled Release, 194 (2014) 168-177. 
[22] C.I. Grainger, L.L. Greenwell, D.J. Lockley, G.P. Martin, B. Forbes, Culture of Calu-3 cells at the air interface provides a representative model of the airway epithelial barrier, Pharm. Res., 23 (2006) 1482-1490.

[23] A. Nieto-Orellana, M. Di Antonio, C. Conte, F.H. Falcone, C. Bosquillon, N. Childerhouse, G. Mantovani, S. Stolnik, Effect of polymer topology on non-covalent polymer-protein complexation: miktoarm versus linear mPEG-poly(glutamic acid) copolymers, Polymer Chemistry, 8 (2017) 2210-2220.

[24] A. Nieto-Orellana, D. Coghlan, M. Rothery, F.H. Falcone, C. Bosquillon, N. Childerhouse, G. Mantovani, S. Stolnik, Dry-powder formulations of non-covalent protein complexes with linear or miktoarm copolymers for pulmonary delivery, Int. J. Pharm., 540 (2018) 78-88.

[25] E. Cingolani, S. Alqahtani, R.C. Sadler, D. Prime, S. Stolnik, C. Bosquillon, In vitro investigation on the impact of airway mucus on drug dissolution and absorption at the airepithelium interface in the lungs, Eur. J. Pharm. Biopharm., 141 (2019) 210-220.

[26] M. Bivas-Benita, R. Zwier, H.E. Junginger, G. Borchard, Non-invasive pulmonary aerosol delivery in mice by the endotracheal route, Eur. J. Pharm. Biopharm., 61 (2005) 214-218.

[27] R. Rosiere, M. Van Woensel, V. Mathieu, I. Langer, T. Mathivet, M. Vermeersch, K. Amighi, N. Wauthoz, Development and evaluation of well-tolerated and tumor-penetrating polymeric micelle-based dry powders for inhaled anti-cancer chemotherapy, Int. J. Pharm., 501 (2016) 148-159.

[28] M.R. Dawson, D.G. Duda, S.S. Chae, D. Fukumura, R.K. Jain, VEGFR1 activity modulates myeloid cell infiltration in growing lung metastases but is not required for spontaneous metastasis formation, PLoS One, 4 (2009) e6525.

[29] G.J. Russell-Jones, S.W. Westwood, A.D. Habberfield, Vitamin B12 mediated oral delivery systems for granulocyte-colony stimulating factor and erythropoietin, Bioconjug. Chem., 6 (1995) 459-465.

[30] P. Tuma, A.L. Hubbard, Transcytosis: crossing cellular barriers, Physiol. Rev., 83 (2003) 871-932.

[31] R. Fowler, D. Vllasaliu, F.H. Falcone, M. Garnett, B. Smith, H. Horsley, C. Alexander, S. Stolnik, Uptake and transport of B(12)-conjugated nanoparticles in airway epithelium, J. Controlled Release, 172 (2013) 374-381.

[32] R. Fowler, D. Vllasaliu, F.F. Trillo, M. Garnett, C. Alexander, H. Horsley, B. Smith, I. Whitcombe, M. Eaton, S. Stolnik, Nanoparticle transport in epithelial cells: pathway switching through bioconjugation, Small, 9 (2013) 3282-3294.

[33] A.O. Saeed, J.P. Magnusson, E. Moradi, M. Soliman, W. Wang, S. Stolnik, K.J. Thurecht, S.M. Howdle, C. Alexander, Modular construction of multifunctional bioresponsive celltargeted nanoparticles for gene delivery, Bioconjug. Chem., 22 (2011) 156-168.

[34] C.J. Dix, I.F. Hassan, H.Y. Obray, R. Shah, G. Wilson, The transport of vitamin B12 through polarized monolayers of Caco-2 cells, Gastroenterology, 98 (1990) 1272-1279.

[35] K.S. Ramanujam, S. Seetharam, M. Ramasamy, B. Seetharam, Expression of cobalamin transport proteins and cobalamin transcytosis by colon adenocarcinoma cells, Am. J. Physiol., 260 (1991) G416-422.

[36] G.J. Russell-Jones, L. Arthur, H. Walker, Vitamin B12-mediated transport of nanoparticles across Caco-2 cells, Int. J. Pharm., 179 (1999) 247-255.

[37] K.B. Chalasani, G.J. Russell-Jones, A.K. Jain, P.V. Diwan, S.K. Jain, Effective oral delivery of insulin in animal models using vitamin B12-coated dextran nanoparticles, J. Control. Release, 122 (2007) 141-150. 
[38] R. Kozyraki, O. Cases, Vitamin B12 absorption: Mammalian physiology and acquired and inherited disorders, Biochimie, 95 (2013) 1002-1007.

[39] R. Green, L.H. Allen, A.-L. Bjørke-Monsen, A. Brito, J.-L. Guéant, J.W. Miller, A.M. Molloy, E. Nexo, S. Stabler, B.-H. Toh, P.M. Ueland, C. Yajnik, Vitamin B12 deficiency, Nature Reviews Disease Primers, 3 (2017) 17040.

[40] C. Gherasim, M. Lofgren, R. Banerjee, Navigating the B12 Road: Assimilation, Delivery, and Disorders of Cobalamin, J. Biol. Chem., 288 (2013) 13186-13193.

[41] C.R. Benoit, A.E. Stanton, A.C. Tartanian, A.R. Motzer, D.M. McGaughey, S.R. Bond, L.C. Brody, Functional and phylogenetic characterization of noncanonical vitamin B12-binding proteins in zebrafish suggests involvement in cobalamin transport, J. Biol. Chem., 293 (2018) 17606-17621.

[42] S. Bose, S. Seetharam, N.M. Dahms, B. Seetharam, Bipolar functional expression of transcobalamin II receptor in human intestinal epithelial Caco-2 cells, J. Biol. Chem., 272 (1997) 3538-3543.

[43] O. Aseem, J.L. Barth, S.C. Klatt, B.T. Smith, W.S. Argraves, Cubilin expression is monoallelic and epigenetically augmented via PPARs, BMC Genomics, 14 (2013) 405.

[44] R. Respaud, L. Vecellio, P. Diot, N. Heuzé-Vourc'h, Nebulization as a delivery method for mAbs in respiratory diseases, Expert Opinion on Drug Delivery, 12 (2015) 1027-1039.

[45] P.J. Borm, W. Kreyling, Toxicological hazards of inhaled nanoparticles--potential implications for drug delivery, Journal of nanoscience and nanotechnology, 4 (2004) 521-531. [46] K. Donaldson, V. Stone, C.L. Tran, W. Kreyling, P.J. Borm, Nanotoxicology, Occup. Environ. Med., 61 (2004) 727-728.

[47] P.H. Pandya, D.S. Wilkes, Complement system in lung disease, Am. J. Respir. Cell Mol. Biol., 51 (2014) 467-473.

[48] D. Filpula, H. Zhao, Releasable PEGylation of proteins with customized linkers, Adv. Drug Del. Rev., 60 (2008) 29-49.

[49] M. Takano, Y. Koyama, H. Nishikawa, T. Murakami, R. Yumoto, Segment-selective absorption of lysozyme in the intestine, Eur. J. Pharmacol., 502 (2004) 149-155.

[50] E.V. Seliverstova, N.P. Prutskova, Receptor-mediated endocytosis of lysozyme in renal proximal tubules of the frog Rana temporaria, Eur. J. Histochem., 59 (2015) 2482.

[51] F. Meng, G.H. Engbers, J. Feijen, Polyethylene glycol-grafted polystyrene particles, J. Biomed. Mater. Res. A, 70 (2004) 49-58.

[52] A. Alshehri, A. Grabowska, S. Stolnik, Pathways of cellular internalisation of liposomes delivered siRNA and effects on siRNA engagement with target mRNA and silencing in cancer cells, Sci. Rep., 8 (2018) 3748.

[53] H. Ayame, N. Morimoto, K. Akiyoshi, Self-Assembled Cationic Nanogels for Intracellular Protein Delivery, Bioconjugate Chem., 19 (2008) 882-890.

[54] S. De Koker, B.G. De Geest, C. Cuvelier, L. Ferdinande, W. Deckers, W.E. Hennink, S.C. De Smedt, N. Mertens, In vivo Cellular Uptake, Degradation, and Biocompatibility of Polyelectrolyte Microcapsules, Adv. Funct. Mater., 17 (2007) 3754-3763.

[55] A. Beyerle, A. Braun, A. Banerjee, N. Ercal, O. Eickelberg, T.H. Kissel, T. Stoeger, Inflammatory responses to pulmonary application of PEI-based siRNA nanocarriers in mice, Biomaterials, 32 (2011) 8694-8701.

[56] H.P. Patil, D. Freches, L. Karmani, G.A. Duncan, B. Ucakar, J.S. Suk, J. Hanes, B. Gallez, R. Vanbever, Fate of PEGylated antibody fragments following delivery to the lungs: Influence of delivery site, PEG size and lung inflammation, J. Controlled Release, 272 (2018) 62-71. 
[57] M.C. Jones, S.A. Jones, Y. Riffo-Vasquez, D. Spina, E. Hoffman, A. Morgan, A. Patel, C. Page, B. Forbes, L.A. Dailey, Quantitative assessment of nanoparticle surface hydrophobicity and its influence on pulmonary biocompatibility, J. Control. Release, 183 (2014) 94-104.

[58] A. Kumar, L.A. Dailey, B. Forbes, Lost in translation: what is stopping inhaled nanomedicines from realizing their potential?, Ther. Deliv., 5 (2014) 757-761.

[59] A. Yamamoto, S. Okumura, Y. Fukuda, M. Fukui, K. Takahashi, S. Muranishi, Improvement of the pulmonary absorption of (Asu1,7)-eel calcitonin by various absorption enhancers and their pulmonary toxicity in rats, J. Pharm. Sci., 86 (1997) 1144-1147.

[60] R.U. Agu, M.I. Ugwoke, M. Armand, R. Kinget, N. Verbeke, The lung as a route for systemic delivery of therapeutic proteins and peptides, Respir. Res., 2 (2001) 198-209.

[61] L. Heinemann, W. Klappoth, K. Rave, B. Hompesch, R. Linkeschowa, T. Heise, Intraindividual variability of the metabolic effect of inhaled insulin together with an absorption enhancer, Diabetes Care, 23 (2000) 1343-1347.

[62] M. Morello, C.L. Krone, S. Dickerson, E. Howerth, W.A. Germishuizen, Y.L. Wong, D. Edwards, B.R. Bloom, M.K. Hondalus, Dry-powder pulmonary insufflation in the mouse for application to vaccine or drug studies, Tuberculosis, 89 (2009) 371-377.

[63] N. Wauthoz, P. Deleuze, J. Hecq, I. Roland, S. Saussez, I. Adanja, O. Debeir, C. Decaestecker, V. Mathieu, R. Kiss, K. Amighi, In vivo assessment of temozolomide local delivery for lung cancer inhalation therapy, Eur. J. Pharm. Sci., 39 (2010) 402-411.

[64] C. Gabay, Interleukin-6 and chronic inflammation, Arthritis Res. Ther., 8 (2006) S3-S3.

[65] K. Ren, R. Torres, Role of interleukin-1beta during pain and inflammation, Brain Res. Rev., 60 (2009) 57-64.

[66] C. Alexander, E.T. Rietschel, Bacterial lipopolysaccharides and innate immunity, J. Endotoxin Res., 7 (2001) 167-202.

[67] I.M. El-Sherbiny, N.M. El-Baz, M.H. Yacoub, Inhaled nano- and microparticles for drug delivery, Global Cardiology Science \& Practice, 2015 (2015) 2.

[68] C. Duret, N. Wauthoz, R. Merlos, J. Goole, C. Maris, I. Roland, T. Sebti, F. Vanderbist, K. Amighi, In vitro and in vivo evaluation of a dry powder endotracheal insufflator device for use in dose-dependent preclinical studies in mice, Eur. J. Pharm. Biopharm., 81 (2012) 627-634.

[69] V. Capel, D. Vllasaliu, P. Watts, P.A. Clarke, D. Luxton, A.M. Grabowska, G. Mantovani, S. Stolnik, Water-soluble substituted chitosan derivatives as technology platform for inhalation delivery of siRNA, Drug Deliv., 25 (2018) 644-653.

[70] D. Li, Y. Li, G. Li, Y. Zhang, J. Li, H. Chen, Fluorescent reconstitution on deposition of PM2.5 in lung and extrapulmonary organs, Proc. Natl. Acad. Sci. U. S. A., 116 (2019) 2488-2493. 


\title{
Supporting Information
}

\section{Targeted PEG-poly(glutamic acid) complexes for inhalation protein delivery to the lung}

\author{
A. Nieto-Orellana, ${ }^{a}{ }^{1}$ H. Li, ${ }^{a},{ }^{1}$ R. Rosiere, ${ }^{b}$ N. Wauthoz, ${ }^{b}$ H. Williams, ${ }^{c}$ C. J. Monteiro, ${ }^{a}$ C. Bosquillon, ${ }^{a}$ N. \\ Childerhouse, ${ }^{d}$ G. Keegan, ${ }^{d}$ D. Coghlan, ${ }^{d}$ G. Mantovani ${ }^{a,}{ }^{*}$ and S. Stolnik ${ }^{a, *}$
}

aMolecular Therapeutics and Formulation Division, School of Pharmacy, University of Nottingham, Nottingham, UK; ${ }^{b}$ Laboratory of Pharmaceutics and Biopharmaceutics (ULBGAL), Université Libre de Bruxelles, Bruxelles, BE; ${ }^{c}$ Centre for Biomolecular Sciences, University of Nottingham, Nottingham, UK; ${ }^{d}$ Vectura Group plc, Chippenham, UK. ${ }^{1}$ These authors contributed equally to this paper

* Corresponding authors.

\section{Contents}

Materials

Instrumentation .43

Synthesis of polymers and intermediates 45

Synthesis of cyanocobalamin fluorescent probe pyr- $\mathrm{B}_{12}$. 56

Synthesis of Lysozyme-Cyanine 5 (Lysozyme-Cy5) 62

Dry powders: Particle size distribution on Transwell ${ }^{\circledR}$ inserts 62 


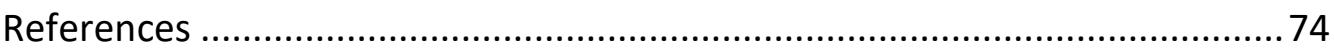




\section{Materials}

3,4,5-tris(allyloxy)benzoic acid,[23] Y-benzyl-L-glutamate $N$-carboxyanhydride,[23] and 2-(2(2-azidoethoxy)ethoxy)ethanol[71] were prepared as described previously. L-Glutamic acid - $^{-}$ benzyl ester ( $\geq 99.0 \%)$, allyl bromide $(97 \%)$, cysteamine hydrochloride $(\geq 98 \%), 4-(4,6$ dimethoxy-1,3,5-triazin-2-yl)-4-methylmorpholinium chloride (DMTMM), $p$-toluenesulfonyl chloride ( $\geq 99.0 \%)$, trimethylamine $(\geq 99.0 \%$ ), sodium bicarbonate, sodium azide $(\geq 99.0 \%)$, cyanocobalamin (vitamin $\mathrm{B}_{12}, \geq 98.0 \%$ ), 1,1'-carbonyldiimidazole (CDI), dibenzocyclooctyneamine, sodium phosphate dibasic $(99.9 \%)$, sodium phosphate monobasic dehydrate $(\geq 99.0 \%)$, L-leucine, D-(+)-trehalose dehydrate, 1-butanol, 1M ammonium hydroxide solution, acetonitrile (anhydrous, 99.8\%), dichloromethane (anhydrous, $\geq 99.8 \%$ ), tetrahydrofuran (THF, anhydrous, $\geq 99.9 \%$ ), methanol (MeOH, anhydrous, 99.8\%), dimethyl sulfoxide (DMSO, anhydrous, $\geq 99.9 \%)$, deuterated chloroform $\left(\mathrm{CDCl}_{3}, 99.8\right.$ atom $\left.\% \mathrm{D}\right)$, deuterium oxide $\left(\mathrm{D}_{2} \mathrm{O}\right.$, 99.9 atom \% D), deuterated methanol ( $\mathrm{CD}_{3} \mathrm{OD}, 99.8$ atom \% D), Dulbecco's Minimal Eagle Medium: Nutrient mixture F-12 (DMEM/F12), foetal bovine serum (10\%), L-glutamine (200 $\mathrm{mM}$ ), antibiotic solution (100 $\mathrm{U} \mathrm{mL}^{-1}$ penicillin and $0.1 \mathrm{mg} \mathrm{mL}^{-1}$ streptomycin), non-essential aminoacids (100\%), trypsin/EDTA solution, DPBS and Hanks' Balanced Salts (HBSS) were purchased from Sigma Aldrich. Methyl 3,4,5-trihydroxybenzoate (98.0\%), potassium carbonate anhydrous ( $\geq 99.0 \%)$, sodium hydroxide ( $\geq 97.0 \%)$, 2,2-dimethoxy-2phenylacetophenone (DPAP) (99.0\%), hydrochloric acid, magnesium sulfate dried, toluene, methanol, diethyl ether anhydrous, propan-2-ol and petroleum ether were supplied by Fisher Scientific. Triphosgene $\mathbf{9 8 . 0 \%}$ and lysozyme molecular biology grade were purchased from Alfa Aesar and AppliChem, respectively. O-(2-aminoethyl)polyethylene glycol $3.0 \mathrm{kDa}$ and cyanine 5 NHS ester were supplied by Iris Biotech and Lumiprobe, respectively. All the chemicals were used as received without further purification. Anhydrous solvents were used 
as received and stored under dry and inert atmosphere. Thin layer chromatography (TLC) was carried out on pre-coated TLC sheets ALUGRAM ${ }^{\circledR}$ SIL G/UV254 purchased from MachereyNagel. TLCs were visualized by exposure to UV light $(254 \mathrm{~nm})$ followed by staining with $\mathrm{KMnO}_{4}$. Calu-3 cells were purchased from the American Type Culture Collection (ATCC ${ }^{\circledR}$ HTB$55^{\mathrm{TM}}$ ). Phosphate buffer saline tablets were obtained from Oxoid (Basingstoke, UK). CellTiter $96^{\circledR}$ aqueous one solution cell proliferation assay (MTS) was supplied by Promega UK (Southampton, UK). Sheep erythrocytes and rabbit anti-sheep erythrocytes were purchased from Eurobio (Les Ulis, France).

\section{Instrumentation}

Nuclear Magnetic Resonance (NMR) Spectroscopy. 1D ${ }^{1} \mathrm{H}$ and ${ }^{13} \mathrm{C}$ NMR spectra were recorded on a Bruker DPX $400 \mathrm{MHz}$. Analysis of spectra was done using MestRENova 6.0.2, Mestrelab Research S.L. All chemical shifts are reported in ppm ( $\delta)$, using residual solvent as an internal standard ( $\left.\mathrm{CDCl}_{3}: \delta_{\mathrm{H}} 7.26, \delta_{\mathrm{C}} 77.16 ; \mathrm{D}_{2} \mathrm{O}: \delta_{\mathrm{H}} 4.79 ; \mathrm{CD}_{3} \mathrm{OD}: \delta_{\mathrm{H}} 3.31\right)$. The following abbreviations were used to explain the multiplicities: bd=broad singlet, $s=s i n g l e t, d=d o u b l e t$, t=triplet, m=multiplet. 2D HSQC NMR spectra were recorded on a $800 \mathrm{MHz}$ Avance III spectrometer equipped with a $5 \mathrm{~mm} \mathrm{QCl}$ cryoprobe.

Electrospray ionization mass spectrometry (ESI-MS). Mass spectra were recorded on a Micromass LCT KC453 spectrometer by electrospray $\left(\mathrm{ES}^{+}\right)$. Samples were analyzed as solutions in acetonitrile, water and formic acid.

Fourier Transform Infrared Spectroscopy (FT-IR) was performed on Thermo Scientific Nicolet IR 200 FT-IR and spectra were analyzed using Omnic 8.0 1992-2008 Thermo Fisher Scientific Inc. IR samples were either prepared as diluted solution in chloroform or used in their solid form. 
Size exclusion chromatography (SEC). Aqueous SEC was performed on a Shimadzu UPLC system fitted with a differential refractive index detector. The mobile phase was aqueous 0.10 $\mathrm{M} \mathrm{NaNO}_{3}, 0.02(\mathrm{w} / \mathrm{v}) \mathrm{NaN}_{3}, \mathrm{pH} 10.0$ at $35^{\circ} \mathrm{C}$ and a flow rate of $1.0 \mathrm{~mL} \mathrm{~min}{ }^{-1}$. The instrument was fitted with a Polymer Labs aquagel-OH guard column $(50 \times 7.5 \mathrm{~mm}, 8 \mu \mathrm{m})$ followed by three PL aquagel-OH columns (30, 40 and 50; $300 \times 7.5 \mathrm{~mm}, 8 \mu \mathrm{m})$. Narrow PEO standards $(0.2-130 \mathrm{kDa})$ were used to calibrate the SEC. Molecular weights and dispersity values were calculated using Shimadzu LabSolutions software with SEC analysis add-on.

The absence of unreacted DBCO- $\mathrm{B}_{12}$ in $\mathrm{B}_{12}-\mathrm{PEG}_{3 \mathrm{k}}$-lin- $\left(\mathrm{GA}_{24}\right)$ and miktoarm azide-PEG $\mathrm{F}_{3 \mathrm{k}}-$ mik$\left(\mathrm{GA}_{17}\right)_{3}$ targeted copolymers was evaluated with a Wyatt down $8^{+} 1200$ infinity series in a system equipped with an Agilent PL aquagel-OH $8 \mu \mathrm{m}$ SEC column. DPBS was used as the mobile phase, with a flow rate of $1 \mathrm{~mL} \mathrm{~min}^{-1}$ and UV detection at $\lambda=360 \mathrm{~nm}$. The resulting chromatograms were analyzed using ASTRA $^{\circledR}$ software V.6.1.2.84 (Wyatt Tech Corp).

Size Exclusion - High Performance Liquid Chromatography (SE-HPLC). Analyses were carried out on a Shimadzu HPLC system (LC-20 AP pump). A Wyatt SEC 40 XL (300 x 7.8 mm) column (Bio Rad, Hercules, CA) was used, with $50 \mu \mathrm{L}$ samples being injected each time, with standard Dulbecco's Phosphate Buffered Saline as the mobile phase, with UV detection at $\lambda=280 \mathrm{~nm}$, and fluorescence detection at $\lambda_{\mathrm{ex},}=647 \mathrm{~nm}$ and $\lambda_{\mathrm{em},}=665 \mathrm{~nm}$.

Reversed-phase High Performance Liquid Chromatography (RP-HPLC). Analyses were carried out using a Shimadzu HPLC system (LC-20 AP pump) equipped with a Jupiter C18 300 $\AA$ A $(250 \times 4.6 \mathrm{~mm})$ column (Phenomenex, Macclesfield, UK) with $50 \mu \mathrm{L}$ injection volume, with water/acetonitrile as the mobile phase in gradient from $5 \%$ to $90 \% \mathrm{v} / \mathrm{v}$ of acetonitrile and with UV detection at $\lambda=360 \mathrm{~nm}$.

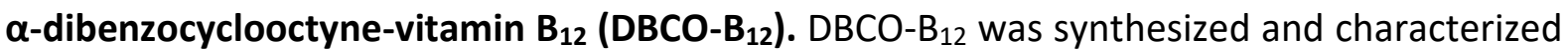
as described in the Materials and Methods section of the manuscript. RP-HPLC analysis of 
below.

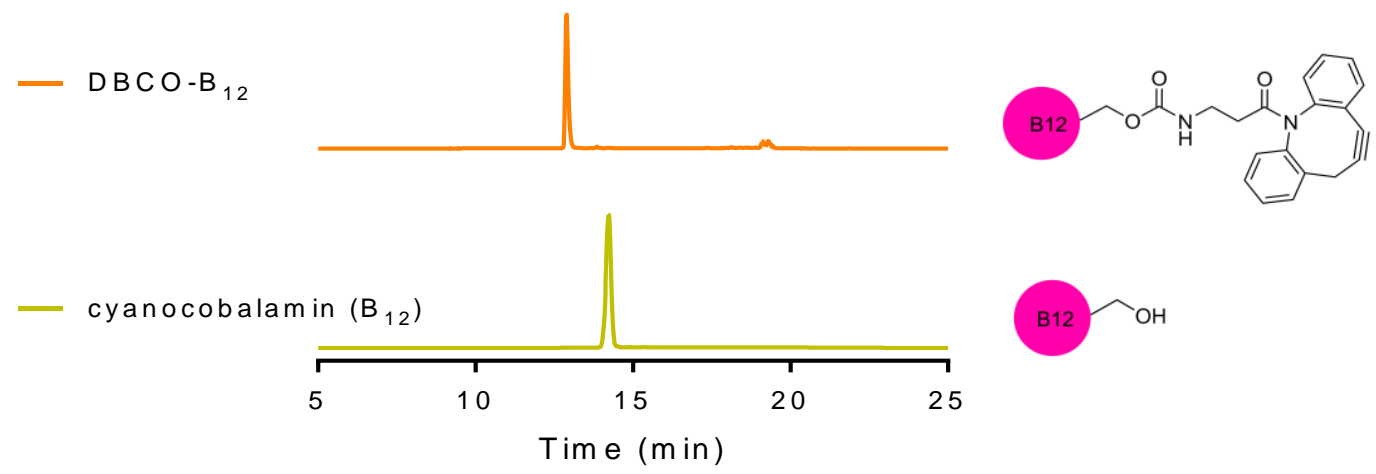

Figure S1. $C_{18}$ RP HPLC chromatograms of $\alpha$-dibenzocyclooctyne-vitamin $B_{12}$, DBCO-B12, (top) and cyanocobalamin, vitamin $B_{12}$, starting material (bottom). Water/acetonitrile was used as the mobile phase in gradient from $5 \%$ to $90 \%(\mathrm{v} / \mathrm{v})$ of acetonitrile and UV detection at $\lambda=360 \mathrm{~nm}$.

\section{Synthesis of polymers and intermediates.}

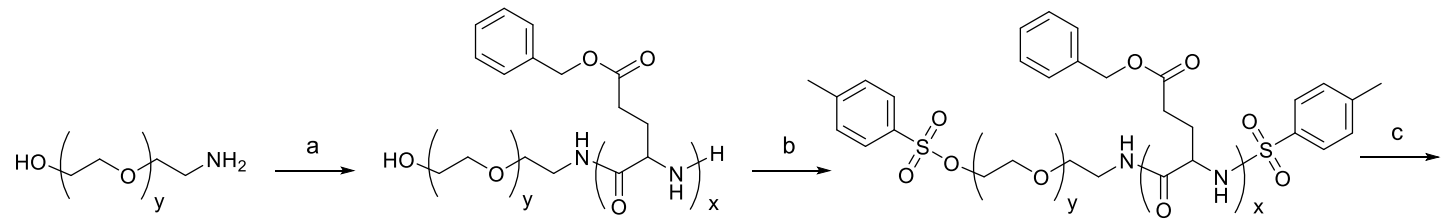

(A)

(B)

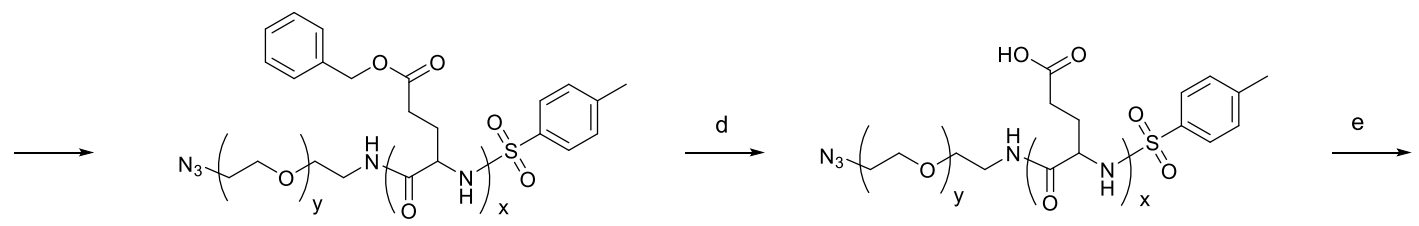

(C)

(1)

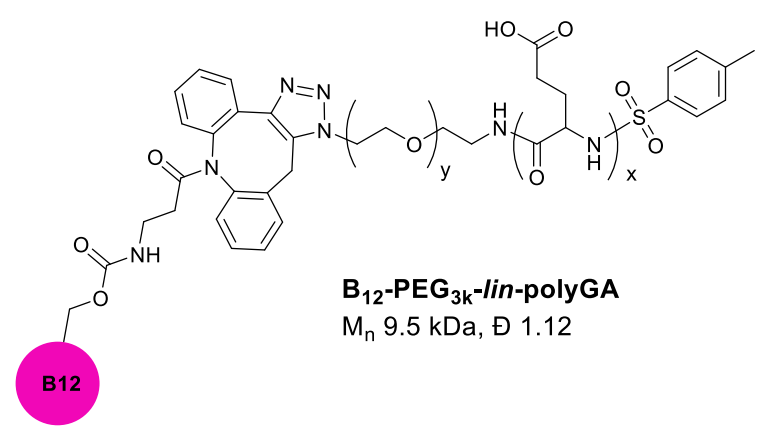

Figure S2. Synthesis of $\mathrm{B}_{12} \mathrm{PEG}_{3 \mathrm{k}}$-lin- $\mathrm{GA}_{24}$. Reactions and conditions: a. $\mathrm{p}$-benzyl-L-glutamate $\mathrm{NCA}, \mathrm{CH}_{2} \mathrm{Cl}_{2}, 5$ days; b. $p$-toluene sulfonyl chloride, triethylamine, $\mathrm{CH}_{2} \mathrm{Cl}_{2}, 12$ h; c. $\mathrm{NaN}_{3}$, DMSO, 24 h; d. $\mathrm{NaOH}, \mathrm{H}_{2} \mathrm{O} / \mathrm{THF}, 2$ days; e. $\alpha-$ dibenzocyclooctyne-vitamin $\mathrm{B}_{12}\left(\mathrm{DBCO}-\mathrm{B}_{12}\right), \mathrm{DMSO} / \mathrm{H}_{2} \mathrm{O}, 15 \mathrm{~h}$. 


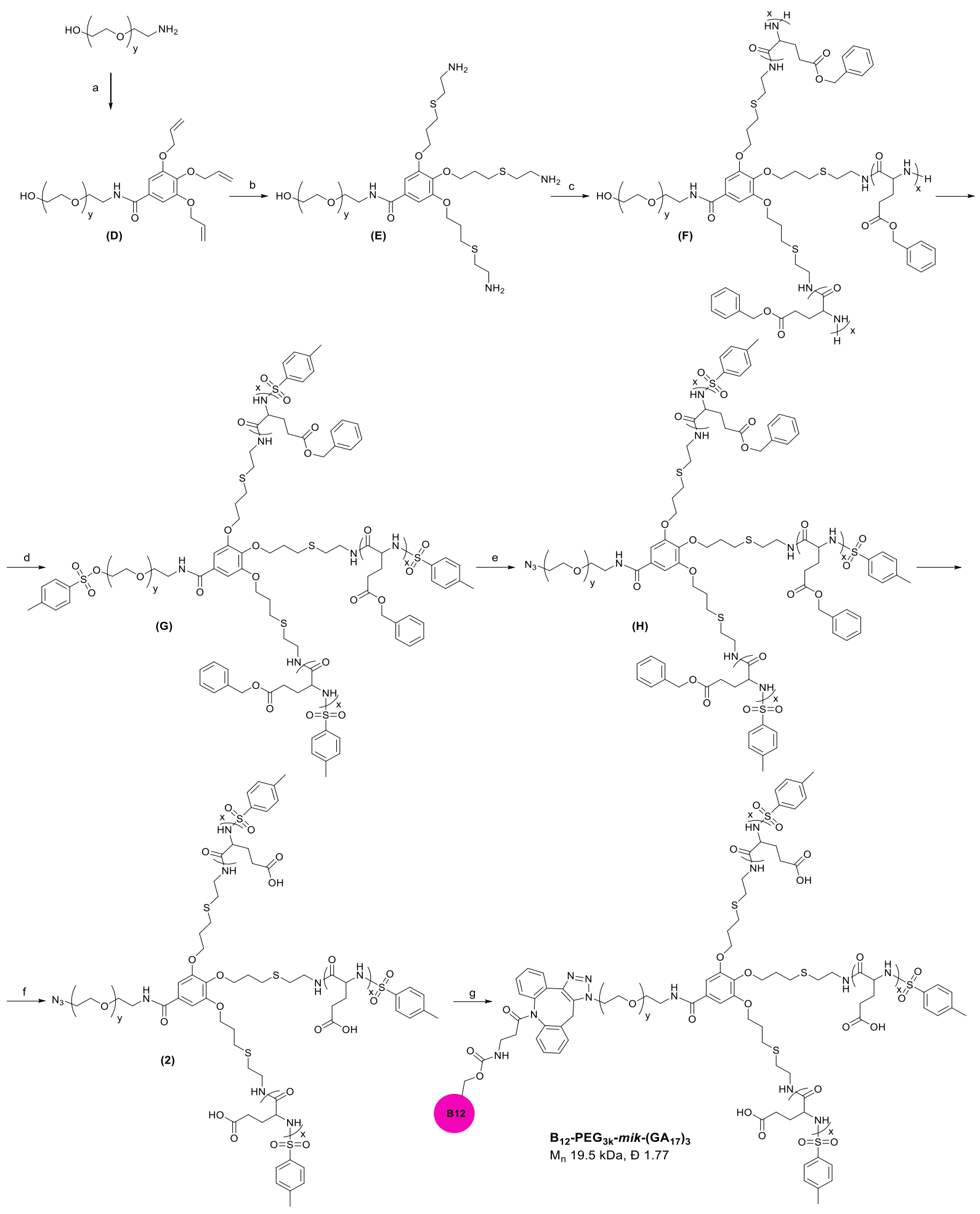

Figure S3. Synthesis of $\mathrm{B}_{12}-\mathrm{PEG}_{3 \mathrm{k}}-$ mik-(GA $\left.\mathrm{G}_{17}\right)_{3}$. Reactions and conditions: a. 3,4,5-tris(allyloxy)benzoic acid, DMTMM, methanol, 2 days; b. cysteamine hydrochloride, DPAP, $\mathrm{MeOH}, \mathrm{UV}, 3 \mathrm{~h}$; c. $y$-benzyl-L-glutamate $\mathrm{NCA}, \mathrm{CH}_{2} \mathrm{Cl}_{2}, 5$ days; d. $p$ toluene sulfonyl chloride, triethylamine, $\mathrm{CH}_{2} \mathrm{Cl}_{2}, 12 \mathrm{~h}$; e. sodium azide, DMSO, $24 \mathrm{~h}$; f. $\mathrm{NaOH}, \mathrm{H}_{2} \mathrm{O} / \mathrm{THF}, 2$ days; g. $\alpha-$ dibenzocyclooctyne-vitamin $\mathrm{B}_{12}\left(\mathrm{DBCO}-\mathrm{B}_{12}\right)$, DMSO/ $\mathrm{H}_{2} \mathrm{O}, 15 \mathrm{~h}$. 
Hydroxy-PEG ${ }_{3 \mathrm{k}}$ triallyl ether (D). O-(2-aminoethyl)polyethylene glycol $3.0 \mathrm{kDa}$ (500 mg, 0.170 mmol) was dissolved in toluene $(50 \mathrm{~mL})$ and solvent was then removed under reduced pressure. This process was repeated five times in order to remove traces of water from the PEG starting material before starting the reaction. 3,4,5-tris(allyloxy)benzoic acid (prepared as described previously[23], (73 mg, $0.25 \mathrm{mmol}, 1.5 \mathrm{eq}$.), O-(2-aminoethyl)polyethylene glycol 3.0 kDa (500 mg, $0.170 \mathrm{mmol}, 1$ eq.) and 4-(4,6-Dimethoxy-1,3,5-triazin-2-yl)-4methylmorpholinium chloride (DMTMM) (70 mg, $0.25 \mathrm{mmol}, 1.5 \mathrm{eq}$.) were dissolved in anhydrous methanol $(50 \mathrm{~mL})$ under inert atmosphere. The mixture was stirred during two days at room temperature, after which time ${ }^{1} \mathrm{H}$ NMR analysis showed that the reaction was completed (aromatics signals shifted from 7.35 to $7.20 \mathrm{ppm}$ ). The solvent was then removed under reduced pressure and the resulting residue suspended in $60 \mathrm{~mL}$ of water. Insoluble materials were removed by filtration, and the aqueous solution was dialyzed against water (MWCO $1 \mathrm{kDa}$ ) then freeze-dried. Hydroxy-PEG ${ }_{3 \mathrm{k}}$ triallyl ether (D) was isolated as a white

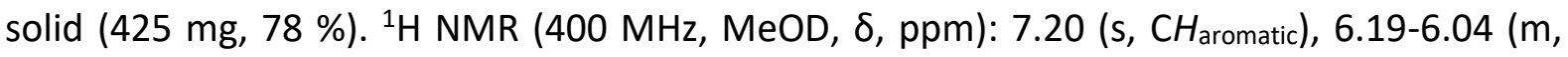
$\left.H_{\text {allyl }}\right), 5.55-5.15\left(\mathrm{~m}, H_{\text {allyl }}\right), 4.68-4.56\left(\mathrm{~m}, \mathrm{OCH}_{2}\right), 3.70-3.55\left(\mathrm{~s}, \mathrm{OCH}_{2}\right.$ of PEG).

Triamino-hydroxy-PEG ${ }_{3 k}$ (E). Hydroxy-PEG ${ }_{3 k}$ triallyl ether (D) (425 mg, 0.130 mmol, 1 eq.), cysteamine hydrochloride (160 mg, $2.07 \mathrm{mmol}, 16$ eq.) and 2,2-dimethoxy-2phenylacetophenone (DPAP) (10 mg, $0.039 \mathrm{mmol}, 0.3$ eq.) were dissolved in methanol $(5 \mathrm{~mL})$. The mixture was then irradiated using a 36 Watt UV Lamp equipped with $4 \times 9 \mathrm{~W}$ Light bulbs at $\lambda=365 \mathrm{~nm}$ for 3 hours, when allyl signals could no longer be detected by ${ }^{1} \mathrm{H}$ NMR. Methanol was then evaporated under reduced pressure and the resulting residue was suspended in water. The mixture was extracted with ethyl acetate to remove traces of DPAP and corresponding decomposition products. The aqueous phase was then dialyzed (MWCO 1 $\mathrm{kDa}$ ), and then freeze-dried. Triamino-hydroxy-PEG $3 \mathrm{k}$ (E) was isolated as a white solid (352 


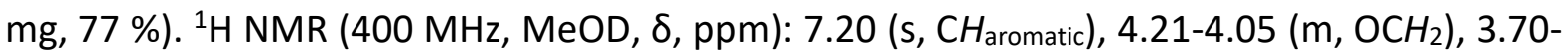
$3.43\left(\mathrm{~s}, \mathrm{OCH}_{2}\right.$ of PEG), $3.11\left(\mathrm{~m}, \mathrm{CH}_{2} \mathrm{~N}\right), 2.80\left(\mathrm{~m}, \mathrm{CH}_{2} \mathrm{~S}\right), 2.15-1.90\left(\mathrm{~m}, \mathrm{OCH}_{2} \mathrm{CH}_{2} \mathrm{CH}_{2} \mathrm{~S}\right)$.

Hydroxy-PEG 3 -poly(benzyl-glutamic acid) copolymers (linear: (A), miktoarm: (F)): Triaminohydroxy-PEG $3 \mathrm{k}$ (E) $(91 \mathrm{mg}, 0.026 \mathrm{mmol}, 1$ eq.) or commercially available $0-(2-$ aminoethyl)polyethylene glycol 3.0 kDa (200 mg, $0.0670 \mathrm{mmol}, 1$ eq.) were dissolved in dry dichloromethane $(10 \mathrm{~mL})$ in a round bottom flask. $\gamma$-Benzyl-L-glutamate NCA (821 mg, 3.12 mmol, 120 eq.) or ( $2.11 \mathrm{~g}, 8.04 \mathrm{mmol}, 120$ eq.) to form hydroxy-PEG $\mathrm{sk}_{3 \mathrm{k}}-\mathrm{mik}$-poly $\left(\mathrm{OBn}-\mathrm{GA}_{17}\right)_{3}$ and hydroxy-PEG $3 \mathrm{k}$-lin-poly(OBn-GA 24$)$ copolymers, respectively, was dissolved in anhydrous dichloromethane $(30 \mathrm{~mL})$ and added to the solution containing the amino-PEG initiator. The mixture was stirred at room temperature under inert atmosphere. After 5 days the solutions were concentrated under vacuum $(5 \mathrm{~mL})$ and precipitated with diethyl ether to give the desired copolymers as white solids. The number of glutamic acid repeating units per polymer chain was estimated by ${ }^{1} \mathrm{H} \mathrm{NMR}$, by comparing the integrals of the $\mathrm{OCH}_{2} \mathrm{CH}_{2}$ of the PEG block, with those of the $\mathrm{OCH}_{2}$ and phenyl groups of the $\mathrm{OBn}-\mathrm{GA}$ repeating units.

Hydroxy-PEG ${ }_{3 k}-l i n-\left(O B n-G_{24}\right)$ (A) 493 mg. ${ }^{1} \mathrm{H}$ NMR (400 MHz, $\left.\mathrm{CDCl}_{3}, \delta, \mathrm{ppm}\right):$ 7.40-7.15 (bs, $\mathrm{CH}_{\text {aromatic }}$, 5.13-4.93 (bs, $\mathrm{C}(\mathrm{O}) \mathrm{OCH}_{2}$ ), 4.00-3.80 (bs, $\left.\mathrm{HNCHCO}\right), 3.72-3.56$ (s, $\mathrm{OCH}_{2}$ of PEG), 2.70$1.95\left(\mathrm{~m}, \mathrm{CH}_{2} \mathrm{CH}_{2} \mathrm{C}(\mathrm{O}) \mathrm{O}\right)$.

Hydroxy-PEG ${ }_{3 k}-m i k-\left(O B n-G A_{17}\right)_{3}$ (F): 403 mg. ${ }^{1} \mathrm{H}$ NMR (400 MHz, $\left.\mathrm{CDCl}_{3}, \delta, p p m\right):$ 7.35-7.15 (bs, $\mathrm{CH}_{\text {aromatic }}$ ), 5.16-4.92 (bs, $\mathrm{C}(\mathrm{O}) \mathrm{OCH}_{2}$ ), 4.05-3.80 (bs, $\mathrm{HNCHCO}$ ), 3.69-3.57 (s, $\mathrm{OCH}_{2}$ of PEG), 2.75-1.97 (m, $\left.\mathrm{CH}_{2} \mathrm{CH}_{2} \mathrm{C}(\mathrm{O}) \mathrm{O}\right)$.

$p$-toluene-sulfonyl-PEG $3 k-l i n-\left(O B n-G_{24}\right)(B)$, and $p$-toluene-sulfonyl-PEG ${ }_{3 k}-m i k-\left(O B n-G_{17}\right)_{3}$ (G). Hydroxy-PEG 3 -mik-(OBn-GA $\left.{ }_{17}\right)_{3}$ (G) $(300 \mathrm{mg}, 0.0120 \mathrm{mmol}, 1$ eq.) or hydroxy-PEG 3 -linpoly(OBn-GA 24$)$ (B) (300 mg, 0.0300 mmol, 1 eq.) were dissolved in dry dichloromethane (50 
$\mathrm{mL}$ ) in a round bottom flask. While stirring, $p$-toluene sulfonyl chloride $(23 \mathrm{mg}, 0.12 \mathrm{mmol}, 10$ eq. or $57.0 \mathrm{mg}, 0.300 \mathrm{mmol}, 10$ eq.) and triethylamine (1.82 g, $18 \mathrm{mmol}, 150$ eq. or $1.52 \mathrm{mg}$, $15 \mathrm{mmol}, 50$ eq.) were added to the solution containing the hydroxy-PEG ${ }_{3 k}$-poly(benzyl-GA) copolymers. The reaction solutions were stirred at room temperature under inert atmosphere for $12 \mathrm{~h}$. The mixtures were then neutralized with $1 \mathrm{M} \mathrm{HCl}$, filtered and an excess of sodium bicarbonate was slowly added. The suspension was stirred, filtered again and the solutions concentrated to a volume of ca. $2 \mathrm{~mL}$. Copolymers (B) and (G) were recovered by precipitation in diethyl ether, followed by filtration and removal of traces of solvent under reduced pressure.

p-toluene-sulfonyl-PEG 3 -lin-(OBn-GA 24$)$ (B) 213 mg, $67 \% .{ }^{1} \mathrm{H}$ NMR (400 MHz, $\left.\mathrm{D}_{2} \mathrm{O}, \delta, \mathrm{ppm}\right)$ : 7.79-7.74 (s, $\mathrm{CH}_{\text {aromatic }}$ ), 7.38-7.16 (s, $\left.\mathrm{CH}_{\text {aromatic}}\right), 7.14-7.10$ (s, $\mathrm{CH}_{\text {aromatic }}$ ), 5.16-4.91 (bs, $\mathrm{C}(\mathrm{O}) \mathrm{OCH}_{2}$ ), 3.97-3.83 (bs, $\mathrm{HNCHCO}$ ), 3.69-3.59 (bs, $\mathrm{OCH}_{2}$ of PEG), 2.65-2.0 (m, $\left.\mathrm{CH}_{2} \mathrm{CH}_{2} \mathrm{C}(\mathrm{O}) \mathrm{O}\right)$. p-toluene-sulfonyl-PEG sk-mik-(OBn-GA $\left._{17}\right)_{3}$ (G) $153 \mathrm{mg}, 50 \% .{ }^{1} \mathrm{H} \mathrm{NMR}\left(400 \mathrm{MHz}, \mathrm{CDCl}_{3}, \delta\right.$,

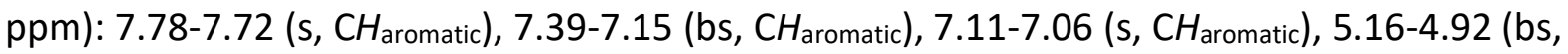
$\mathrm{C}(\mathrm{O}) \mathrm{OCH}_{2}$ ), 4.02-3.84 (bs, $\left.\mathrm{HNCHCO}\right), 3.67-3.60$ (s, $\mathrm{OCH}_{2}$ of PEG), 2.75-1.95 (m, $\left.\mathrm{CH}_{2} \mathrm{CH}_{2} \mathrm{C}(\mathrm{O}) \mathrm{O}\right)$.

Azide-PEG ${ }_{3 k}-l i n-\left(O B n-G_{24}\right)$ (C) and azide-PEG ${ }_{3 k}-m i k-\left(O B n-G_{17}\right)_{3}$ (H). p-toluene-sulfonyl-

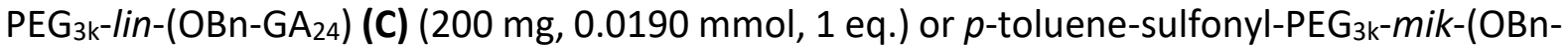
$\left.\mathrm{GA}_{17}\right)_{3}(\mathbf{H})(150 \mathrm{mg}, 0.006 \mathrm{mmol}, 1$ eq.) were dissolved in anhydrous DMSO $(5 \mathrm{~mL})$ in a round bottom flask. Sodium azide (12 mg, $0.19 \mathrm{mmol}, 10$ eq.; or $4 \mathrm{mg}, 0.06 \mathrm{mmol}, 10$ eq.) to form

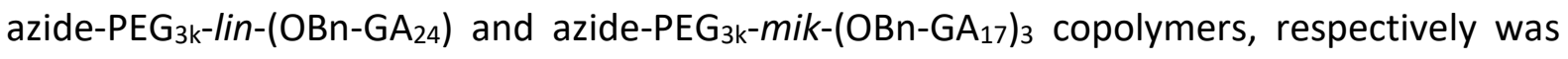
added to the round bottom flask. The solutions were stirred at room temperature under inert atmosphere for $24 \mathrm{~h}$. The reaction solution was then added to an excess of diethyl ether, and 
the residue dissolved in THF and filtered again. The solvent was then removed under reduced pressure to give the desired azide-functionalized copolymers.

Azide-PEG ${ }_{3 k}-l i n-\left(O B n-A_{24}\right)$ (C). 113 mg. FT-IR: $2089 \mathrm{~cm}^{-1}\left(\bar{U}_{\mathrm{N} 3}\right)$.

Azide-PEG ${ }_{3 k}-$ mik-$\left._{\text {(OBn-GA }}\right)_{3}$ (H). 98 mg. FT-IR: $2042 \mathrm{~cm}^{-1}\left(\bar{U}_{\mathrm{N} 3}\right)$.

Azide-PEG ${ }_{3 k}-l i n-\left(G_{24}\right)$ (1) and azide-PEG $3 k-m i k-\left(G_{17}\right)_{3}$ (2). Azide-PEG $3 k-l i n-\left(O B n-G_{24}\right)$ (C) (113 mg, $0.0110 \mathrm{mmol})$, or azide-PEG ${ }_{3 k}-$ mik-(OBn-GA $\left.{ }_{17}\right)_{3}$ (H) $(98 \mathrm{mg}, 0.0040 \mathrm{mmol})$ were dissolved in THF in a round bottom flask. 10 or $28 \mu \mathrm{L}$ of a $1.0 \mathrm{M} \mathrm{NaOH}$ aqueous solution (2.5 equiv. of $\mathrm{NaOH}$ per benzyl group) were then slowly added under vigorous stirring to hydrolyze benzyl ester repeating units. The reaction was left to stir for 2 days at room temperature, then the solvents were removed under reduce pressure. The residue was dissolved in deionized water $(50 \mathrm{~mL})$ and the resulting solution was dialyzed (MWCO $3.5 \mathrm{kDa})$. The solution was then freeze-dried to give the desired copolymers as off-white solids.

Azide-PEG ${ }_{3 k}$-lin-(GA24) (1) 76 mg. ${ }^{1} \mathrm{H}$ NMR (400 MHz, $\left.\mathrm{D}_{2} \mathrm{O}, \delta, \mathrm{ppm}\right):$ 7.76-7.66 (s, $\left.\mathrm{CH}_{\text {aromatic }}\right)$, 7.48-7.32 (s, $\mathrm{CH}_{\text {aromatic}}$ ), 4.44-4.02 (bs, $\mathrm{HNCHCO}$ ), 3.77-3.59 (s, $\mathrm{OCH}_{2}$ of PEG), 2.48-1.83 (m, $\mathrm{CH}_{2} \mathrm{CH}_{2} \mathrm{COOH}$ ).

Azide-PEG ${ }_{3 k}-$ mik-(GA $\left(\mathrm{G}_{17}\right)_{3}$ (2). $60 \mathrm{mg} .{ }^{1} \mathrm{H}$ NMR $\left(400 \mathrm{MHz}, \mathrm{D}_{2} \mathrm{O}, \delta, \mathrm{ppm}\right): 4.44-4.26$ (bs, HNCHCO), 3.77-3.63 (s, $\mathrm{OCH}_{2}$ of PEG), 2.38-1.85 (m, $\left.\mathrm{CH}_{2} \mathrm{CH}_{2} \mathrm{COOH}\right)$.

$\mathbf{B}_{12}-$ PEG $_{3 k}-$ lin-( $\left(\mathrm{GA}_{24}\right)$ and $\mathbf{B}_{12}-\mathrm{PEG}_{3 \mathrm{k}}-\mathbf{m i k}-\left(\mathrm{GA}_{17}\right)_{3}$ were synthesized by Cu-free alkyne-azide cycloaddition of $\alpha$-dibenzocyclooctyne-vitamin $B_{12}\left(D_{B C O} B_{12}\right)$, and azide-PEG $G_{3 k}-\operatorname{lin}-\left(\mathrm{GA}_{24}\right)(\mathbf{1})$ and azide-PEG ${ }_{3 k}-m i k-\left(\mathrm{GA}_{17}\right)_{3}(2)$, respectively, and characterized as described in the Materials and Methods section of the manuscript. Reversed-phase HPLC (RP-HPLC) analysis of $B_{12}$ (DBCO- $\left.\mathrm{B}_{12}\right)$, and $\mathrm{B}_{12}-\mathrm{PEG}_{3 k}-$ lin- $\left(\mathrm{GA}_{24}\right)$ and $\mathrm{B}_{12}-\mathrm{PEG}_{3 k}-$ mik- $\left(\mathrm{GA}_{17}\right)_{3}$, (Figure S4), and the 
shown below.
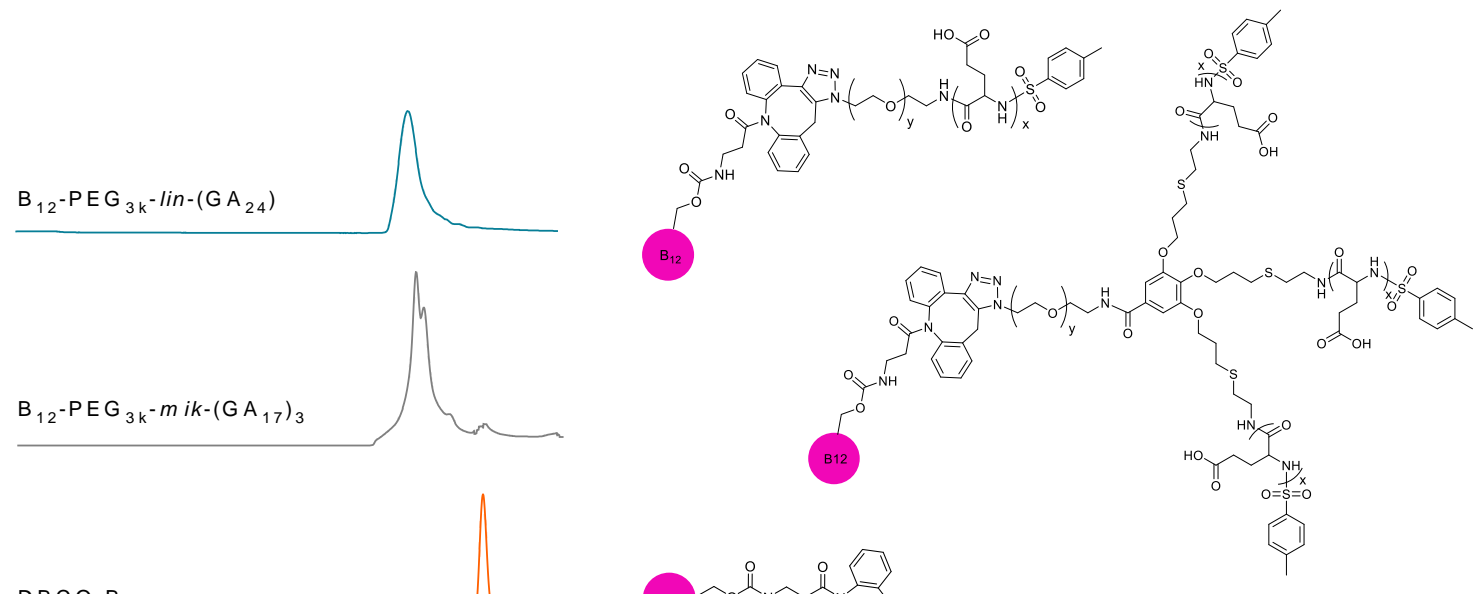

Figure S4. $\mathrm{C}_{18}$ RP-HPLC chromatograms of $\mathrm{B}_{12}-\mathrm{PEG}_{3 k}-$ lin- $\left(\mathrm{GA}_{24}\right)$ and $\mathrm{B}_{12}-\mathrm{PEG}_{3 k}-m i k-\left(\mathrm{GA}_{17}\right)_{3}$ copolymers, and free $\alpha-$ dibenzocyclooctyne-vitamin $\mathrm{B}_{12}$ (DBCO-B ${ }_{12}$ ). Water/acetonitrile was used as the mobile phase in gradient from $5 \%$ to $90 \%(v / v)$ of acetonitrile and UV detection at $\lambda=360 \mathrm{~nm}$.

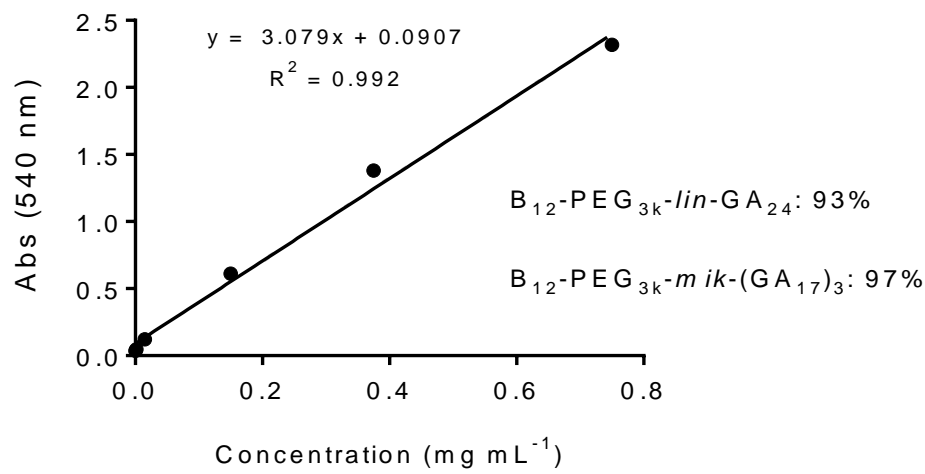

Figure S5. Efficiency (\%) of attachment of DBCO-B 12 to azide-functional linear mPEG 3 -poly(GA) copolymers, was calculated by UV-vis analysis $(\lambda=540 \mathrm{~nm})$, using deionized water as the solvent. The figures shows the calibration curve utilized for this calculation, which was built using cyanocobalamin $\left(\mathrm{B}_{12}\right)$ solutions of known concentration.

\section{Cu-free alkyne-azide cycloaddition using DBCO-B 12 : NMR investigation. HSQC NMR}

(together with UV-vis spectrometry) was used to monitor the copper-free click cycloaddition

of $\mathrm{DBCO}-\mathrm{B}_{12}$ and azide-PEG $3 \mathrm{k}-\mathrm{lin}-\left(\mathrm{GA}_{24}\right)$ (1), and azide-PEG $\mathrm{Bk}_{3 \mathrm{k}}-\mathrm{mik}-\left(\mathrm{GA}_{17}\right)_{3}$ (2). Given the 
complexity of the NMR spectra of these polymers, a small-scale synthesis of simpler cyclooctyne and azide compounds was carried out (Figure S6), and the corresponding cycloadducts characterized by HSQC NMR. Accordingly, 1,2,3-triazoles (4) were synthesized in two steps from dibenzocyclooctyne-amine, and HSQC NMR confirmed the success of the click reaction with 2-(2-(2-azidoethoxy)ethoxy)ethanol, with low field shift of the $\alpha-\mathrm{CH}_{2}$ signals of the dibenzocyclooctyne-carbamate (3) at 5.2/56 ppm to $6.1 / 52 \mathrm{ppm}\left({ }^{1} \mathrm{H} /{ }^{13} \mathrm{C}\right.$ signals). Signals for both regioisomeric cycloadducts were clearly visible in the spectrum of the purified products (4) and (4)' (Figure S7). An analogous shift was observed when dibenzocyclooctyne-carbamate (3) was replaced by DBCO-B 12 (Figure S7).

a)
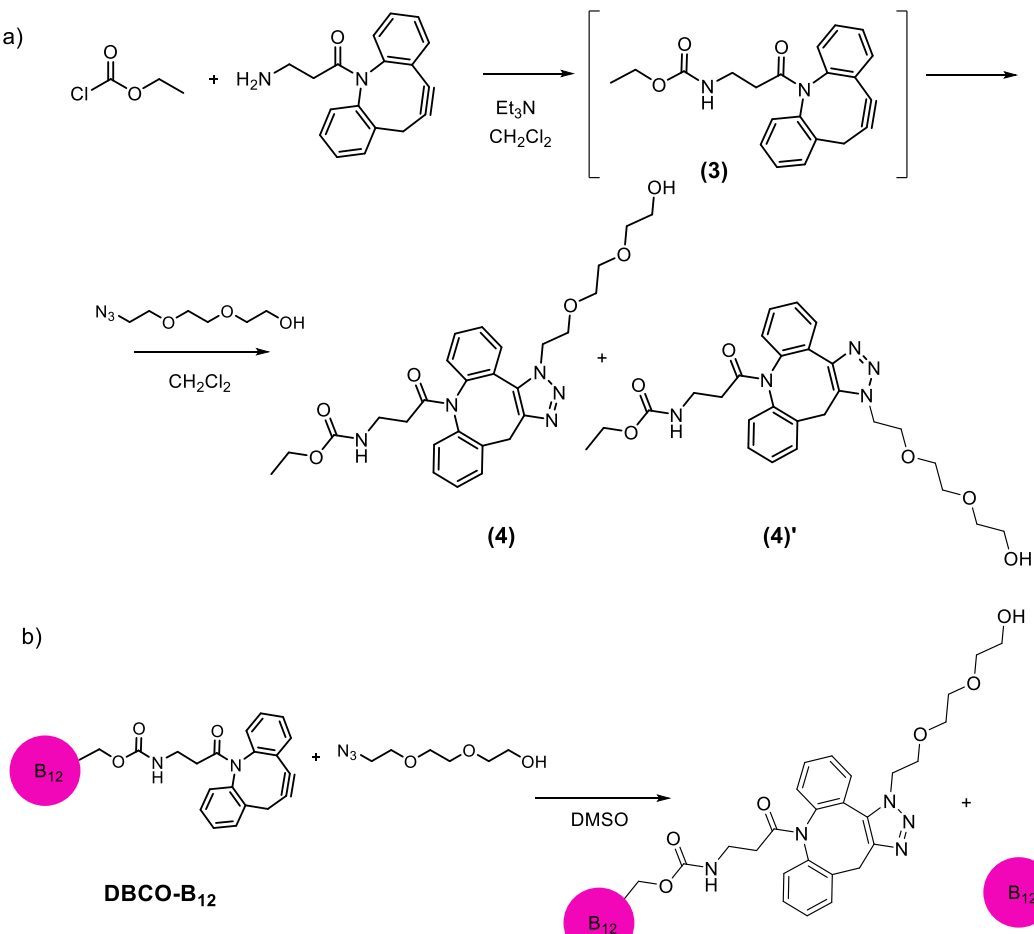

(5)

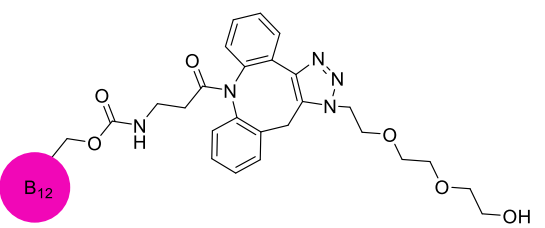

$(5)^{\prime}$

Figure S6. Synthesis of model clicked 1,2,3-triazoles (4) and (4)', and (5) and (5)'. 
A

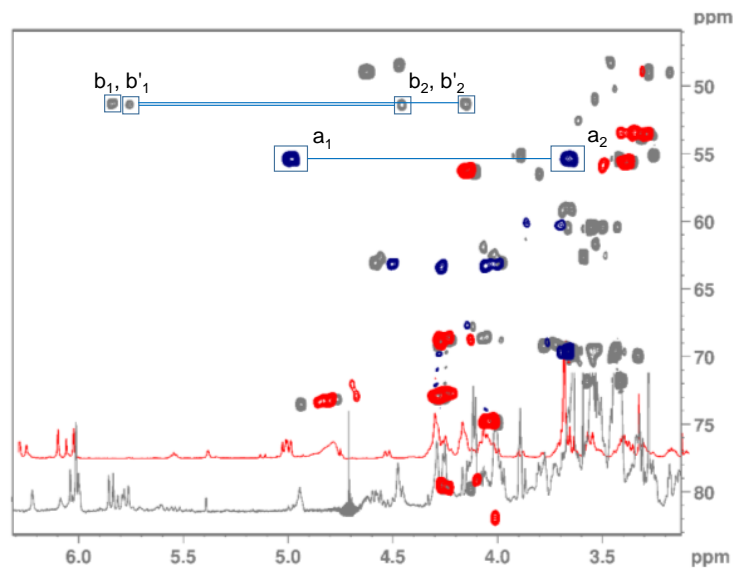

B

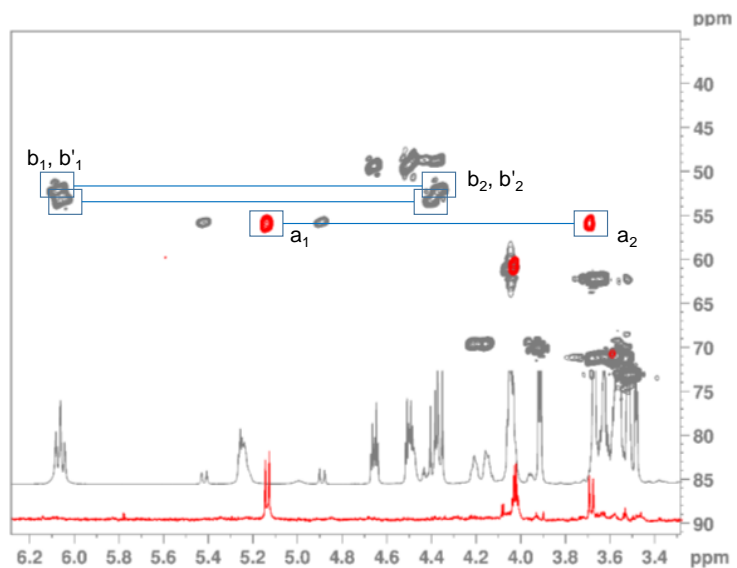

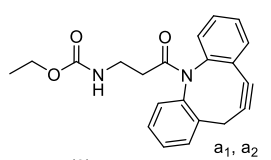

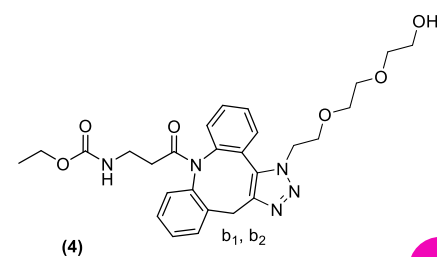

(4)
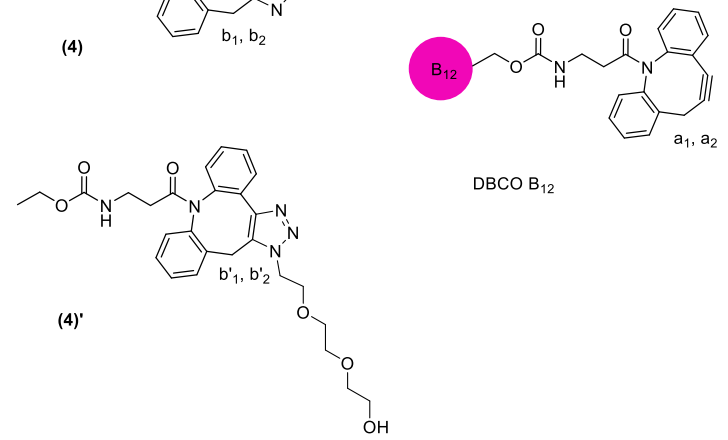

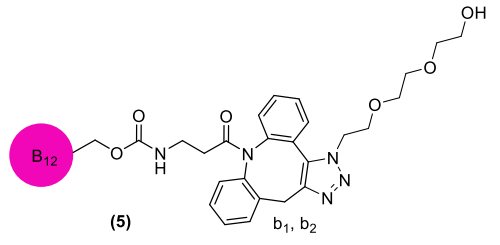

DBCO B 12

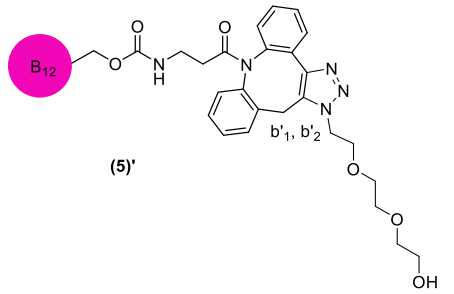

Figure S7. 2D HSQC NMR spectra showing the shift of the $\alpha-\mathrm{CH}_{2}$ proton signals of the $\alpha$-dibenzocyclooctyne ring of A. Carbamate (3), and B. DBCO-B 12 , following 1,3-dipolar cycloaddition with 2-(2-(2azidoethoxy)ethoxy)ethanol.

\section{Ethyl(3-(1-(2-(2-(2-hydroxyethoxy)ethoxy)ethyl)-1,13-dihydro-8H-}

\section{dibenzo[b,g][1,2,3]triazolo[4,5-d]azocin-8-yl)-3-oxopropyl)carbamate (4) and (4)'.}

Dibenzocyclooctyne-amine (20 mg, $0.072 \mathrm{mmol}, 1.0$ eq.) was dissolved in DCM (2 mL) and reacted with an excess of ethyl chloroformate (16 $\mathrm{mg}, 0.14 \mathrm{mmol}, 2.0$ eq.) and triethylamine (15 mg, $0.14 \mathrm{mmol}, 2.0$ eq.) under stirring for $24 \mathrm{~h}$, to give the intermediate (3). Methanol (2 $\mathrm{mL})$ was then added to quench the excess of ethyl chloroformate and 2-(2-(2azidoethoxy)ethoxy)ethanol ( $25 \mathrm{mg}, 0.145 \mathrm{mmol}, 2.0$ eq.) was added. After $12 \mathrm{~h}$, and after 12 
hours (4) and (4)' were purified by preparative TLC, and isolated as a mixture of the two regioadducts $2 \mathrm{D}$ HSQC NMR is shown in Figure S7.

Cyanocobalamin

(3-(1-(2-(2-(2-hydroxyethoxy)ethoxy)ethyl)-1,13-dihydro-8H-

dibenzo[b,g][1,2,3]triazolo[4,5-d]azocin-8-yl)-3-oxopropyl)carbamate (5) and (5)'. DBCO-B 12 (10 mg, $0.0060 \mathrm{mmol}, 1.0$ eq.) was added to a solution of 2-(2-(2-azidoethoxy)ethoxy)ethanol (3.1 mg, $0.018 \mathrm{mmol}, 3.0$ eq.) in DMSO $(1 \mathrm{~mL}$ ). Purification by preparative TLC ('PrOH/n$\left.\mathrm{BuOH} / \mathrm{H}_{2} \mathrm{O} / \mathrm{NH}_{4} \mathrm{OH} 30 / 45 / 21 / 4\right)$ gave the desired clicked cycloadducts (5) and (5)'. 2D HSQC NMR (Figure S7) showed patterns for the methylene signals of the cyclooctyne $\left(a, a^{\prime}\right)$, and its correspondent cycloadduct ( $b$, and $b^{\prime}$ ) analogous to those observed for the $B_{12}-P_{E G} G_{3 k}-l i n-$ $\left(\mathrm{GA}_{24}\right)$ and $\mathrm{B}_{12}-\mathrm{PEG}_{3 \mathrm{k}}-$ mik- $\left(\mathrm{GA}_{17}\right)_{3}$ targeted copolymers (Figure 1 of the manuscript), thus further confirming the successful grafting of cyanocobalamin $\left(B_{12}\right)$ to the corresponding azidefunctional polymer precursors 


\section{Synthesis of cyanocobalamin fluorescent probe pyr-B $B_{12}$.}
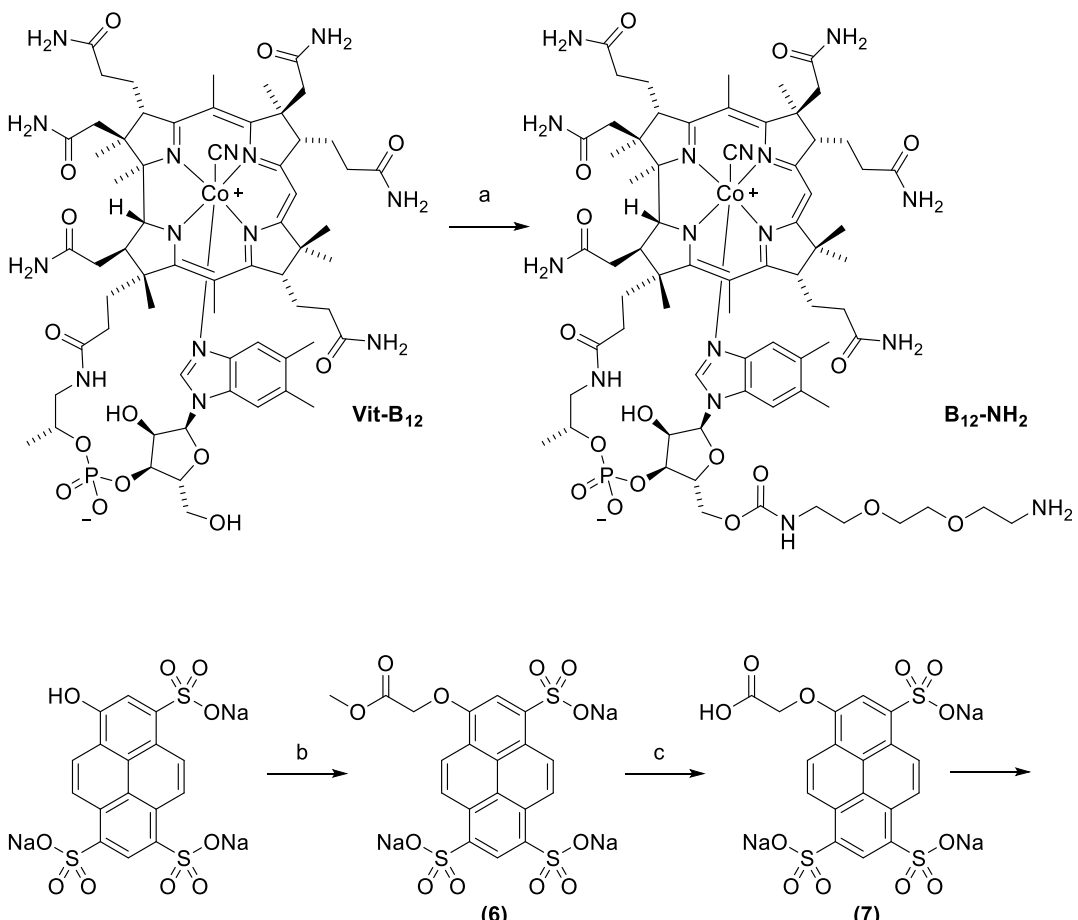

(6)

(7)
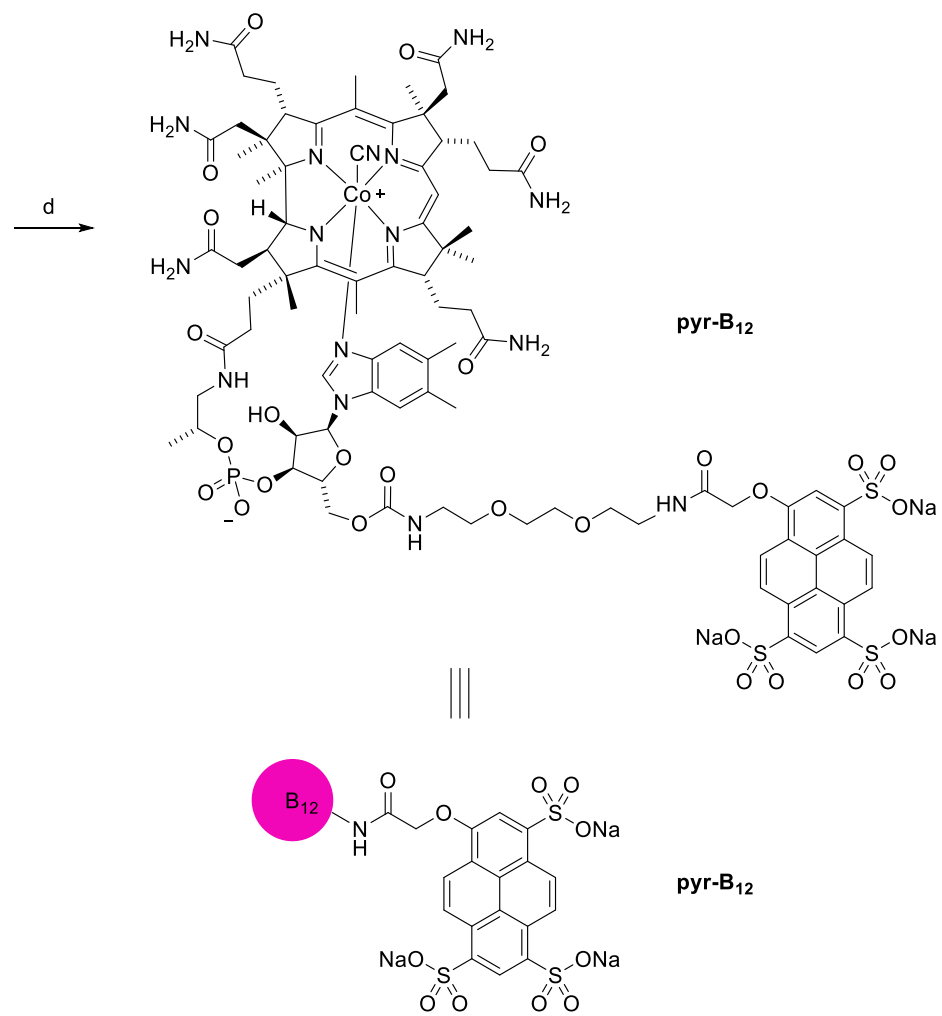

Figure S8. Synthesis of pyranine-tagged vitamin cyanocobalamin (pyr- $\mathrm{B}_{12}$ ). Reactions and conditions: a. i. 1,1'carbonyldiimidazole, DMSO ii. 2,2'-(ethylenedioxy)bis(ethylamine); b. methyl bromoacetate, DIPEA, methanol reflux. c. $\mathrm{NaOH}_{\mathrm{aq}} ;$. d. $\mathrm{B}_{12}-\mathrm{NH}_{2}$, DMTMM, methanol. 
Pyranine methyl ester (6). 8-Hydroxypyrene-1,3,6-trisulfonic acid trisodium salt (pyranine, $1.00 \mathrm{~g}, 1.91 \mathrm{mmol}, 1$ eq.) was added to methanol $(60 \mathrm{~mL})$ and heated to reflux under stirring to ensure full dissolution, protected from light. Methyl bromoacetate $(1.11 \mathrm{~g}, 7.24 \mathrm{mmol}, 3.8$ eq.) and DIPEA ( $N, N$-diisopropylethylamine, $0.690 \mathrm{~g}, 5.32 \mathrm{mmol}, 2.8 \mathrm{eq}$.$) were dissolved in$ methanol $(6 \mathrm{~mL})$ in a separate flask, and the resulting solution added portion wise - a third of the total volume every 1.5 hours, to the refluxing solution of pyranine. The resulting yellow mixture was further refluxed for 3 hours, still protected from light, and then left stirring at room temperature overnight before precipitation in isopropanol. The solid was then collected by centrifugation, residual traces of solvent were removed under reduced pressure, and the resulting crude product (6) used for the next step without further purification. Yield: $938 \mathrm{mg}$, $82 \% .{ }^{1} \mathrm{H}$ NMR (400 MHz, methanol- $\left.d_{4}\right) \delta 9.44\left(\mathrm{~s}, 1 \mathrm{H}, \mathrm{CH}_{\text {aromatic }}\right), 9.28(\mathrm{~d}, J=9.7 \mathrm{~Hz}, 1 \mathrm{H}$, $\left.\mathrm{CH}_{\text {aromatic }}\right), 9.26\left(\mathrm{~d}, J=9.7 \mathrm{~Hz}, 1 \mathrm{H}, \mathrm{CH}_{\text {aromatic }}\right), 9.18\left(\mathrm{~d}, J=9.8 \mathrm{~Hz}, 1 \mathrm{H}, \mathrm{CH}_{\text {aromatic }}\right), 8.75(\mathrm{~d}, J=9.6$ $\left.\mathrm{Hz}, 1 \mathrm{H}, \mathrm{CH}_{\text {aromatic }}\right), 8.32\left(\mathrm{~s}, 1 \mathrm{H}, \mathrm{CH}_{\text {aromatic }}\right), 5.21\left(\mathrm{~s}, 2 \mathrm{H}, \mathrm{OCH}_{2}\right), 3.87\left(\mathrm{~s}, 3 \mathrm{H}, \mathrm{OCH}_{3}\right)$. ESI-TOF mass spectrometry: expected $\mathrm{m} / \mathrm{z}\left[\mathrm{M}-\mathrm{Na}^{+}\right]$618.89, found 618.90 .

Carboxyl pyranine (7). Pyranine methyl ester (6) (200 mg, $0.336 \mathrm{mmol}, 1$ eq.) was dissolved in deionised water $(5 \mathrm{ml})$ containing sodium hydroxide $(16 \mathrm{mg}, 0.40 \mathrm{mmol}, 1.2 \mathrm{eq}$.$) , and the$ resulting solution stirred at $60^{\circ} \mathrm{C}$ for $30 \mathrm{~min}$. After cooling to room temperature, the solution was neutralised with aqueous hydrochloric acid, and the desired product was precipitated in isopropanol. The orange precipitate was collected by vacuum filtration, and residual traces of solvent were removed under reduced pressure, to give the intermediate (7) as an orange solid. Yield: $104 \mathrm{mg}, 53 \% .{ }^{1} \mathrm{H}$ NMR (400 MHz, methanol- $\left.d_{4}\right) \delta 9.44\left(\mathrm{~s}, 1 \mathrm{H}, \mathrm{CH}_{\text {aromatic }}\right), 9.28$ (d, J = 9.7 Hz, 1H, CHaromatic), 9.26 (d, J = 9.7 Hz, 1H, CHaromatic), 9.18 (d, J = 9.8 Hz, $\left.1 \mathrm{H}, \mathrm{CH}_{\text {aromatic }}\right)$, $8.79\left(\mathrm{~d}, \mathrm{~J}=9.6 \mathrm{~Hz}, 1 \mathrm{H}, \mathrm{CH}_{\text {aromatic }}\right), 5.16\left(\mathrm{~s}, 2 \mathrm{H}, \mathrm{OCH}_{2}\right.$. ESI-TOF mass spectrometry: expected $\mathrm{m} / \mathrm{z}$ $\left[\mathrm{M}-\mathrm{Na}^{+}\right] 604.88$, found 604.88 . 
Amino cyanocobalamin (B12-NH2). Carbonyldiimidazole (CDI) $(144 \mathrm{mg}, 0.890 \mathrm{mmol}, 4$ eq.) was added to cyanocobalamin $(0.300 \mathrm{~g}, 0.221 \mathrm{mmol}, 1$ eq.) previously dissolved in anhydrous dimethyl sulfoxide (DMSO) $(10 \mathrm{~mL})$. The mixture was stirred for $2 \mathrm{~h}$ at $30^{\circ} \mathrm{C} .2,2^{\prime}-$ (Ethylenedioxy)bis(ethylamine) (132 mg, $0.89 \mathrm{mmol}, 4$ eq.) was then added, and the mixture stirred at room temperature for further $24 \mathrm{~h}$. The mixture was poured into ethyl acetate, and the resulting precipitate was isolated by centrifugation and purified by silica column chromatography (mobile phase: 30:45:4:21 2-propanol: $n$-butanol: ammonia (1M) : water vol:vol:vol:vol) and then lyophilized. Yield: $68 \mathrm{mg}, 21 \%$. ESI-TOF mass spectrometry: expected $\mathrm{m} / \mathrm{z}\left[\mathrm{M}^{+}\right]$1529.68, found 1529.67 .

Pyranine $B_{12}$ fluorescent probe (pyr- $\left.B_{12}\right)$. Carboxypyranine (7) $(16 \mathrm{mg}, 0.028 \mathrm{mmol}$, 2eq.) and 4-(4,6-dimethoxy-1,3,5-triazin-2-yl)-4-methylmorpholinium chloride (DMTMM) (8 mg, 0.06 $\mathrm{mmol}, 4$ eq.) were dissolved in methanol, in separate flasks ( $2 \mathrm{ml}$ of methanol per flask). The DMTMM solution was added to the carboxypyranine solution dropwise, and the resulting solution left to stir for $1 \mathrm{~h}$ at room temperature, followed by addition of a solution of $\mathrm{B}_{12}-\mathrm{NH}_{2}$ (20 mg, $0.014 \mathrm{mmol}, 1$ eq.) in methanol $(5 \mathrm{~mL}$ ). The resulting mixture was left to stir overnight at room temperature, concentrated under reduced pressure, and the product purified by preparative thin layer chromatography (TLC) (30:40:4:26 2-propanol: $n$-butanol: ammonia (1M) : water vol:vol:vol:vol), extracting the desired fluorescent pyr- $\mathrm{B}_{12}$ probe from the relevant TLC band with methanol (yield: $7.7 \mathrm{mg}, 54 \%) .{ }^{1} \mathrm{H}$ NMR (400 MHz, MeOD, $\delta, p p m$ ): the appearance of the peaks between 9.5-8.5 which corresponded to the aromatic groups within the pyranine structure confirmed the success of conjugation. ESI-TOF mass spectrometry: expected $\mathrm{m} / \mathrm{z}\left[\mathrm{M}^{+}\right]$2024.58, found 2024.60. 


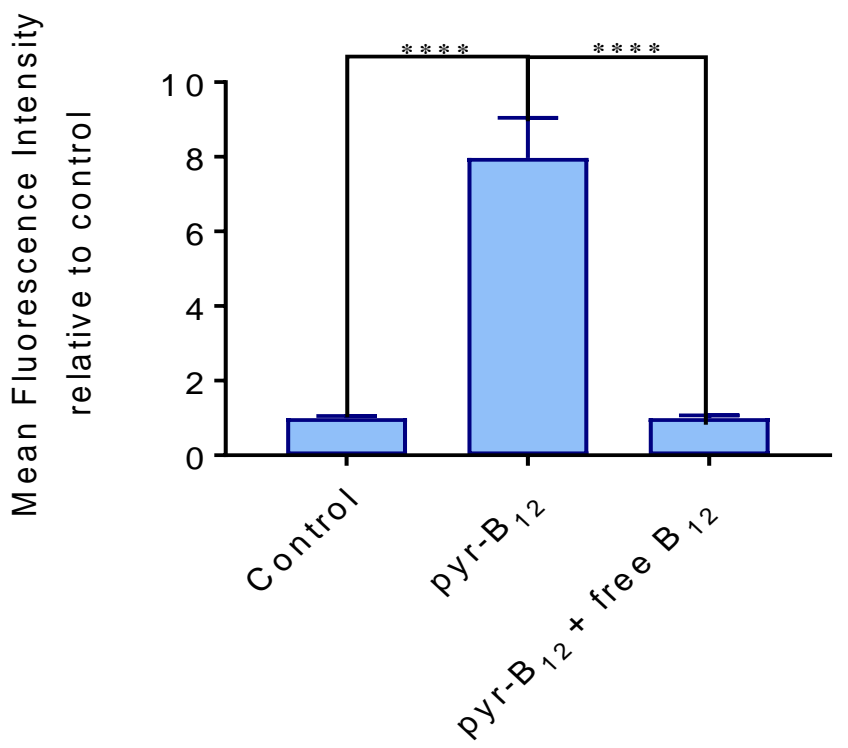

Figure S9. Cellular internalization of pyr-B 12 fluorescent probe by Caco-2 the presence or absence of free B12 competitive ligand, as assessed by flow cytometry. Control: untreated cells. One-way ANOVA was used for statistical analysis. ${ }^{*} \mathrm{P} \leq 0.05,{ }^{*} \mathrm{P} \leq 0.01,{ }^{* * *} \mathrm{P} \leq 0.001,{ }^{* * * *} \mathrm{P} \leq 0.0001$. $\lambda_{\mathrm{ex}}: 401 \mathrm{~nm}$ and $\lambda_{\mathrm{em}}: 421 \mathrm{~nm}$. Caco-2 cells are known to express both cubilin [72]and TCN2 B12 [42] receptors, and 'free' B12 is a competitor to both transport mechanism.
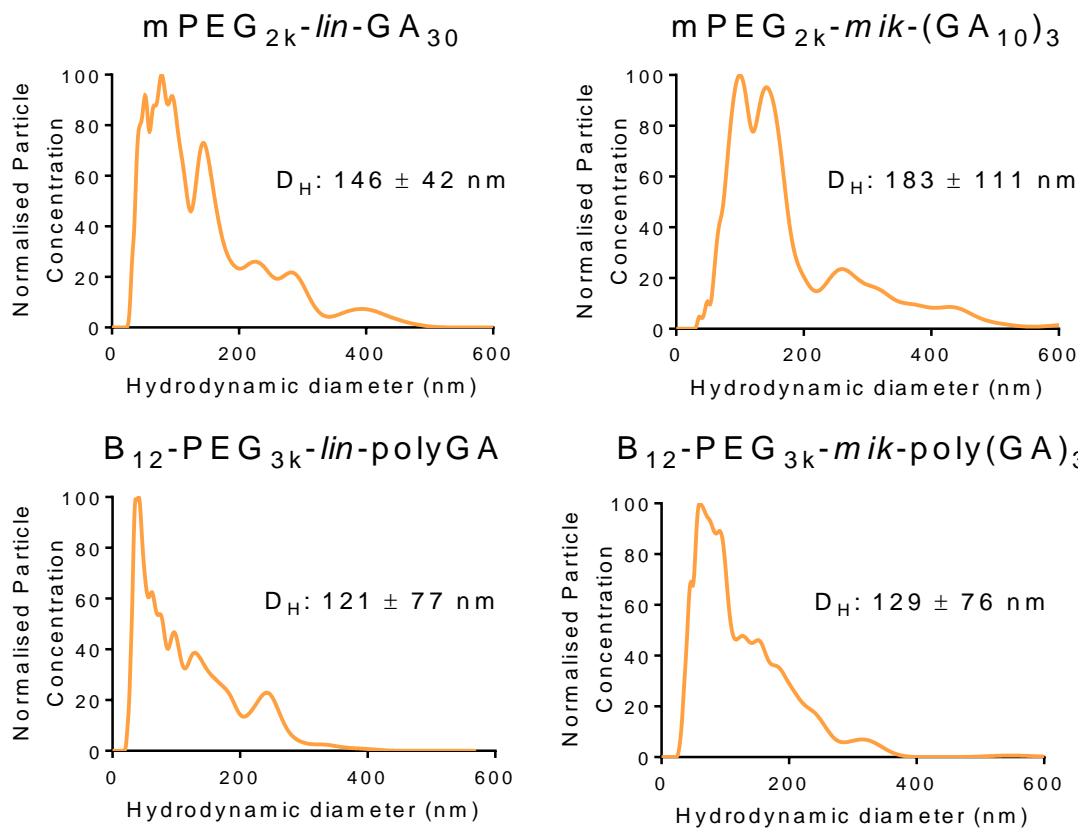

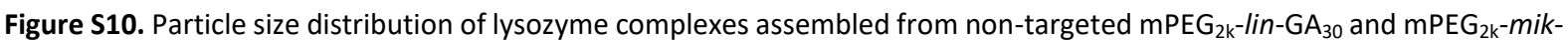
$\left(\mathrm{GA}_{10}\right)_{3}$; and targeted $\mathrm{B}_{12}-\mathrm{PEG}_{3 \mathrm{k}}-$ lin- $\mathrm{GA}_{24}$ and $\mathrm{B}_{12}-\mathrm{PEG}_{3 \mathrm{k}}-$ mik- $\left(\mathrm{GA}_{17}\right)_{3}$, as assessed by nanoparticle tracking analysis (NTA). $\mathrm{B}_{12}{ }^{-}$ $P E G_{3 k}$-lin- $\left(G_{24}\right)$ and $B_{12}-P_{3 k}-$ mik- $\left(G_{17}\right)_{3}$ (bottom panels) refer to complexes assembled with 85:15 mol:mol $B_{12}-$ targeted:non-targeted complexing copolymers. $\mathrm{DH}$ is the average hydrodynamic diameter $( \pm \mathrm{SD})$ of polymer-protein complexes. 

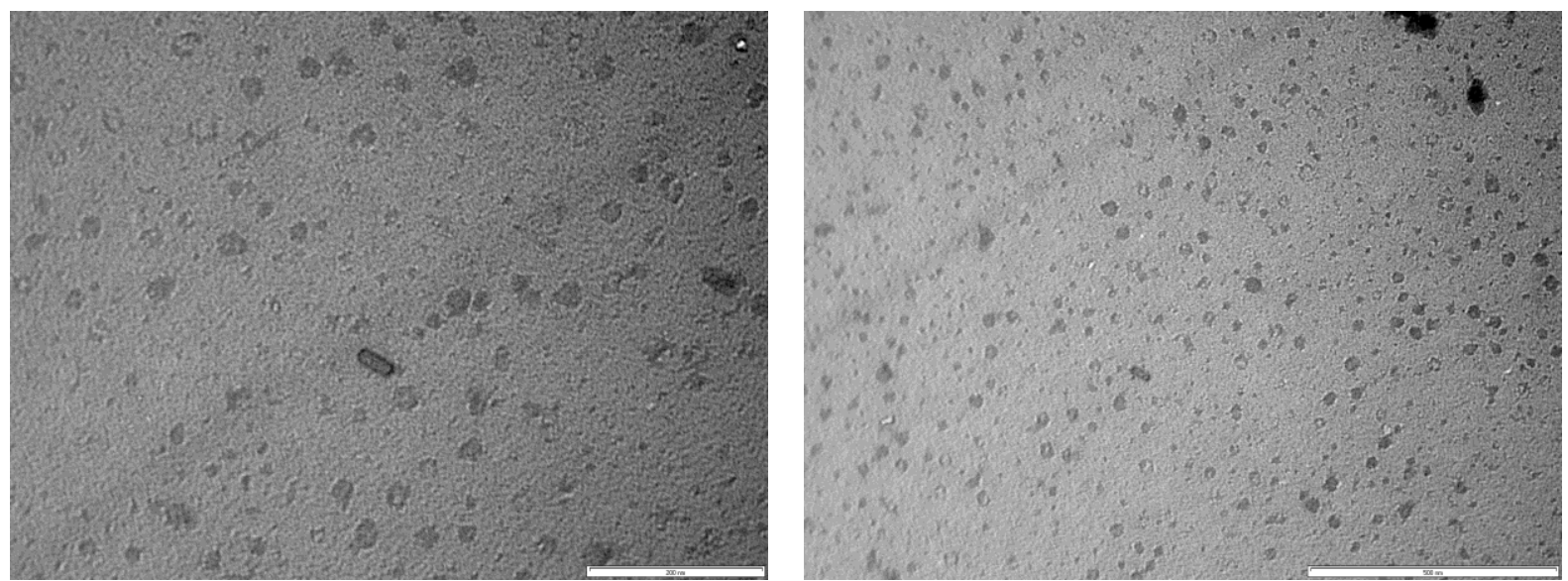

Figure S11. TEM images of lysozyme-mPEG ${ }_{2 k}$-lin-GA $\mathrm{GA}_{30}$ complexes prepared at $r: 2.5$ as detailed in method section. Image scale bar: (Left) $200 \mathrm{~nm}$ and (right) $500 \mathrm{~nm}$. TEM analysis was performed using a Tecnai G2 (FEI, Oregon, USA). Images were captured using Megaview III. Lysozyme-mPEG ${ }_{2 k}$-lin- $\mathrm{GA}_{30}$ nanocomplexes prepared at $r 2.5$ were loaded at a protein concentration of $70 \mu \mathrm{g} \mathrm{mL}^{-1}$. Samples were prepared by placing complexes suspension onto $3.05 \mathrm{~mm}$ Nickel grid, Formvar/Carbon supported film, 100 HEX. No staining was used in the sample preparation.
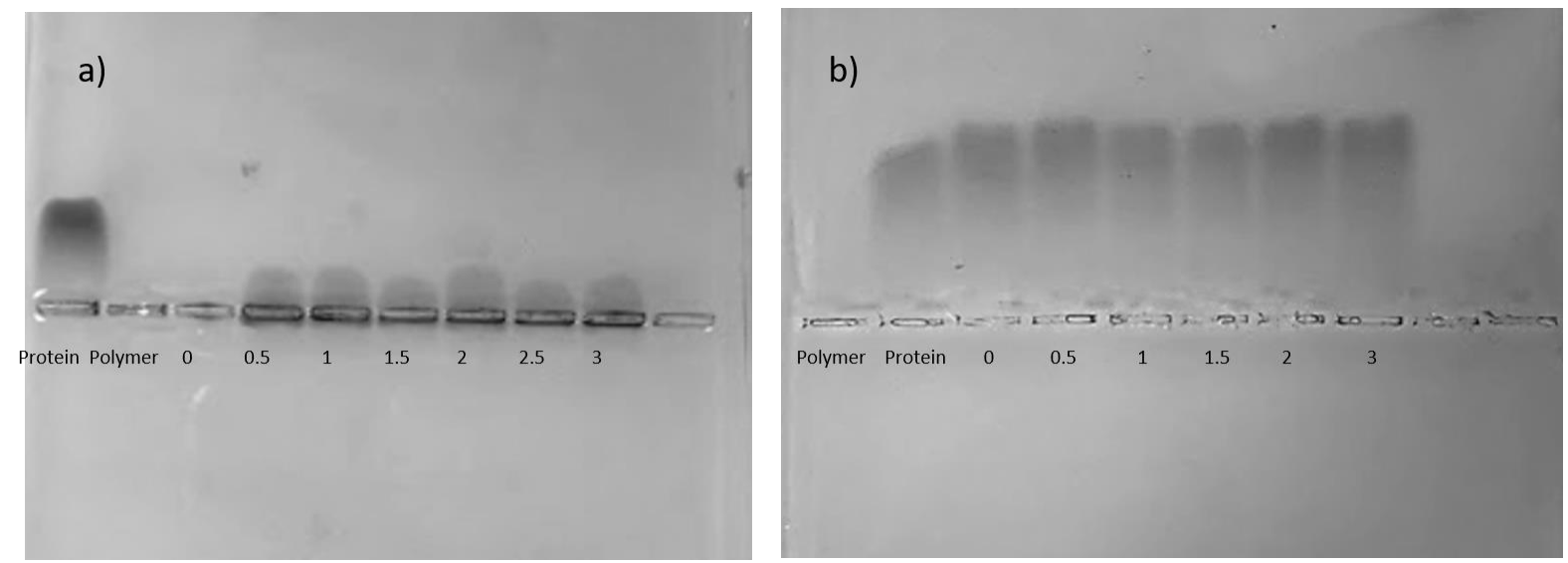

Figure S12. Electrophoretic mobility of protein (lysozyme), polymer (mPEG-lin-GA $A_{30}$ ), and lysozyme-mPEG $2 \mathrm{k}$-lin-GA $\mathrm{A}_{30}$ complexes prepared at $r$ : 2.5 following incubation in a) cell culture medium (DMEM, pH 7.4 without phenol red), and $b$ ) in simulated lysosomal environment at pH 4.5 (a $50: 50$ mixture of $1 \mathrm{M}$ sodium acetate and $1 \mathrm{M}$ hydrochloric acid). Incubated samples were withdrawn and $50 \mu$ l loaded in each well on a $1 \%$ agarose gel, run $2 \mathrm{~h}$ at $100 \mathrm{~mA}$ in trisacetate-EDTA buffer. Numbers in the gel indicated timepoints. 


\section{Synthesis of Lysozyme-Cyanine 5 (Lysozyme-Cy5)}

Lysozyme (40 mg, $2.8 \mu \mathrm{mol}, 1$ equiv) was dissolved in $4.5 \mathrm{~mL}$ of a $100 \mathrm{mM}$ sodium bicarbonate solution, pH 8.4. Cyanine 5 NHS ester ( $4.9 \mathrm{mg}, 6.4 \mu \mathrm{mol}, 3$ equiv) was then dissolved in $10 \mathrm{mM}$ phosphate buffer before being added slowly to the lysozyme solution, and the resulting reaction mixture was very gently stirred overnight, protected from light. The mixture was then dialyzed against deionized water using $10 \mathrm{kDa}$ MWCO dialysis membrane. The absence of free unreacted Cyanine 5 dye was confirmed by size exclusion - high performance liquid chromatography (SE-HPLC). The degree of labelling- defined as the average number of dye molecules per protein - of lysozyme after dialysis was determined to be $\sim 0.7$ by using Tech Tip \#31 Calculate dye:protein (F/P) molar ratios equations [73].

\section{Dry powders: Particle size distribution on Transwell inserts}

Preparation of polymer-lysozyme complexes and corresponding dry powder formulations is described in the Materials and Methods section of the manuscript.

Calu-3 cells were cultured on Transwell ${ }^{\circledR}$ inserts over 21 days as described in main paper [74]. Culture medium was then removed and dry powders were sprayed twice ( $2 \mathrm{mg}$ per dose) using a Dry Powder Insufflator ${ }^{\mathrm{TM}}$ model DP4-M ${ }^{\circledR}$ (Penn-Century ${ }^{\circledast}$ ) into the Transwell $^{\circledR}$ inserts as follows [25]:

Four Transwell ${ }^{\circledR}$ inserts were placed into a desiccator at equal distance from the center (Figure S11) as previously shown within our group. $2 \mathrm{mg}$ of dry powder formulations were then sprayed twice from a Penn-Century ${ }^{\circledR}$ device. Next, $0.5 \mathrm{~mL}$ of Hank's Balanced Salts Solution (HBSS) were added to the basolateral chamber of the Transwell ${ }^{\circledR}$ inserts and cells were incubated at $37^{\circ} \mathrm{C}$ and $5 \% \mathrm{CO}_{2}$ for $3 \mathrm{~h}$. Cells were then detached with trypsin/EDTA, washed 
twice with DPBS and lysozyme-Cy5 uptake was analyzed by flow cytometry in quadruplicate experiments, with more than 10,000 cells measured in each sample.

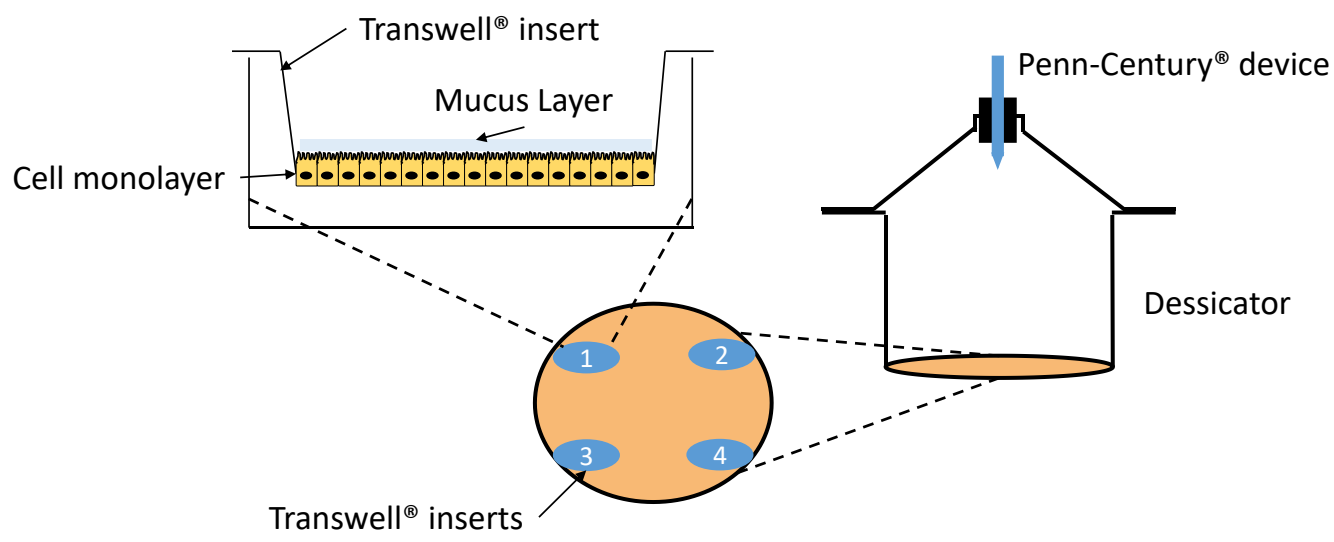

Figure S13. Spraying of dry powder formulations on top of Calu-3 cell monolayers using a Penn-Century ${ }^{\circledast}$ device.

Table S1. Emitted mass, particle size $\left(D_{50}\right)$ and uniformity of mass delivery of dry powder formulations tested in study.

\begin{tabular}{|c|c|c|c|c|}
\hline Formulation $^{\mathrm{a}}$ & Complexes $(w / w)$ & $\begin{array}{l}\text { Emitted } \\
\text { mass (\%) }\end{array}$ & $\begin{array}{l}\text { Particle Size } \\
\left(D_{50}, \mu \mathrm{m}\right)^{b}\end{array}$ & $\operatorname{RSD}(\%)^{c}$ \\
\hline UDP & 0\% Complexes & $83 \pm 10$ & $4.1 \pm 0.2$ & $11 \%$ \\
\hline UDP-P & $5 \%$ Lysozyme & $93 \pm 4$ & $4.3 \pm 0.6$ & $5 \%$ \\
\hline UDP-TC & $10 \%$ Complexes $^{d}$ & $93 \pm 7$ & $4.4 \pm 0.6$ & $10 \%$ \\
\hline
\end{tabular}

To ensure that all Transwell ${ }^{\circledR}$ inserts placed into the desiccator receive similar dose, particle size ( $\left.D_{90}\right)$ and particle distribution were investigated. $2 \mathrm{mg}$ of dry powder formulations were sprayed twice from a Penn-Century ${ }^{\circledR}$ device as shown in Figure S7, and each Transwell ${ }^{\circledR}$ insert (without cells) was examined by optical microscopy. Images were then analyzed by ImageJ 
Software to give $\mathrm{D}_{90}$ - diameter below which $90 \%$ of the particle population lie - and dry powder distribution.

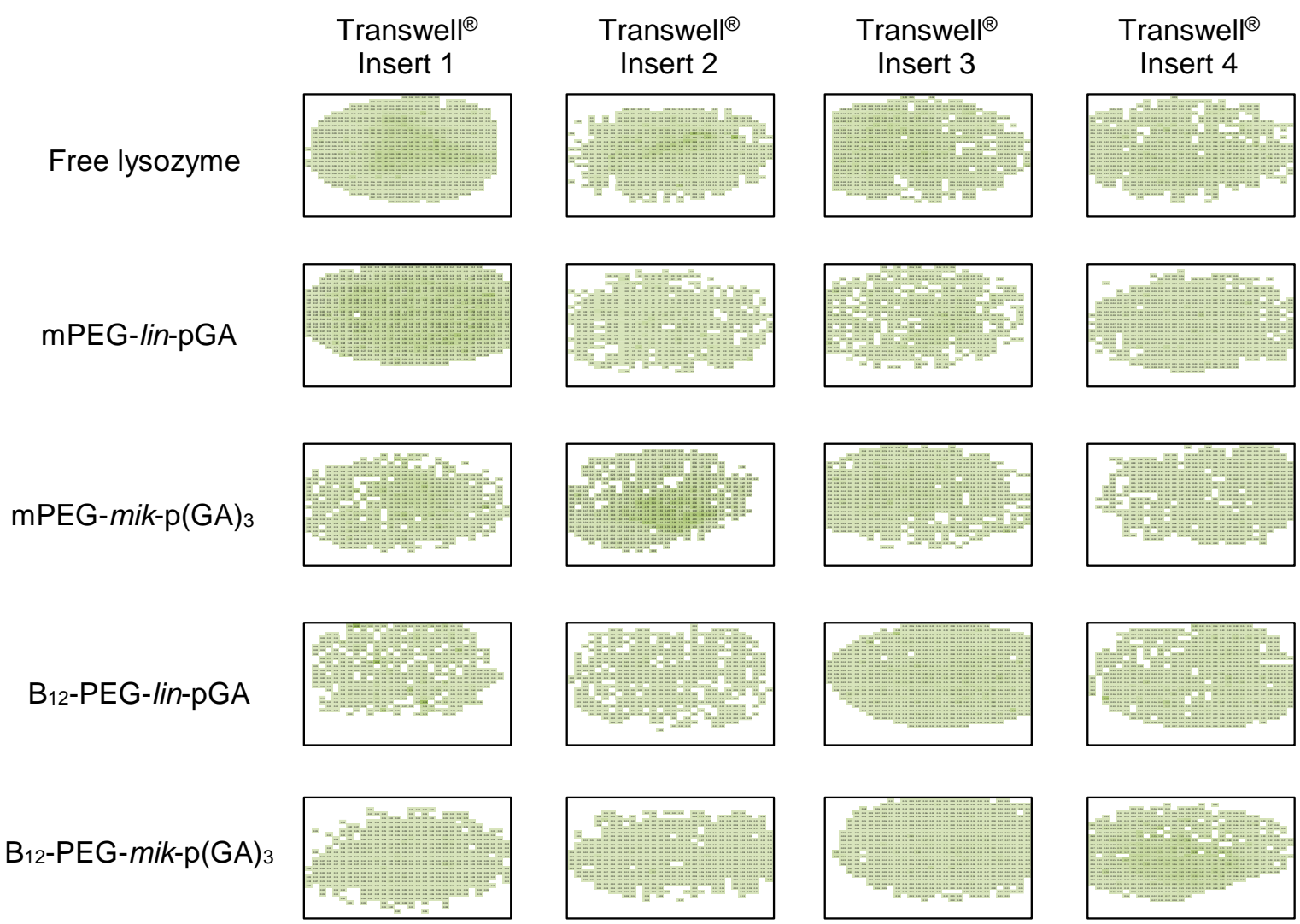

Figure S14. Dry powder distribution after spraying them twice (2 mg per dose) using a Penn-Century device. Four Transwell ${ }^{\oplus}$ inserts were used for each formulation. Each big square contains up to 900 small colored squares that correspond to each image taken from each Transwell ${ }^{\varpi}$ insert by an optical microscope. The different colors depends on the particle concentration on each image. Light green: $0 \%$ of particles, green: $5 \%$ particles, red: $10 \%$ particles. 
Table S2. Particle size distribution ( $\left.d_{90}\right)$ of dry powders after spraying twice (2 mg per dose) using a Penn Century device.

Four Transwell ${ }^{\circ}$ inserts were used for each formulation. All dry powder contains phosphate buffer salts $(6.6 \% w / w)$, leucine

$(10 \% w / w)$, and trehalose (up to $100 \% w / w)$.

Particle size distribution $d_{90}(\mu \mathrm{m})$

\begin{tabular}{ccccc}
\hline Dry powder formulation & $\begin{array}{c}\text { Transwell }^{\circ} \\
\text { insert 1 }\end{array}$ & $\begin{array}{c}\text { Transwell }^{\circ} \\
\text { insert 2 }\end{array}$ & $\begin{array}{c}\text { Transwell }^{\circ} \\
\text { insert 3 }\end{array}$ & $\begin{array}{c}\text { Transwell }^{\circ} \\
\text { insert 4 }\end{array}$ \\
\hline Free lysozyme & 3.9 & 6.6 & 6.5 & 5.6 \\
mPEG 2 -lin-GA $\mathrm{A}_{30}$ & 6.0 & 5.1 & 5.7 & 5.6 \\
mPEG $_{2 k}$-mik- $\left(\mathrm{GA}_{10}\right)_{3}$ & 6.2 & 6.7 & 7.1 & 6.1 \\
$\mathrm{~B}_{12}-\mathrm{PEG}_{3 k}-$ lin- $\left(\mathrm{GA}_{24}\right)$ & 4.9 & 3.8 & 7.3 & 6.4 \\
$\mathrm{~B}_{12}-\mathrm{PEG}_{3 k}-$ mik- $\left(\mathrm{GA}_{17}\right)_{3}$ & 5.8 & 4.5 & 6.0 & 8.0 \\
\hline
\end{tabular}

Untreated mice

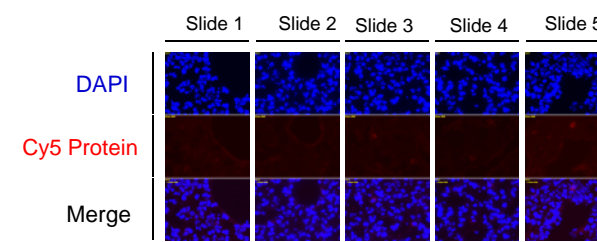

$\mathrm{Oh}$

$3 \mathrm{~h}$

$14 \mathrm{~h}$
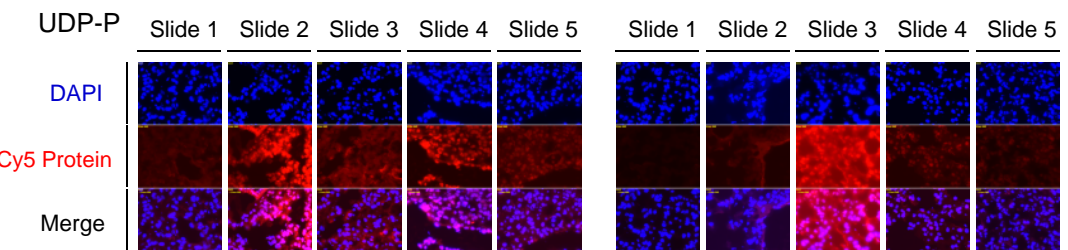

Slide 1 Slide 2 Slide 3 Slide 4 Slide 5

UDP-NT
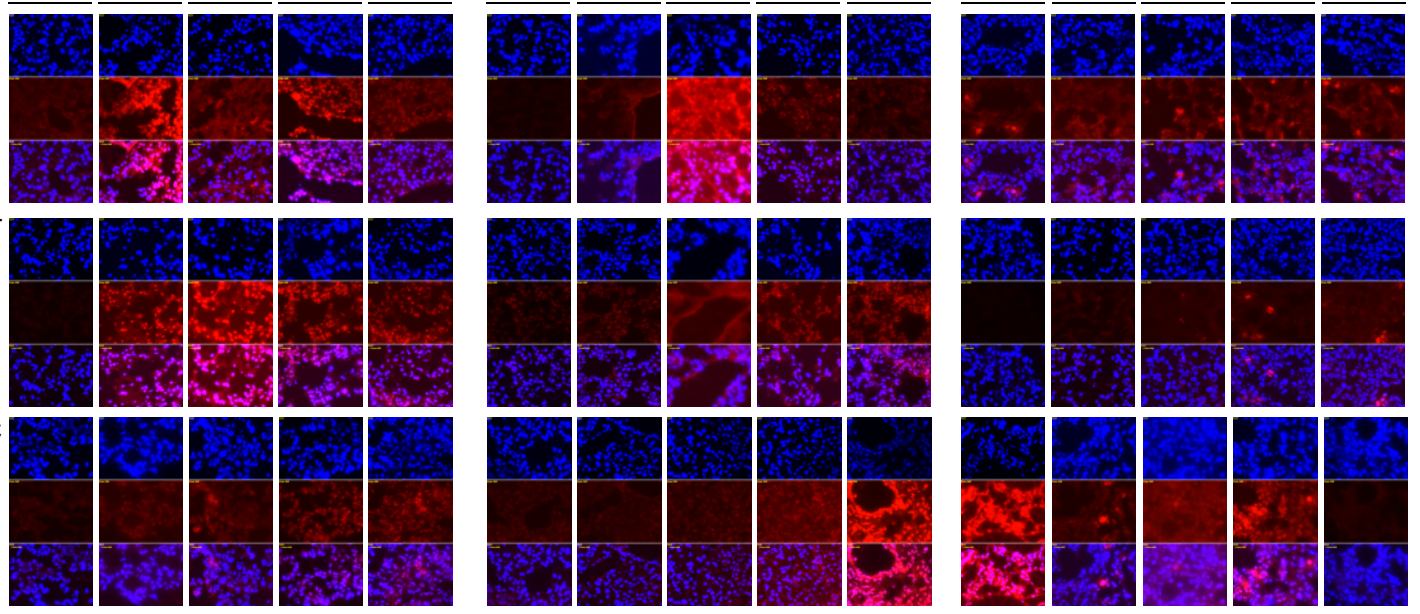

Figure S15. Distribution in lung tissue samples of red labelled Cy5-lysozyme, the blue fluorescent nuclear stain DAPI and merged images at different time points following administration of $2 \mathrm{mg}$ of dry powder formulation to healthy mice using the pulmonary delivery device Penn-Century; LDP-P (free protein dry powder formulation), LDP-NT (non-targeted complexes dry powder formulation, and LDP-TC (targeted complexes dry powder formulation). Untreated mice were used as a negative control. The representative examples shown in the main text. 


\section{a-dibenzocyclooctyne-vitamin $\mathrm{B}_{12}$ (DBCO-B ${ }_{12}$ )}

Cyanocobalamin (vitamin $B_{12}, 135 \mathrm{mg}, 0.0995 \mathrm{mmol}, 1$ eq.) was dissolved in anhydrous DMSO (10 mL) under inert atmosphere. CDI $(32.2 \mathrm{mg}, 0.199 \mathrm{mmol}, 2$ eq.) was then added to the round bottom flask and the reaction was stirred at $30^{\circ} \mathrm{C}$ for $1.5 \mathrm{~h}$ prior to addition of dibenzocyclooctyne-amine (100 mg, $0.362 \mathrm{mmol}, 3.65$ eq.) in DMSO $(5 \mathrm{~mL})$. The resulting pink solution was then stirred at room temperature protected from light for a further $24 \mathrm{~h}$, precipitated in diethyl ether, and the pink solid was collected by filtration, following resolubilisation in methanol. The product was then purified by preparative-TLC (30:45:4:21 2propanol: n-butanol: ammonia: water vol:vol:vol:vol) and extracted using methanol. Chemical identity of DBCO-B ${ }_{12}$ was confirmed by MS - expected m/z [M-Na++] theor. 851.85, found 851.33 - and ${ }^{1} \mathrm{H}$ NMR (Figure S26). (Yield 31\%). 


\section{NMR spectra}
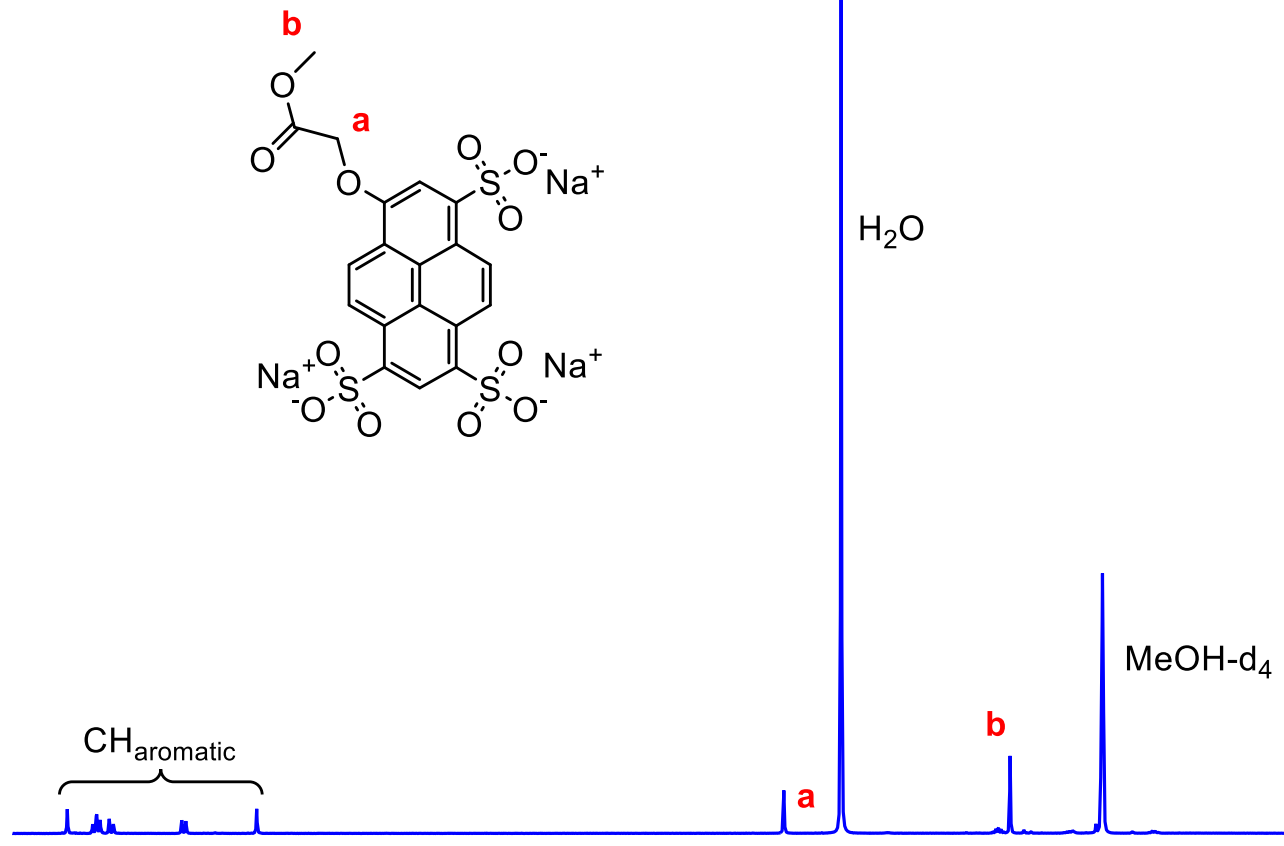

Propanol
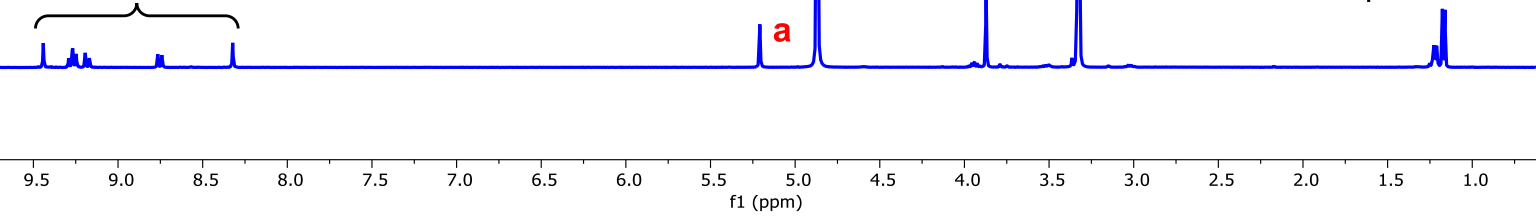

Figure S16. ${ }^{1} \mathrm{H}$ NMR spectrum of pyranine methyl ester (6) in $\mathrm{CD}_{3} \mathrm{OD}$. 


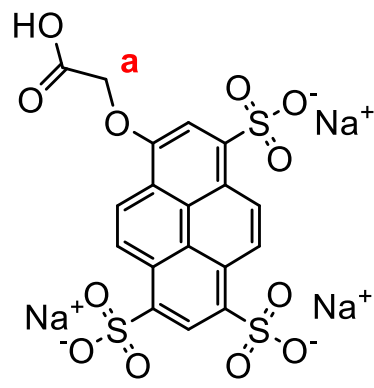

$\mathrm{H}_{2} \mathrm{O}$

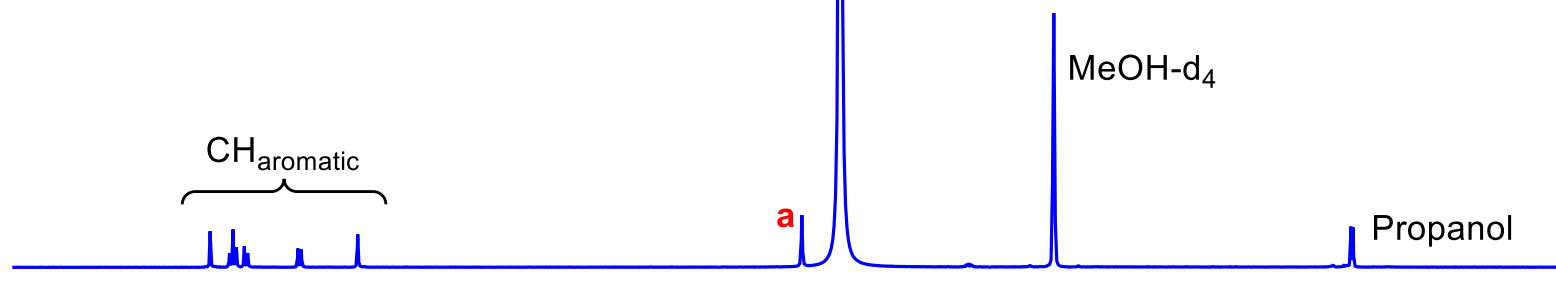

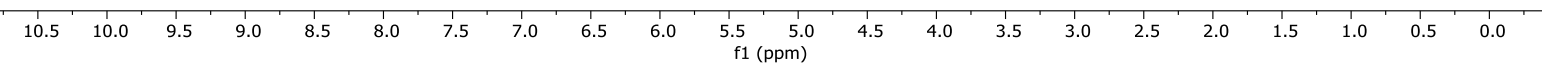

Figure S17. ${ }^{1} \mathrm{H}$ NMR spectrum of carboxypyranine (7) in $\mathrm{CH}_{3} \mathrm{OD}$.

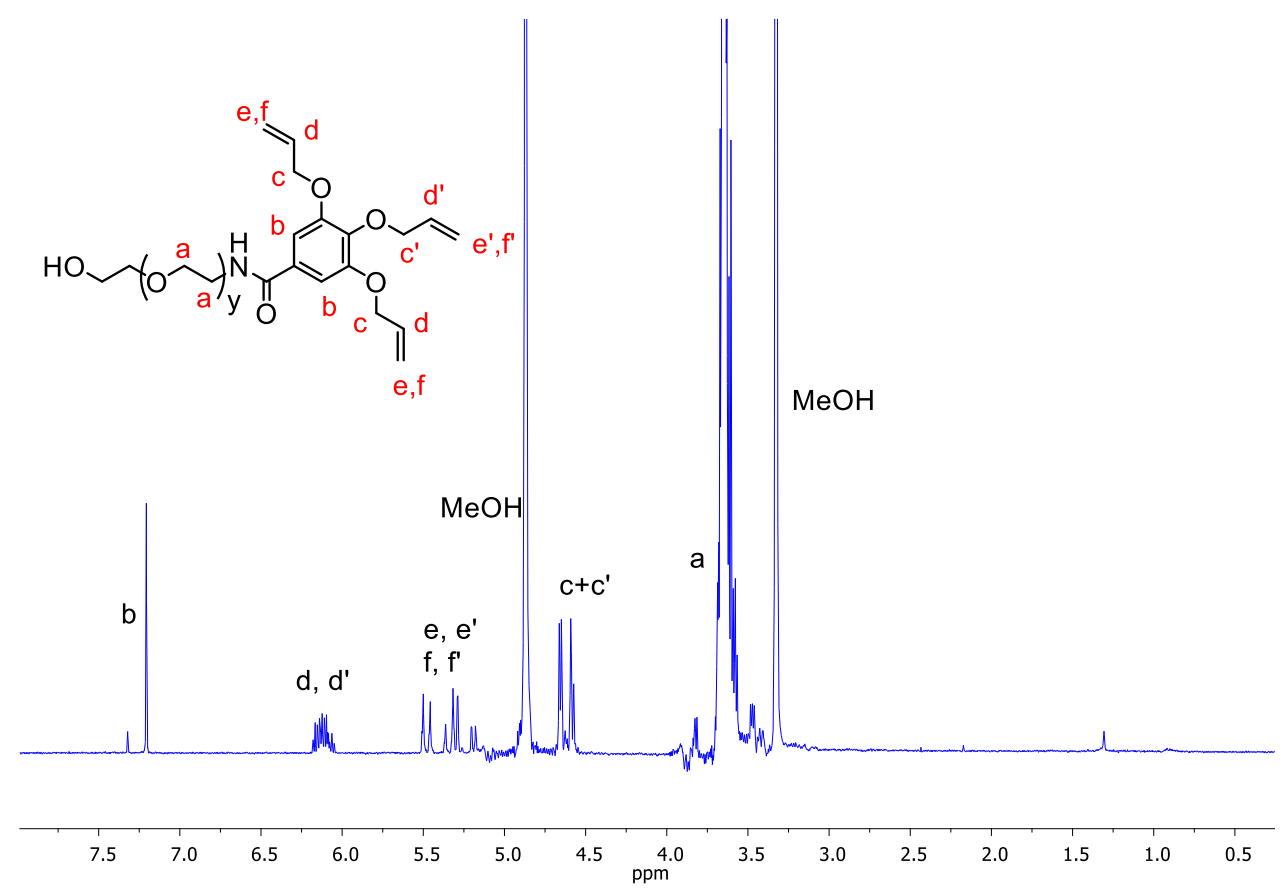

Figure S18. ${ }^{1} \mathrm{H}$ NMR spectrum of hydroxy-PEG 3 triallyl ether (D) in $\mathrm{CH}_{3} \mathrm{OD}$. 


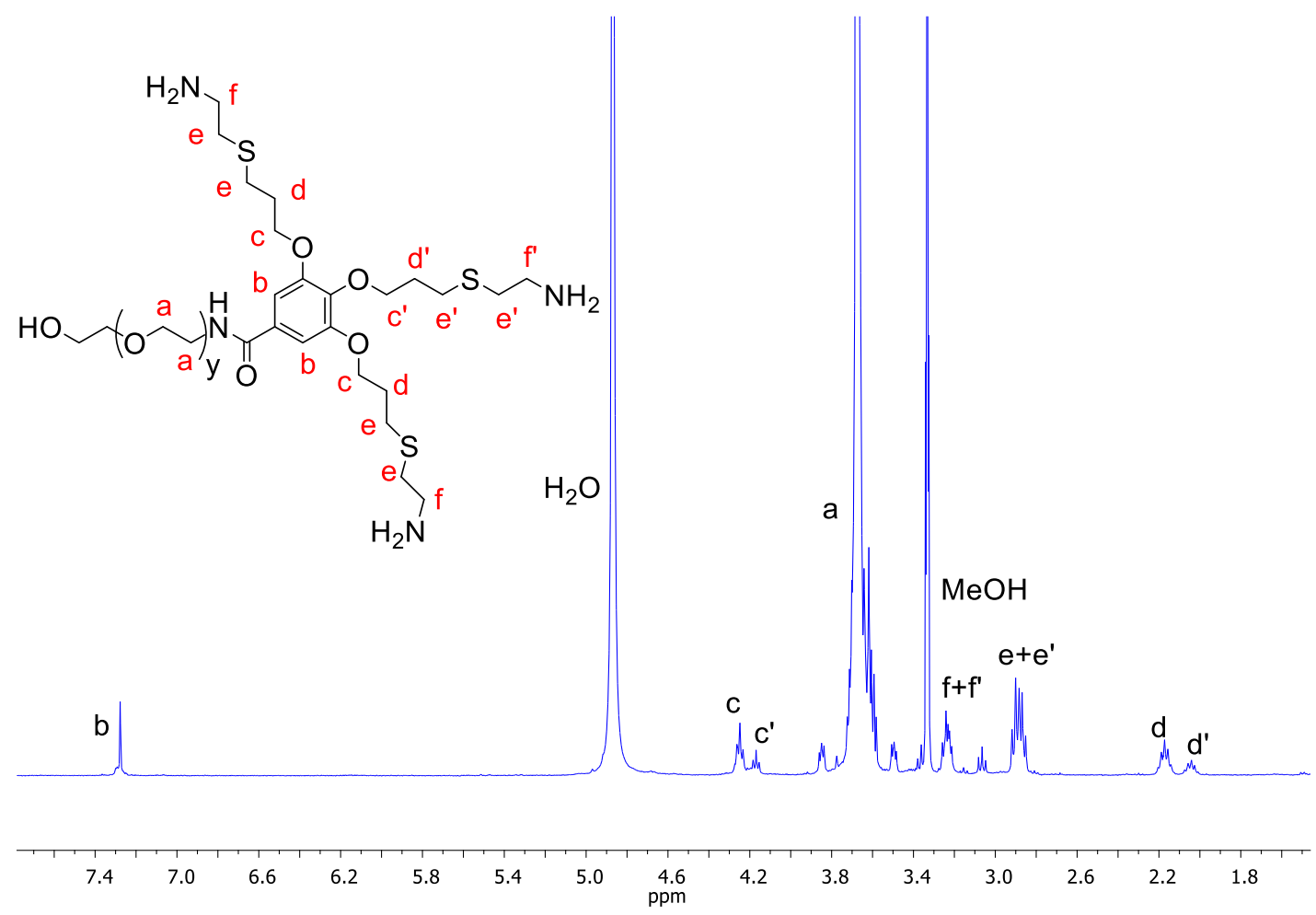

Figure S19. ${ }^{1} \mathrm{H}$ NMR spectrum of triamino-hydroxy-PEG ${ }_{3 k}(\mathrm{E})$ in $\mathrm{CH}_{3} \mathrm{OD}$.

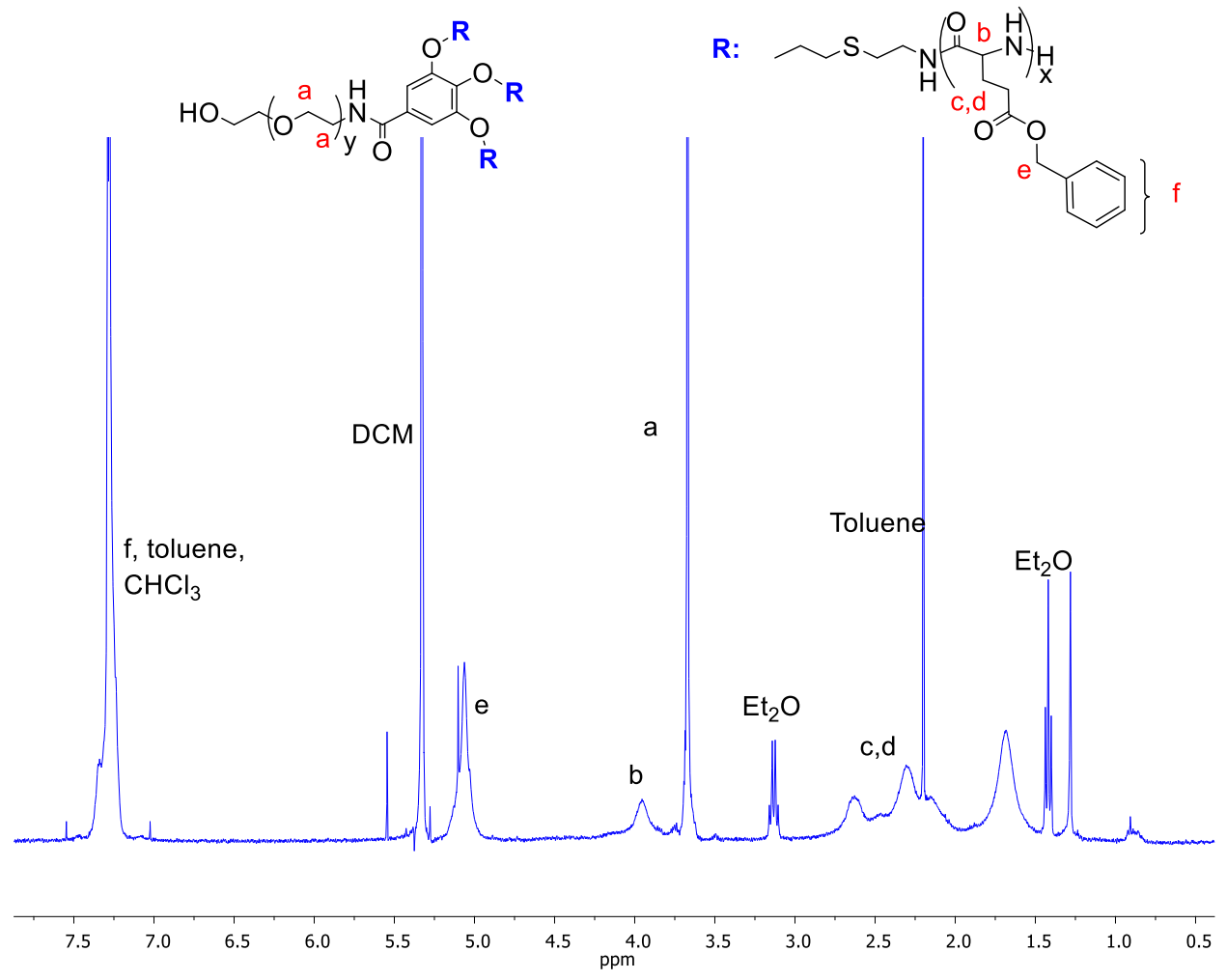

Figure S20. ${ }^{1} \mathrm{H}$ NMR spectrum of hydroxy-PEG $\mathrm{G}_{3 k}-m i k-\left(\mathrm{OBn}-\mathrm{GA}_{17}\right)_{3}$ (F) in $\mathrm{CDCl}_{3}$. 


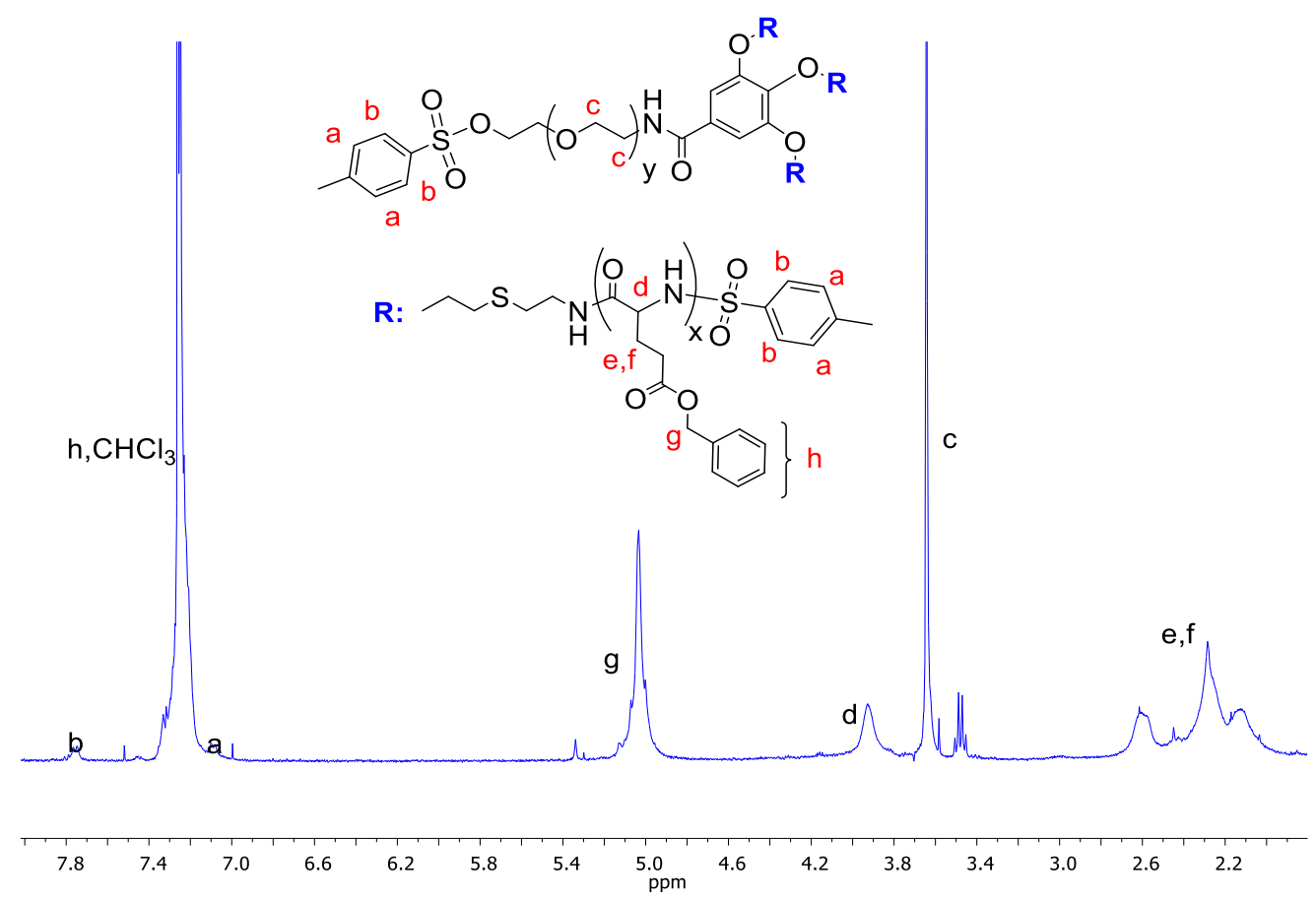

Figure S21. ${ }^{1} \mathrm{H}$ NMR spectrum of p-toluene-sulfonyl-PEG $\mathrm{Hk}_{3 \mathrm{k}}-m i k-\left(\mathrm{OBn}-\mathrm{GA}_{17}\right)_{3}(\mathrm{G})$ in $\mathrm{CDCl}_{3}$.

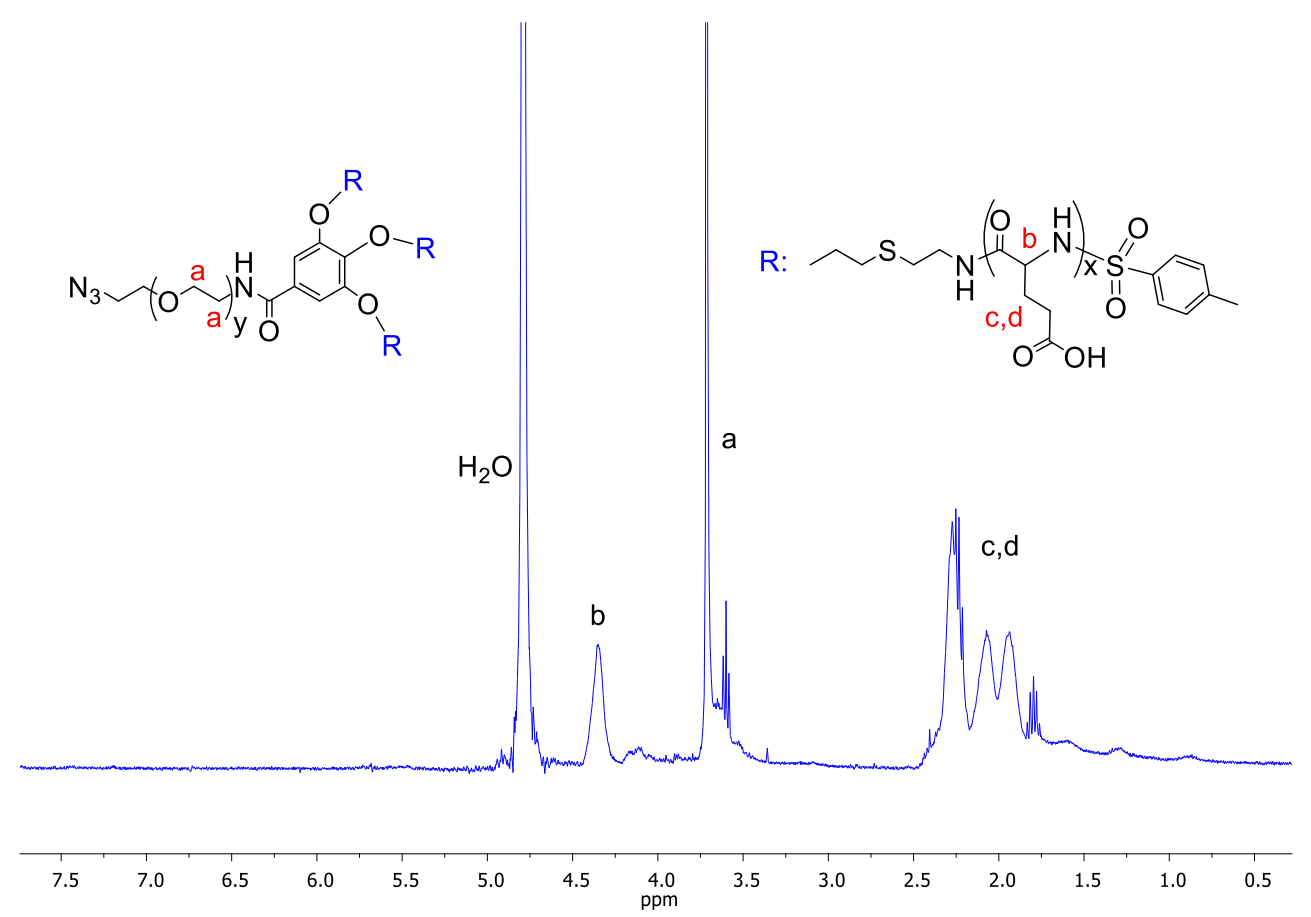

Figure S22. ${ }^{1} \mathrm{H}$ NMR spectrum of azide-PEG $3 \mathrm{k}-m i k-\left(\mathrm{GA}_{17}\right)_{3}(2)$ in $\mathrm{D}_{2} \mathrm{O}$. 


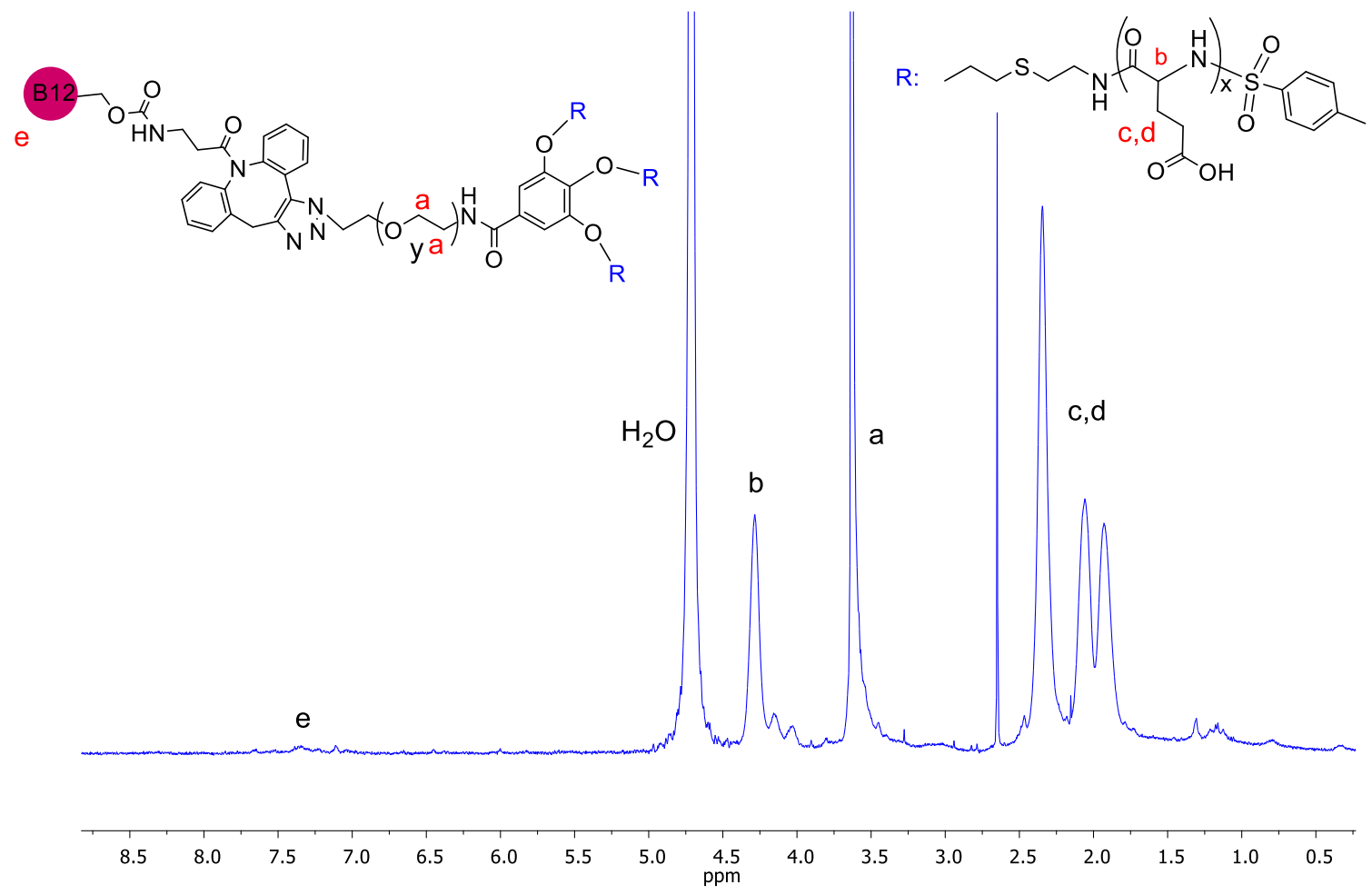

Figure S23. ${ }^{1} \mathrm{H}$ NMR spectrum of $\mathrm{B}_{12}-\mathrm{PEG} \mathrm{G}_{3 \mathrm{k}}-m i k-\mathrm{p}\left(\mathrm{GA}_{17}\right)_{3}$ in $\mathrm{D}_{2} \mathrm{O}$.

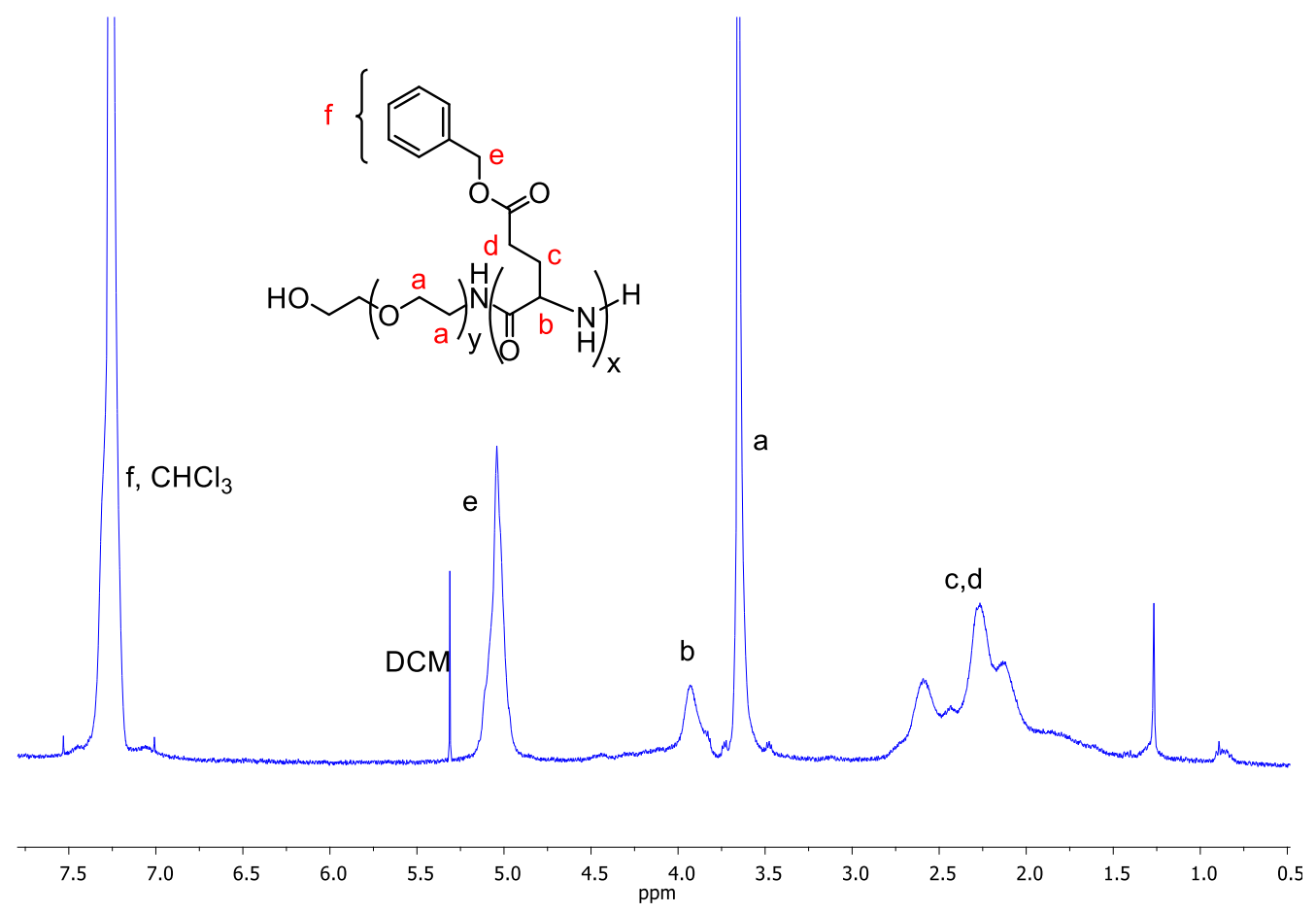

Figure S24. ${ }^{1} \mathrm{H}$ NMR spectrum of hydroxy-PEG $3 \mathrm{k}$-lin-(OBn-GA$\left.{ }_{24}\right)(A)$ in $\mathrm{CDCl}_{3}$. 


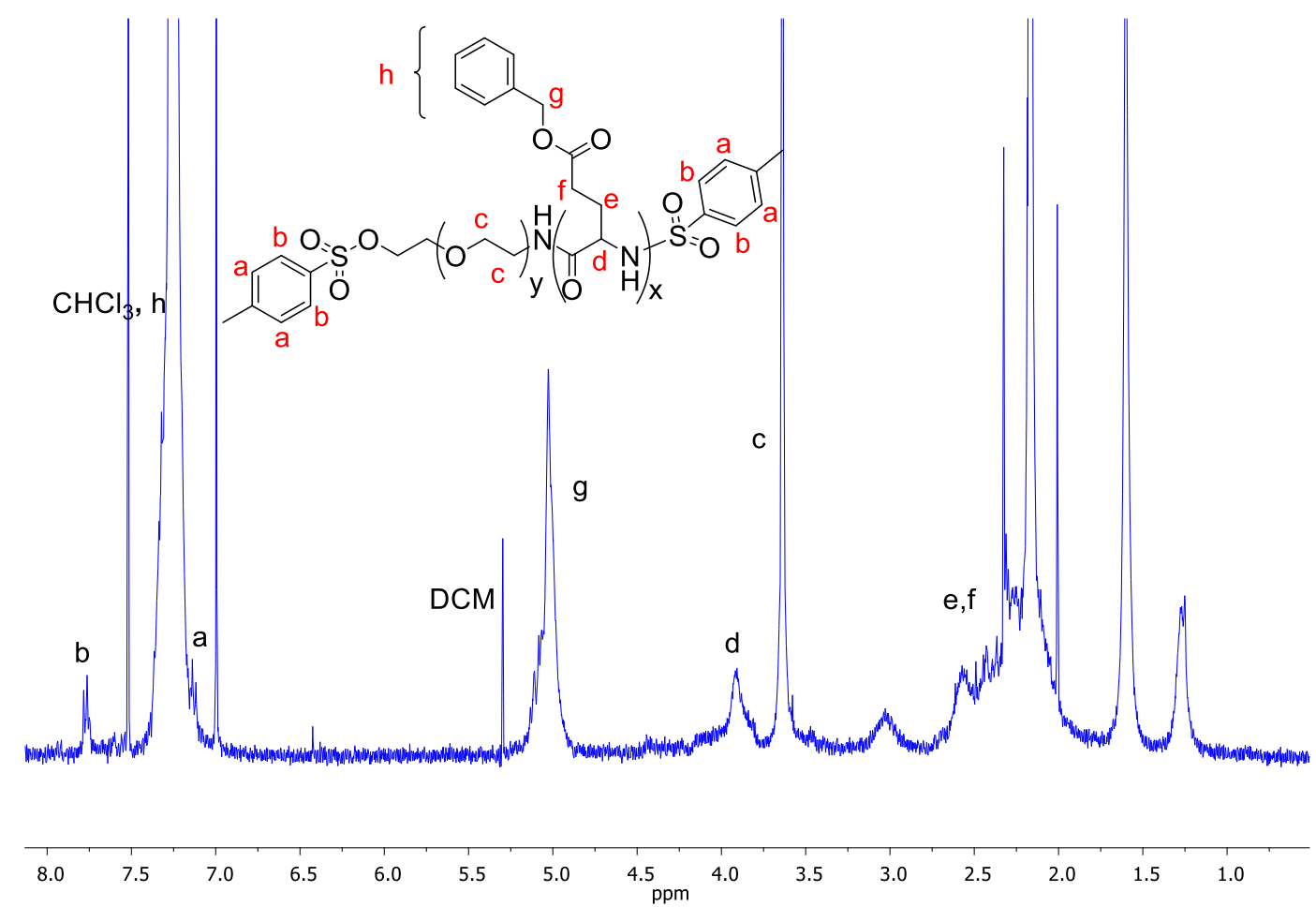

Figure S25. ${ }^{1} \mathrm{H}$ NMR spectrum of $p$-toluene-sulfonyl-PEG $3 \mathrm{k}-$-lin-(GA24) (B) in $\mathrm{CDCl}_{3}$.

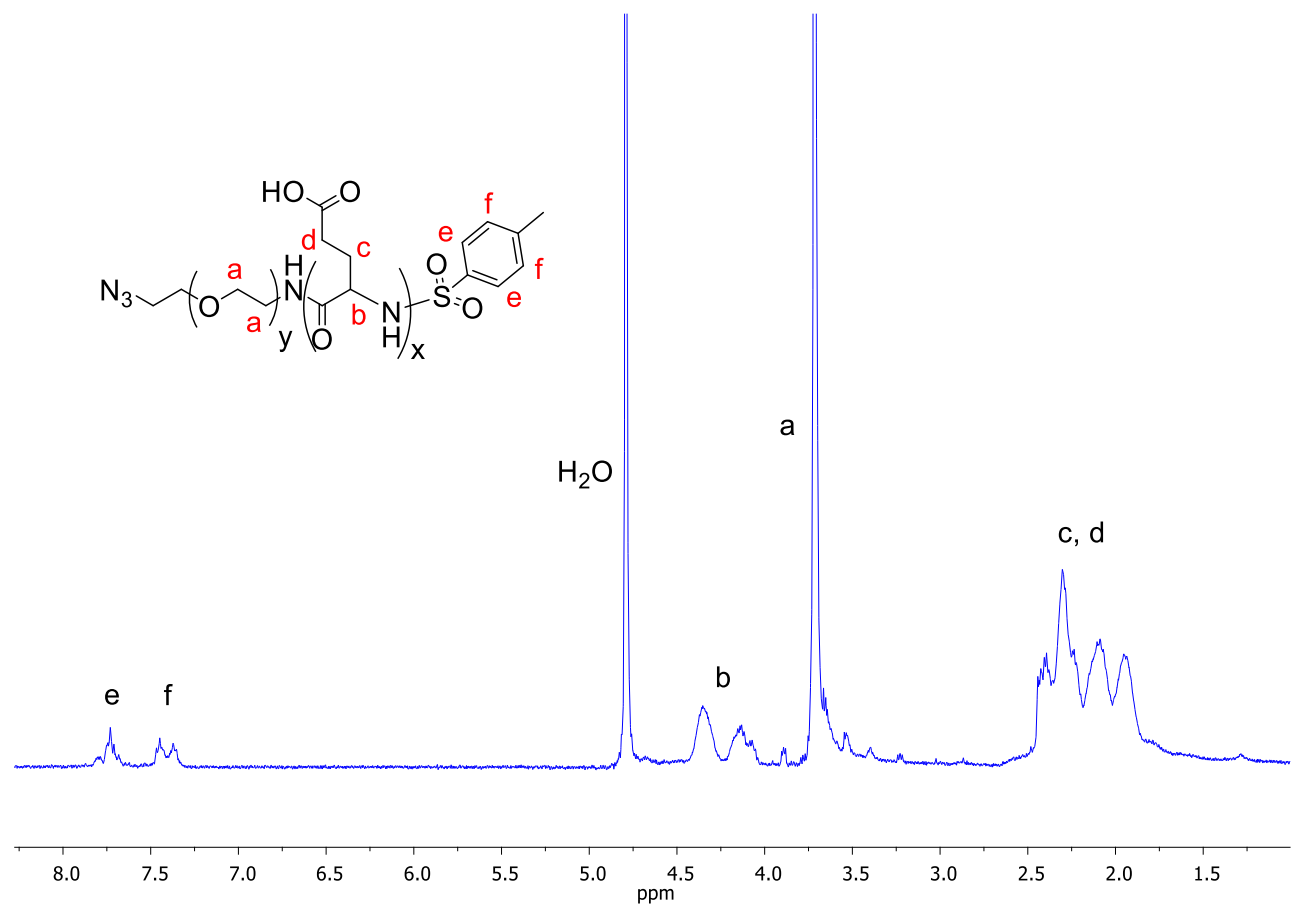

Figure S26. ${ }^{1} \mathrm{H}$ NMR spectrum of azide-PEG ${ }_{3 k}-$ lin- $-\mathrm{A}_{24}(\mathrm{C})$ in $\mathrm{D}_{2} \mathrm{O}$. 


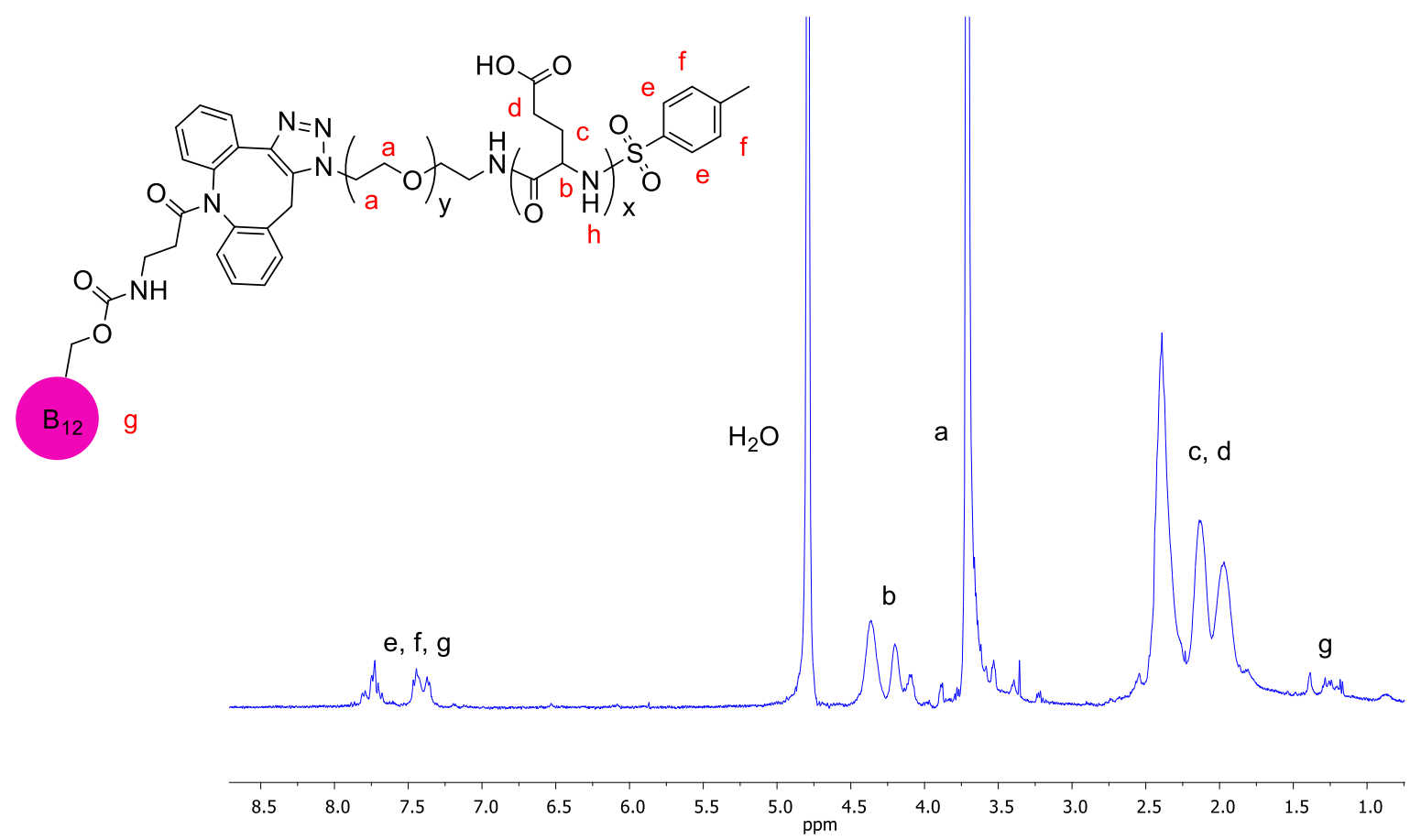

Figure S27. ${ }^{1} \mathrm{H}$ NMR spectrum of $\mathrm{B}_{12}-\mathrm{PEG}_{3 \mathrm{k}}-$ lin- $\mathrm{GA}_{24}$ in $\mathrm{D}_{2} \mathrm{O}$.

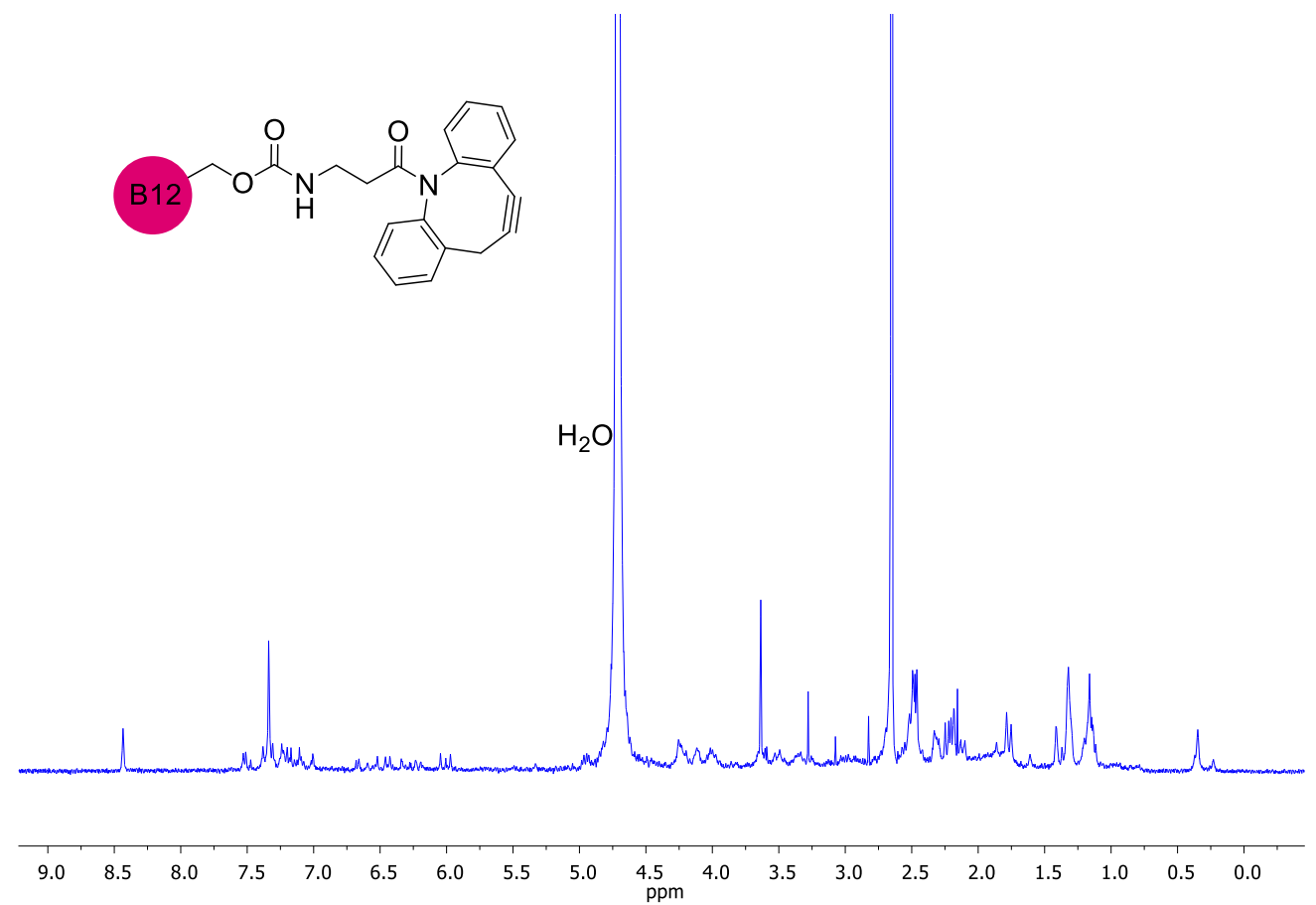

Figure S28. ${ }^{1} \mathrm{H}$ NMR spectrum of $\alpha$-dibenzocyclooctyne-vitamin $\mathrm{B}_{12}$ (DBCO-B 12 ) in $\mathrm{D}_{2} \mathrm{O}$. 


\section{References}

[1] A. Nieto-Orellana, M. Di Antonio, C. Conte, F.H. Falcone, C. Bosquillon, N. Childerhouse, G. Mantovani, S. Stolnik, Effect of polymer topology on non-covalent polymer-protein complexation: miktoarm versus linear mPEG-poly(glutamic acid) copolymers, Polymer Chemistry, 8 (2017) 2210-2220.

[2] D.C. Knapp, J. D'Onofrio, J.W. Engels, Fluorescent Labeling of (Oligo)Nucleotides by a New Fluoride Cleavable Linker Capable of Versatile Attachment Modes, Bioconjugate Chemistry, 21 (2010) 1043-1055.

[3] O. Aseem, J.L. Barth, S.C. Klatt, B.T. Smith, W.S. Argraves, Cubilin expression is monoallelic and epigenetically augmented via PPARs, BMC genomics, 14 (2013) 405-405.

[4] S. Bose, S. Seetharam, N.M. Dahms, B. Seetharam, Bipolar functional expression of transcobalamin II receptor in human intestinal epithelial Caco-2 cells, J. Biol. Chem., 272 (1997) 3538-3543.

[5] T. Scientific, Calculate dye:protein (F/P) molar ratios, in, Thermo Fisher Scientific Inc, 2011.

[6] E. Cingolani, In vitro investigation of factors affecting the fate of dry powders in the lungs, in, 2017.

[7] E. Cingolani, S. Alqahtani, R.C. Sadler, D. Prime, S. Stolnik, C. Bosquillon, In vitro investigation on the impact of airway mucus on drug dissolution and absorption at the airepithelium interface in the lungs, Eur. J. Pharm. Biopharm., 141 (2019) 210-220. 